$r$
$r$

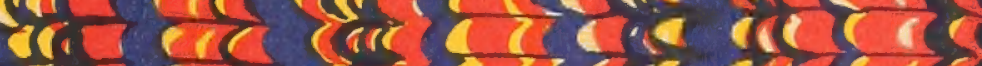

rece

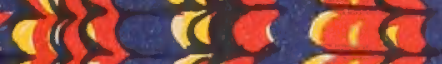

C(s)

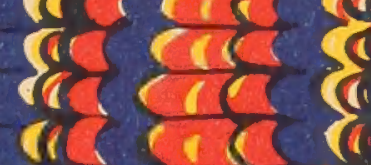

$\operatorname{cac}<C<\mathrm{C}$

$\operatorname{sic}(\mathrm{C} C \mathrm{C}$

126

बeद 40

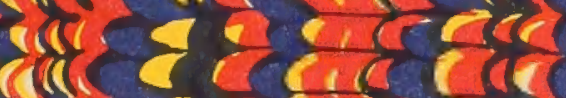

ceire

$\operatorname{arcs} \frac{\cos (1)}{10}$

(1)

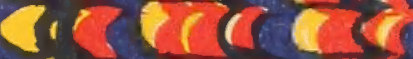

$\operatorname{sic}<1<$

crer 2010

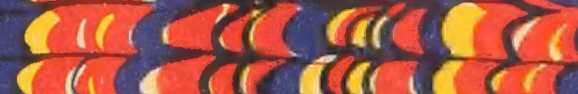

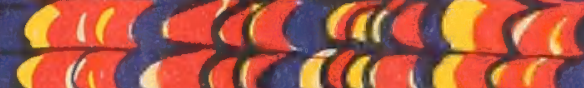

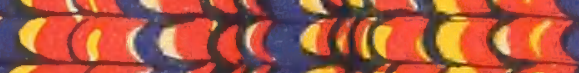

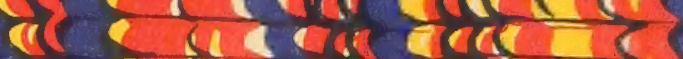

aic 2.12

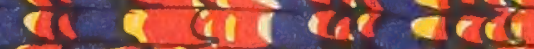

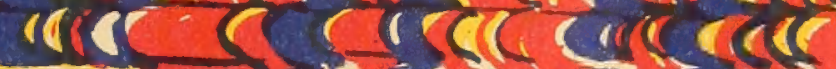

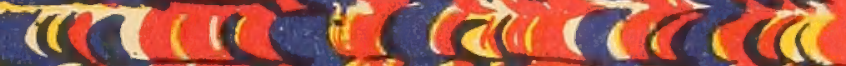

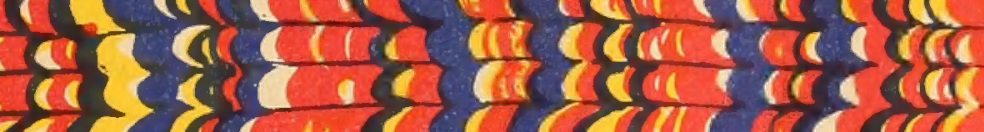

TC

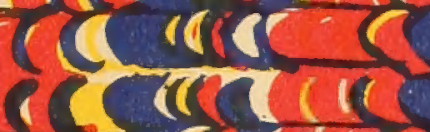

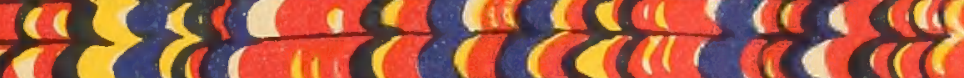

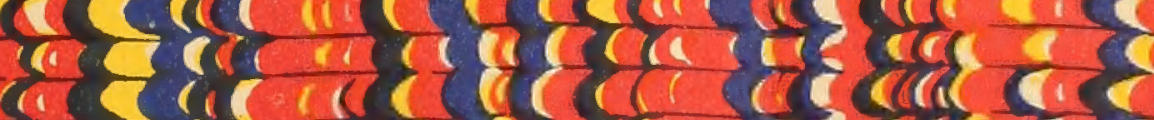

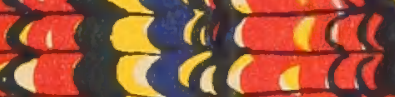

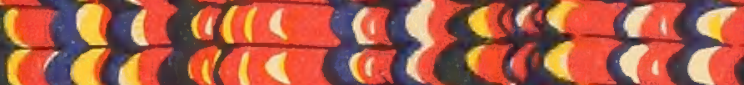

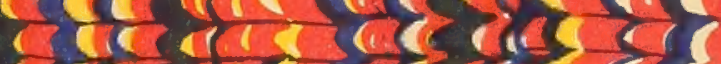

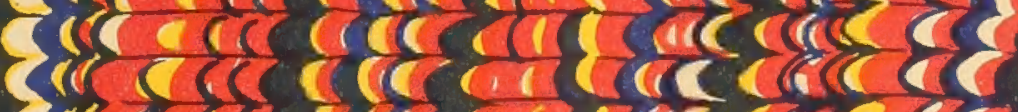

$\operatorname{rac} x$

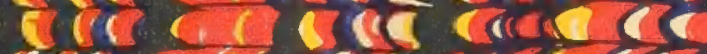

GCO

$\operatorname{arc}$

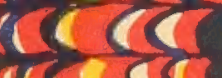

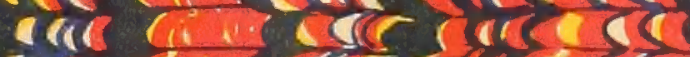

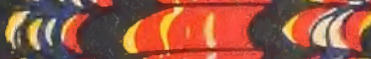

ciracis

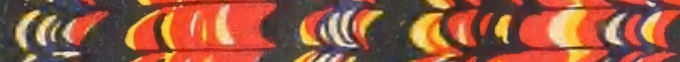

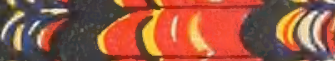

$\frac{\cos (1)}{\operatorname{cic} 2}$

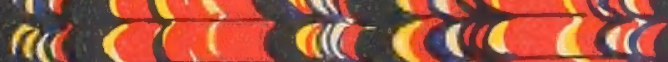

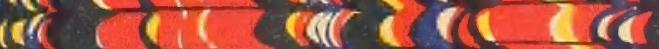

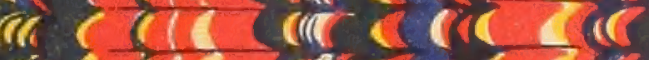

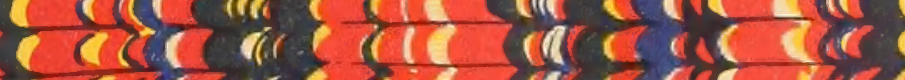

(c)

(

8 (c)

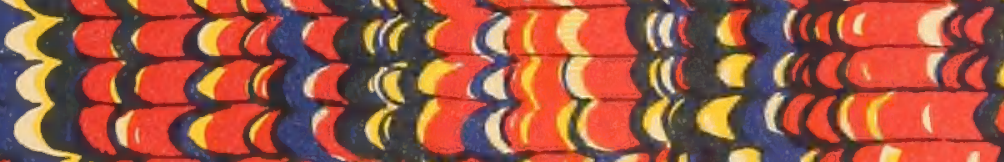

$\operatorname{cic}_{1}$

$\operatorname{coc} c \cos a$

तब

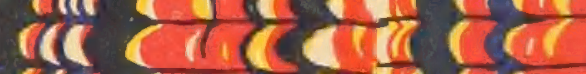

$\pi<\cos$

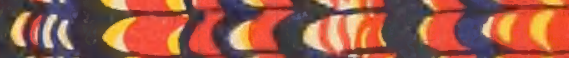

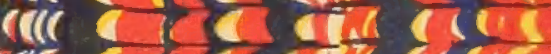

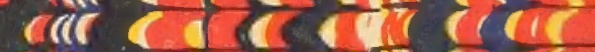

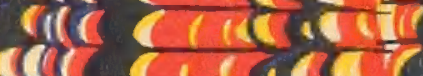

1

$\operatorname{lac}$

C C S

sir acritas

48

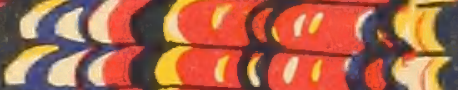

12

$a$
$a$
$a$

$\operatorname{cs}<20$

$\sec <1<$

recarite ere

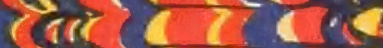

a $\rightarrow$ ac

(c)

a) 20

air 120

$\operatorname{cic} 40$

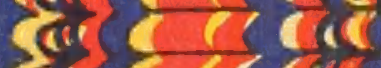

$\int_{6}$

(i)

$\operatorname{sic}\left(\frac{1}{12}\right.$

ace $\cos$

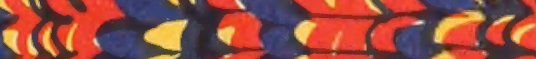

I(c)

$d$ isia erace

7 aíc

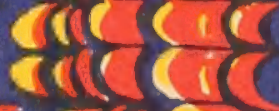

ice 11 r)

$\rightarrow \cos \frac{1}{4}+1$

ic

$\mathrm{CQC}$

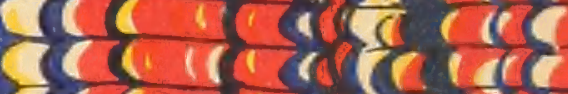

acis $\cos$

(1)

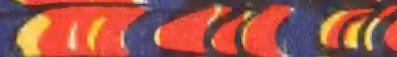

cla arararazé

${ }_{3}^{1}$

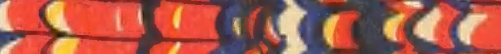

$\operatorname{cic}($

(a)

dic $10<$

$\frac{1}{8}$

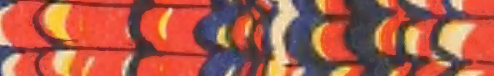

$\operatorname{ig}(i)$

al a a a a cera

(1)

a a ariati -12

$\operatorname{cac}$

C.

C C

ince

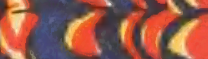

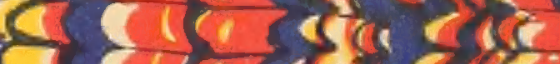

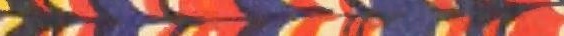

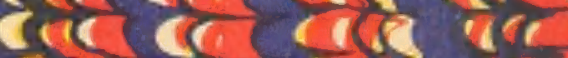

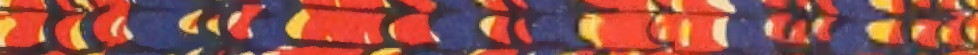

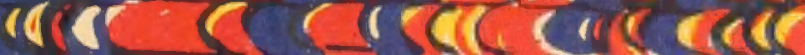

$\operatorname{coc} \rightarrow$

icter cise 




1 Mins Mary Mathoune

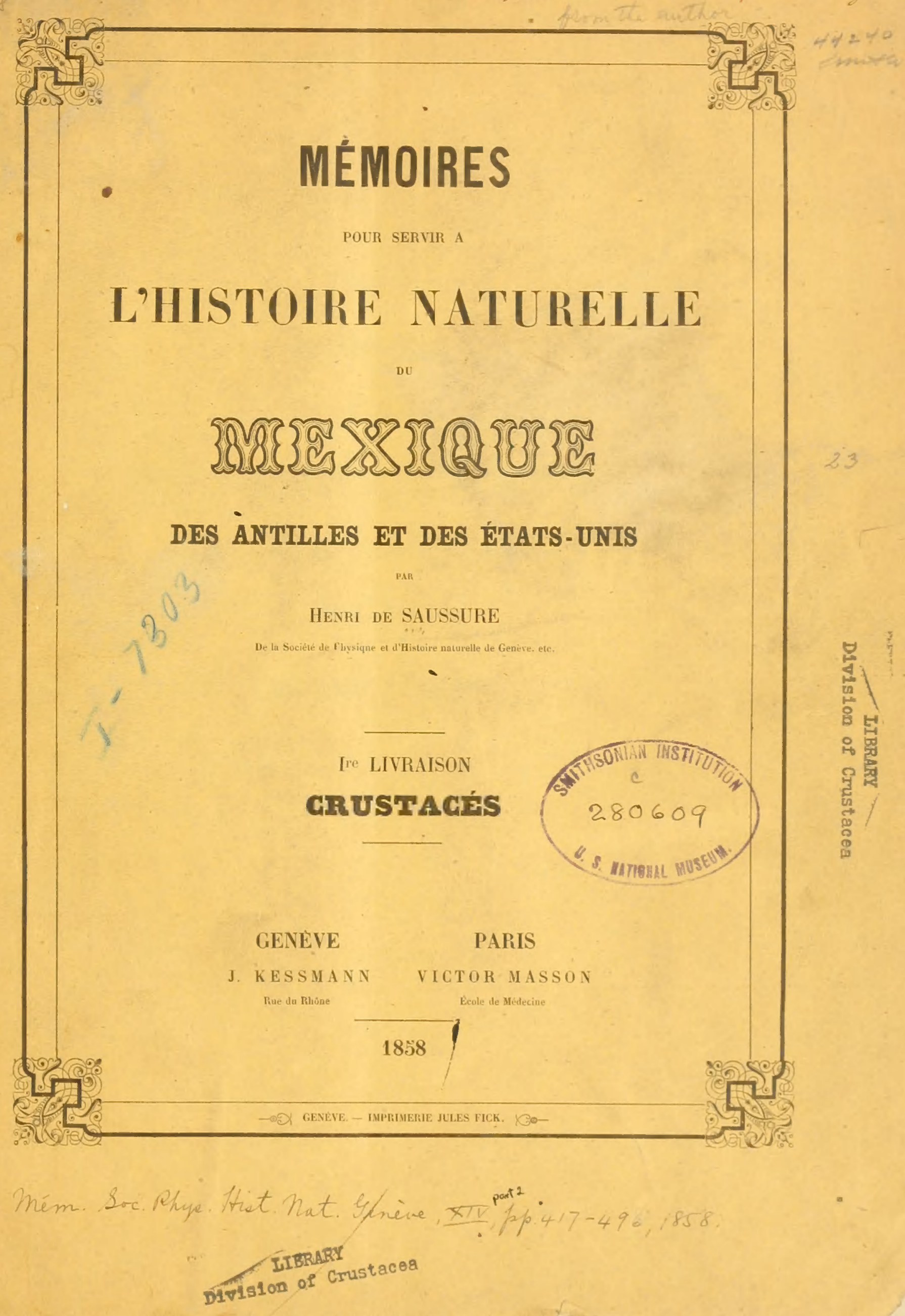





\section{MÉMOIRES}

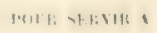

\section{L'HISTOIRE NATURELLE DU VIEXIQLE}

DES ANTILLES ET DES ETATS-UNIS

PREMIER UE IIUIRE 



\section{MÉMOIRE}

SLR DIVERS

\section{CRIST ICÉS NOUVEAUX}

III

\section{MEXIQUE ET DES ANTILLES}

HENRI UE SAUSSLPE:

Dus la Socièté de Physiqune et d'Histoire naturelle de Genève, etc.
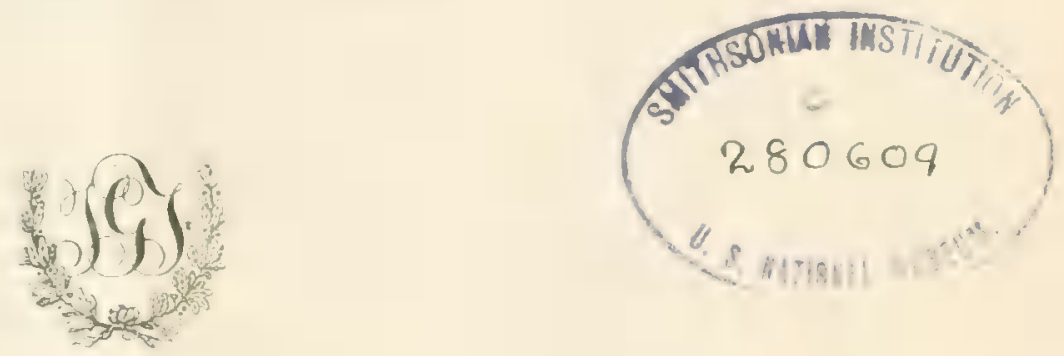

GENETE

IMPRIMERIE HLES-G FH FIK

1858 



\section{MÉMOIRE}

SUR

\section{DIVERS CRLSTACÉS NOLVEAUX}

DES ANTILLES ET DU MEXIQUE.

Les crustacés que ce mémoire doit servir à faire connaitre, ont été recueillis dans le cours de mon voyage en Amérique, soit aux Antilles, soit sur la côte orientale du Mexique. Un assez grand nombre des espèces que jai rapportées de ces contrées étaient déjà connues et je n'en fais mention que lorsque les notions incomplètes qu'on possédait à leur égard nécessitaient un complément.

Quant aux types nouveaux, je les ai étudićs avec soin, et jai cherché à obvier autant que possible par de nombreuses figures à ce que l'insuffisance du langage laisse souvent d'incertain dans les descriptions.

Malheureusement le zoologiste qui n'habite pas un grand centre scientifique et qui n'a pas à sa portée les vastes collections que ces centres renferment, rencontre les plus graves 
difficultés dans la détermination précise des espèces. Cette circonstance m'a forcé de laisser de côté un certain nombre de types indéterminés qui sont peut-être nouveaux, mais que je n’ai pas osé décrire comme tels, faute de pouvoir les comparer avec ceux dont ils se rapprochent le plus.

Le manque de livres est aussi une fréquente cause d'erreur. D'ailleurs la plupart des ouvrages qui traitent des crustacés caractérisent ces animaux par des diagnoses trop brèves et souvent incomplètes, de telle sorte que, lorsque la tradition manque, par suite de labsence de collections, il devient souvent impossible de dire si une espèce est connue ou non. Il est donc probable que, dans le nombre, j'ai décrit comme nouveaux certains types qui ne le sont pas, mais jose espérer quon aura quelque indulgence pour de semblables erreurs, et quion les attribnera anx canses cidessus mentionnées plutôt qu’à une négligence à laquelle je n’ai pas cédé.

Le nombre des espèces qui paraissent nouvelles est considérable pour le peu de temps quil m’a été possible de consacrer à leur recherche. En effet les crustacés forment parmi les animaux un des groupes qui échappent le plus facilement aux recherches des voyageurs, parce que, habitant la profondeur des mers, ils sont difficiles à capturer et parce que la proportion de leurs espèces dont la chair peut servir d'aliment est trop restreinte pour quielles figurent en grand nombre sur les marchés. Cette même raison fait que les pècheurs ne cherchent pas à s'en emparer et quils nont pas lhabitude de les prendre; aussi le voyageur en est ré- 
duit à ses propres forces; il n'acquiert que ce quil capture de lui-même, ou en se faisant assister par les pècheurs. Or rien n'est plus difficile sous les tropiques que de déterminer les indigènes à se prêter à une occupation sortant du cercle de leurs habitudes routinières de chaque jour. Une paresse invincible mêlée à beaucoup d'insouciance leur fait fuir tout travail s'il n'est pas indispensable. Du reste leur esprit est insensible à l'aiguillon de la curiosité; leur intelligence est difficile à exciter et les instruments de toute espèce leur font défaut. C'est dire que la pêche des crustacés marins est à peu près impossible, à moins quion ne se voue soi-mème presque exclusivement à ce métier et quion n'y consacre un temps considérable.

Les décapodes terrestres que leurs mours aériennes mettent plus à notre portée, sont doués de mouvements si agiles qu'ils s'échappent avec une merveilleuse rapiditén et gagnent des trous profonds dans lesquels ils s'enfoncent, on bien disparaissent en courant sur les branches des arbustes ou en se plongeant sous l'eau, à tel point que je ne réussissais à me rendre maitre des plus agiles, quien les tuant de loin à coups de fusil. Ces diflicultés feront comprendre pourquoi je n’ai pas réussi à rassembler un plus grand nombre d'animaux de cette classe, et pourquoi la connaissance des crustacés en général est encore relativement peu avancée.

La proportion très-grande d'espèces nouvelles que ma fourni une collection rélativement petite, montre que nous ne connaissons qu'une partie bien minime de la faune car- 
cinologique de l'Amérique tropicale, et que dans ces régions lointaines un investigateur habile, exclusivement voué à cette étude, pourrait être assuré d'avance de voir ses efforts couronnés d'un très-grand succès.

Une conclusion générale de la plus haute importance, que l'examen de la faune marine du golfe du Mexique vient confirmer, est l'espèce d'anomalie qui règne dans la répartition des crustacés à la surface du globe. IIr Dana fut le premier à signaler que les animaux de cette classe forment une exception remarquable, en ce sens que ce n'est pas dans le voisinage de l'équateur, mais au contraire sous la zone tempérée, qu'elle atteint son maximum de développement.

Les autres classes d'animaux, et tout particulièrement les articulés, offrent des faunes d'autant plus brillantes quion chemine des pôles vers l'équateur. Sous le tropique les espèces existent en plus grande abondance et elles atteignent une taille considérable quion chercherait en vain dans les faunes des régions tempérées. Ces deux circonstances de plus grand développement se montrent au contraire chez les crustacés dans des faunes éloignées de l'équateur, propres à l'Europe et à l'Amérique septentrionale, et situées sous la zone tempérée. Il est probable que, lorsquion connaitra avec plus de détail les productions zoologiques des mers d'Asie et de lOcéan pacifique, cette loi se trouvera confurmée sur toute la surface du globe.

La série de crustacés que j’ai réussi à recueillir et qui provient exclusivement de la zone torride, ne présente pas de grande espèce; le nombre de celles qui atteignent une taille 
moyenne est médiocre, et les petites espèces sont de beaucoup les plus nombreuses. Je dirai plus. J'ai cru entrevoir que les espèces communes aux côtes des Etats-Unis et à celles du Golfe du Mexique ou des Antilles, nacquièrent pas dans ces régions chaudes un accroissement de taille aussi considérable que sous la zone tempérée. Ainsi, les langoustes, prises à Cuba, sont plus petites que celles qui habitent la latitude de Philadelphie et de New-York. Le Peneus setiferus de la Floride est plus grand que la même espèce prise à l'embouchure des rivières du Mexique. Ce fait a toutefois besoin d'ètre confirmé par de nouvelles observations, car un voyageur ne séjourne pas assez longtemps en chaque lieu pour être assuré d'avoir toujours vu des types suffisamment adultes.

La faune carcinologique des eaux douces offre cette mème variété et cette même abondance dans les productions, qui sont le trait caractéristique des caux douces de l'Amérique septentrionale. Ainsi, les lacs et les nombreux cours d'eau des Etats-Unis sont peuplés de plus de douze espèces d'écrevisses, tandis que ceux de l'Europe occidentale n'en offrent qu'une scule. Cette multiplicité dans les productions, bien connue pour les mollusques des eaux douces de l'Amérique boréale, s’étend donc aussi aux crustacés, ce qui montre qu'elle est bien un caractère propre à l'Amérique et non un fait accidentel de la distribution de ces animaux. Au Mexique j’ai trouvé deux espèces nouvelles d'écrevisses, lesquelles, en s’ajoutant à deux autres, déjà décrites par Erichson, nous en montrent quatre, nombre qui permet de conclure à un chiffre plus élevé. Ciest beaucoup pour un pays éminemment sec, dans lequel les ri- 
vières sont rares et petites. On connait déjà deux Cambarus propres à Cuba; cette loi de multiplicité se confirme donc même dans les îles; néanmoins, le nombre des espèces qui vivent sous le tropique paraît être moindre que celui dont la faune de l'Amérique tempérée offre le frappant exemple.

Quant aux crustacés terrestres de ces régions chaudes et variées, jen ai rapporté un nombre trop restreint pour qu'il soit possible de rien formuler de bien précis à leur égard. Un genre nouvear, il est vrai, est venu s'ajouter aux anciens, mais limmense majorité de ces articulés appartient aux mèmes groupes que ceux dont l'Europe est peuplée, et elle offre avec ces derniers une ressemblance si frappante qu'on serait tenté de les prendre pour des espèces identiques. Tonte cette partie de la carcinologie, ainsi que celle qui traite des autres crustacés inférieurs de l'Amérique équinoxiale, est presque entièrement vierge et exigerait, pour être bien connue, de longues recherches, exécutées dans le pays même.

En parlant des crustacés terrestres, jen exclus ici les myriapodes qui feront l'objet d'un autre Mémoire, et dont la série est très-remarquable, tant au point de vue de la variété des espèces qưà celui de leur grandeur.

Nota. - Les diagnoses de la plupart des eruslacés qui sont decrits dans les pages qui suivent, ont paru en $18: 57$ dans la Revue zoologique. Il m'a semblé inutile de les citer ici. 


\title{
ORDRE DES DÉCAPODES.
}

\section{SECTION DES DÉCAPODES BRACIIILES.}

\author{
FAIILLE DES OYYRIIYQUES. \\ THEIBU MES MATENS. \\ Genre MithraX, Leach. \\ Sous-fiemre des Nithrax transtersaux.
}

Miturax inspidus, Herbst.

Je considère comme étant le jeune de celte espèce un petil individu ơ qui offre les parlicularités suivantes: La carapace est aussi longue que large, tandis que chez l'adulte elle est beaucoup plus large que longue; ses bosselures existent à l'état de lubercule; on voit à la base du rostre deux tubercules, plus en arrière deux autres, unc ligne transversale de cinq tubereules sur la portion antérieure de la région stomacale et trois sur sa portion postérieure. Les régions branchiales sont tubereuleuses, etc. Les tubercules des pattes sont à peine marqués el les mains sont grêles, mème chez le o". - Long, 0,014 .

Ce petit cruslacé a été pris à la Guadeloupe.

\section{Mithrax connutes.}

Testa uberculosa, marginibus spinosis; rostro perlongo et cornibus duabus acuminatis composito: pedes spinosi.

Ce crustace appartient, par l'ensemble de ses caracteres, aux Mithrax transversaux de M. lidwards, tandis que par ses formes, on général, il se rapproclie beaucoup plus des .4 . triangulaires. I ce propos, il est inutile de remarquer que 
le caractère tiré de la présence ou de l'absence d'épines aux pattes ambulatoires n'est pas suffisamment général pour servir à distinguer ces deux groupes.

†. Carapace ovoide, beaucoup plus longue que large, mème sans compter le rostre. Fosseltes antennaires dépassant insensiblement le basilaire des antennes externes. Rostre horizontal, formé de deux cornes aiguës et aplaties, peu divergentes; la longueur de ces cornes égale à la distance qui sépare les antennes externes. Orbites plus longues que hautes, entouries de six dents, dont une très-longue appartenant au basilaire de l'antenne, deux moyennes au bord orbitaire inférieur, une à l'angle externe, et deux ou trois très petites au bord supérieur; enfin, il existe encore une longue épine à l'angle interne, placée au-dessus de l'epine antennaire el sensiblement moins longue qu'elle. Bords latéraux de la caparace, armés en outre de doubles et dent la $6^{\text {me }}$. plus petite, est placée en dessus. Toule la caparace est couverte de tubercules dont les plus lateraux sont presque épineux. L'espace placé entre les tubercules et mème les plus gros d'entre eux sont ponctués. Région intestinale portant une rangée presque marginale de sept tubercules spiniformes, dont le médian un peu plus élevé, et les deux latéraux plus longs, regardant en haut. Dessous des régions branchiales armés de petites épines éparses. Pattes grèles, toutes très-épineuses, portant à la face du troisième et du quatrième article deux rangées de longues épines; on voit aussi souvent quelques épines qui sont plus irrégulièrement distribuées. Pattes antérieures grêles et peu allongées, comme chez les Mithrax triangulaires; le bras n'atteignant pas la base du rostre ( $q$ ). Carpes épineux; mains lisses, offrant seulement quelques tubercules a leur bord superieur, très-grêlles ct comprimées, ayant leurs doigts presque égaux. Cinquième et sixiène articles des autres pattes très-grèles, lisses ct glabres. Couleur jaunàtre ou rosée; les pattes souvent roses. - Longueur avec le rostre, 0,034 ( 3 pouces ); largeur sans les épines, 0,032 (1 pouce $4 \frac{1}{2}$ lig.): cornes du rostre, 0,0075 ; distance entre les angles postérieurs de sorbites, 0.020 ; longueur des mains, 0,025 ; du doigt mobile, 0,011 ; largeur uniforme de la main, 0,006 .

Habite: Les mers des Antilles.

Cette belle espèce ressemble beaucoup au. I. rostratus, Bell., mais clle en dillèe par les épines de sa carapace, qui sont différentes, et surtout par l'absence d'une seconde zone de longues épines au-dessus de celles du bord de la carapace: par une luut autre disposition des lubercules de sa carapace, qui est moins épineuse; par ses pattes bien plus grêles et plus épincuses, ete.; mais comme la figure qui accompagne le Mémoire de Bell est faite aver: une grande négligence, il ne serait pas impossible que notre espèce fìt identique à celle de 


\title{
DES AYTHLS ET MI MEXIUE.
}

l'auteur anglais. Voici, du reste, d'autres différences que je troure dans la description assez incomplete qu'il en donne: chez notre espèce les orhites ne sont pas circulaires. les cornes ne sont pas plus petites que la base des pédoncules oculaires; les derniers articles des paltes sont bien plus grêles tet ne sont pas garnis de poils.

La carapace est bien plus élroile antéricurement que chez le .1t spinosissimus et, par ses formes générales, ce crustacé indique une espèce de passage aux Pises, passage deja signalé par Bell à propos de l’eşice citée.

\section{Sous-fiente des Hilluax déprimós.}

\section{Vithrax minutes.}

\author{
(Fig. 1).
}

Minimus, M. sculpto affinissimus, sed testa pars anterior levis, polita.

Ce petit crustacé est pent.être le jeune du $\boldsymbol{H}$. sculptus. mais il offre arec lui quelques diflèrences qui mo le font eroire distinct.

Rostre occupant presque la moitié du front el formant doux lobes à peine partages par une faible echancrure. Orbites offrant a leurs angles internes deux petits tubercules superposés, séparés par une fissure horizontate, et a leurs angles externes deux autres lubercules semblables, moins hien marques. Bord supérieur de l'orbite lisse, coupé par une fissure. Région stomacale lisse. luisante, a peine bombee, saul dans sa partie postérieure; sur l'anterieure, on dirait que les bosselures sont effacés et que la carapace a eté polie; souvent on y voit une bosselure obluse en forme de trèfle ou de croix. Lus régions branchiales sont au contraire profondement seulptees; te chaque colte de la region stomacale on voit deux bourrelets obliques et parallèles, et, plus en arrière, se trouvent de chaque cole trois tubereules arrondis qui forment avec la région cordiale une ligne transversale, ete. Les dentelures des bords de la carapace sont bien marquees. Les pattes sont tres-relues ef nofirent que quelques petits tubercules. Le reste, comme cher le U. sculptus. - Long. 0,012; larg. 0.013.

Habite: Les mers des Antilles. Jen possede plusieurs individus des deux sexes.

La raison qui me porte à penser que ce. Milhrax est bien une espèce nouvelle el non le jeune d'une autre, c'est que la sculpture de sa carapace est moins bien marquec que chez le $y$. sculptus. Or chez les Vithrax on remarque que les bosselures el tubercules s'efineent avee l'àge plutòt qu'ils ne grandissent, 
en sorte que, si nos individus étaient jeunes, ils devraient avoir une carapace plus fortement sculptíe que le $M$. sculptus adulte. L'abdomen des màles présente du reste ses sept segments distincts et parfaitement développés.

\section{Genre PERICERA, Latr.}

Les Péricères offrent des caractères assez variables pour qu'une classificalion de leurs espèces en plusicurs groupes soit une nécessité. Fn effet:

$1^{\circ}$ Chez les unes l'élargissement du premier article des antennes externes est considérable, mais il occupe un plan inféricur; il tapisse la face inférieure du front, sans entrer dans la composition de ses bords; son angle externe concourt parfois à la formation du bord orbitaire inférieur, et les tigelles des antennes sont placées sous les cornes du rostre; les fosseltes des antennes internes s'avancent bien au deli du premier article des antennes externes.

$$
\text { (P. cormuta, Edw. - P. spinosissima, Sauss.) }
$$

$\vartheta^{\circ}$ Chez d'autres le rostre et le front sont plus lamellaires, plus élargis, en sorte que les orbites, plus écartées, permettent à la dent du premier article des antennes externes de s'interposer entre les cornes du rostre et l'orbite, de façon a concourir à la formation du bord du front; le second article de ces antennes s'insère au niveau des angles antérieurs des fossettes antennaires et la tigelle est plus latéralement placée.

$$
\text { (P. trispinosa, Latr. - P. villosa. Bell.) }
$$

$3^{\circ}$ Les antennes externes sont placées latéralement à còté des cornes du rostre; leur premier article, très-dilaté, s'élend au-dessous de l'orbite, et constitue une portion de son bord inférieur; sa dent terminale vient former l'angle orbitaire interne.

$$
\text { (P. heptacante? Bell. - P. bicornis, Sauss.) }
$$

\section{Pericera spinosissima.}

(Fig. 2).

P. rostro brevi, spinis orbitalitus elongatis, tcsta valde spinosi.

Cette nouvelle espece appartient à la division de celles dont l'épine du bord orbitaire supérieur dépasse de beaucoup l'article basilaire des antennes externes. 
q Cornes du rostre médiocres, Iris-divergenles, droites ot styliformes; (comparées à celles de la $P$. cornuta, elles sont aplaties, droites et triangulaires; leur longueur équivaut à la largeur du front, ou a peu près à la moitié de la distance (qui sépare un œil de l'autre). Orbites armées de trois épines longues el aiguës, dont la supérieure moins longue à proportion, mais plus aiguë que chez l'espèce citée. Carapace couverte d'épines Iongues ct aigues, disposées comme suit: Deux grandes, unies par leurs bases, de chaque còté, en arrière et en dessous de l'orbite sur la région branchiale antérieure; au-dessus de la postérieure de ces deux épines, une autre plus petite, souvent double. De cette derniere il part deux rangées de piquants, dont l'une. composée de trois petites épines, se dirige en ligne droite en arrière, et l'autre composée de deux grandes el d'une troisième plus petite, se dirige obliquement vers le bas en suivant la courbure des régions branchiales; au-dessus de la seconde grande épine on en voit encore une petite, et au-dessous deux autres, formant une ligne oblique, dirigée en avant. En arrière du rostre est une grande fossette dont les angles postérieurs sont marques par deux petiles épines. en avant desquelles sont deux petits tubercules. La ligne médiane est occupée par dix longues épines, dont quatre sur la région stomacale, trois sur les régions génitale ct cordiale et trois sur la région intestinale. De chaque còté du premier de ces piquants on en voit encore deux grands sur les côtés de la régrion stomacale; de ehaque côlé du cinquieme, un sur les régions branchiales; un de chaque cóté du septième et, en outre, sur chaque région branchiale deux plus latérales formant une ligne qui deseend vers lat troisième hanche. On voit aussi une ligne transversale de petiles épines non loin du bord postéricur de la earapace. Enfin il est encore des tubercules spiniformes autour du cadre buceal et les deux premiers segments de l'abdomen en portent un sur leur milieu. Les pattes antérieures sont relativement courtes, ear les bras n'atteignent que jusqu'au milieu du rostre; eeux-ci portent en dessus une ligne de cinq épines el offrent en vutre sur les còtés quelques tubercules, ainsi que les carpes. Les mains sont grểles, longues et lisses: les doigls, grêles et réguliers, joignent assez bien. Les pattes de la seconde paire sont bien plus longues que celles de la première et leurs cuisses sont ornées en dessus d'une ligne de tubercules. La couleur de ce crustacé, lorsquon a enlevé les poils du test, est rose de chair avec les doigts violets ou bruns. - Long. 0,061; larg. 0,048; sans compter les épines 0,041 . Longueur des cornes du rostre 0,010 ; distance d'une cornée à l'autre 0,022 .

Habite: Les mers des Antilles; Ia Guadeloupe. 


\section{Pericera bicorvis.}

(Fig. 3).

Minuta, tuberculosa, subtriangularis; rostri cornibus elongatis acuminatisque; testi in angulis lateralibus unispinosâ.

Carapace bombce, tuberculeuse, ayant son bord postérieur arqué et ses bords latero-antérieurs obliques, mais point bombes en debors. Front et rostre minces, lamelleux; dents du rostre formant deux cornes aigues, faiblement divergentes et séparées a leur base par une goultiere qui partage le front. Ce dernier, assez aplati, formant avec te rostre un plan plus incliné que le reste de la carapace. Antennes très-velues, tres-latérales, placécs en dehors du rostre. Les deuxième et troisième arlictes entièrement découverts, trèslongs, alleignant atu milieu de la longueur des cornes du rostre. Orbites peu saillantes, offiant un fable tubercule a leur angle posterieur et un autre a leur bord supéricur. Le basilaire des antennes venant former une longue épine à sou ansle interne of une petite dent a son bord inférieur. Le reste de la carapace bombe, a régions fortement dessinées el a faces latéro-antérieures comme tronques verticalement. Les bosselures des régions, couvertes de gros tubercules qui lui donnent un aspect raboteux. En procédant d'avant en arriore les principaus tubereules sont disposés comme suit: La région stomacale en porte 5 en ligne arquée transversale; la region genitale an prorte 4 , dans l'ordre de 2, 1, 1; la région cordiale 4, dans l'urdre 1, 1, 2. Les régions branchiales sont bosselées et uffreut en dessus de gros, lateralement de petits tubercules; enfin, a leur partie la plus saillante latéralement. clles sont armées de chaque colé d'une épine uniıue, dirigée de còté; sur la région intestinale, on roit quatre tubercules qui se continuent en une serie arquée avec ceux du bord postérieur des régions branchiales, lesquels se fondent souvent en une ligne saillante. (Tous les tubercules ne sont pas toujours égatement bien narqués. Paltes des quatre dernieres paires sans épines notables, cylindriques. Lras eourts, natleignant pas fe buul du rostro. armés a leur face supérieure et chez les plus grands sujets, dequatre ou cinq lubereules spiniformes. Mains lisses et glabres. Couleur rouge ou rose; dessous de la carapare. bras el mains hlanchàtres, marbres ou mouchelés de taches rouges Tout l'animal tress-velu; les pattes surtout l'étant extraordinatrement. Long. 0.031; larg. 0,023; cornes du rostre 0,006 à 0,007 ; bord front11-orbitaire 0,0115 .

Halite: Les coites des Antilles 


\section{TIEIUE IDES PARTHEVAPIEVS.}

\section{Gevre LAMbris, Leach.}

L'espèce que nous ajoutons à ce genre rentre dans la catégorie de celles qui ont une carapace plus large que longue, d dont les mains, inermes a leur face supéricure, ont leurs bords externe et supérıeur armés de nombreuses dentelures.

Quoique appartenant incontestablement aux lambres par la structure de ses antennes externes et de l'abdomen des màles, ce crustacé rappelle un peu le genre Parthenope par la forme triangulaire de sa carapace et par les prolongements de ses angles latero-postérieurs.

\section{Lambres Ciremelatus.}

(Fig. 4.

Rostrum magnum, triangulare, integrum; testa rugosa, utrinque longe spinosa; brachia dilatata et depressa.

Carapace triangulaire, n'étant pas bombee, mais a régions bien dessinées. Rostre furmant un triangle régulier, creusé ainsi que le front en goultière lisse ; sa pointe et ses hords entiers; de chaque côté, en avant de l'orbite, le bord offrant seulement un élargissement tuberculiforme rudimentaire. Orbites presque supères, cchancrant beaucoup la carapace; leur hord supérieur mince el entier; l'inférieur portant trois petits tubereules; leur angle externe recevant la crète tranchante du bord de la carapace. Cette dernière ayant sa région stomacale en tort oblus yui se dilate en une bosselure sur la région cordiale. Bords latero-an. térieurs formant une crète dentée en scie; garnis de chaque còté 6 ou 7 dents triangulaires, mais se terminant extérieurement par une erite entiere qui joint l'orbite el postéricurcment par une longue épine qui forme l'angle latero-posterieur. Face supérieure de la carapace densément ponctuée et portant en assez grand nombre de gros tubereules rugueux, cntre lesquels on en voit de plus petits. Sur la régrion slomacale il n'existe qu'un seul gros tubercule. Sur la portion antérieure de la région cordiale, on en voit trois autres très-espacés, formant une ligne transiersale; sur sa portion postérieure est une autre ligne de trois lubercules exactement semblable; et un tubercule occupe son centre. Les 
régions branchiales portent aussi de gros tulercules et leurs bords latéro-postérieurs offrent en-dessus, de chaque còté, une ligne de trois tubercules spiniformes; une septième dent du même genre oceupe le milieu du bord postérieur de la carapace. Pattes antérieures très-déprimées, !amellaires et très-élargies, joignant parfaitement contre la carapace; leur face inféricure lisse ; leur bord supéricur et interne armé de dents spiniformes rapprochées et le bord externe armé de longues épines lamellaires, tant aux bras quaux carpes et aux mains. Milieu du bras occupé par une ligne de tubercules; main lisse ou portant quelques petits tubercules épars; doigts lisses, aigus et fortement dentés a leur bord interne. Pattes des quatre dernieres paires grèles et lisses; leurs quatre articles terminés par une ejpine. Couleur d'un jaune rosé ou blanchàtre.-Long. 0,018; larg., sans les épines, 0,019; avee les épines, 0,024 ${ }^{\mathrm{m}}$.

Habite: Les mers des Antilles.- Plusieurs individus.

\section{FAMILLE DES CYCLOMÉTOPES.}

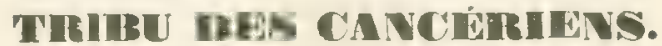

\section{Genre CHLORODIUS Leach.}

\section{Cillorodius americandos.}

(Fig. 5.)

Testa valde gibbosa, haud tuherculosa; frons sulco partita; manus magne, rugosex.

O Carapace n'élant pas tuberculeuse, mais fortement bosselée, sauf su: la région intestinale et sur l'espace qui s'étend de chaque còté de celte région, ou elle est lisse. Front ayant son bord inférieur comme festonné; sa partie médiane plus avancée que les lobes latéraux et parlagée par un petit sillon. Bords de la carapace armés de chaque côté de quatre dents mousses / sans compter l'angle orbitaire interne ); la premiere de ces dents, étant double, composée de deux tubercules superposés. Bosselures de la carapace ainsi disposées: sur la région stomacale, deux siphons à convexité tuurnce en arrière et dont la branche externe est la plus courte; de chaque còté des siphons, sur les régions branchiales, 
deux bosselures séparées par une gouttière, et en arrière de celle-ci, une troisième bossclure correspondant à la troisième dent du bord de la carapace. Région génitale unie. De chaque còté de celle-ci sont encore deux bosselures larges et unies formant, avec la troisième bosselure ct la troisieme dent du bord de la carapace, une série en ligne droite. Toutes les bosselures portent de grosses ponctuations éparses qui deviennent denses vers les bords latéro-postérieurs de la carapace. Pattes antérieures et mains très-yrosses, sans dentelures ni tubercules; carpes rugueux et ponctués, offrant un enfoncement angulaire; mains rugueuses en dessus, olfrant des rides ou des enfoncements réticu leux. Ises autres pattes dépourvues d'épines, ponctuées à leur portion dorsale, ayant les deux pénultièmes articles creusés d'un sillon de chaque côté. Couleur rouge de brique ou jaunâtre avec les doigts noirs, bordés de blanc. - Long. 0,014; larg. 0,022.; largeur du front 0,006 .

J'ai pris cette espèce sur les côtes de Haïti. A en juger d'après la figure, elle ressemble beaucoup au Chl. angulatus Edw., mais ses bras et ses mains sont dépourvus de tubercules.

\section{Genre Panopeus, Miln. Edw.}

Les trois espèces qui suivent appartiennent à la section de celles dont les bords latéraux de la carapace se prolongent jusqu’au niveau de la régiun cordiale.

\section{Panopeus occidentalis.}

$$
\text { (Fig. 6.) }
$$

Testa convexa, marginibus latero-anticis 5-dentatis; manus leves.

Carapace passablement voùtée dans les deux sens, mais surtout dans la direction antéro-postéricure, faiblement bosselce, de façon à offrir ses régions distinctes mais lisses, sans plissures sensibles. Front à peine bilobé, point granuleux. Bords latéro-antéricurs de la carapace atteignant au niveau du bord postéricur de la région stomacale, armés de chaque còté de cinq dents, dont les trois postéricures aiguës et les dcux antérieures obtuses, formant ensemble une crête tranchante bilobece. Echancrures du bord antérieur du cadre buccal bien marquées. Pattes des quatre dernières paires grèles; celles de la première paire forles; bras armés d'une dent vers l'extrémité antéricure de leur bord supérieur; carpe lisse armé d'une dent aiguë à son angle interne, ayant son sillon marginal large et 
profond; mains comprimées, lisses, leurs doigts assez grêles chez la femelle chez qui mème le doigl fixe est dirigé en has. Couleur d'un jaune rougeàtre avec les doigts hruns. - Long. de la caripace 0,016; larg. 0,017. Front 0,006\%.

Habite: Les Antilles, la Guadeloupe. Nous possédons un assez grand nombre d'individus des deux sexes appartenant à cette espèce.

\section{Pavopeus serratus.}

(Fig. 7.)

Testa minus convexa, corrugata, 10-dentata; carpis rugosis.

Carapace aplatic, fort peu voùtée. Front très-peu avancé, à peine bilobé. Angles internes des orbites assez saillants. Régions de la carapace n'étant pas bosselées, si ce n'est en arrière du front, mais offrant dans sa moitie antérieure des plis transversaux; ses bords laléro-antérieurs s’avançant jusquau niveau du bord postérieur de la région stomacale el armés de cinq dents aiguës. Carpes rugueux, armés d'une dent à leur angle interne. Maius grosses, finement rugueuses vers le haut; leur bord supéricur porlant deux crêtes mousses très-faibles.

Cette espèce est très-voisine de la précédente, mais elle parait cependant s'en distinguer par sa carapace moins bombée, par ses carpes rugueux et par ses mains rugueuses a leur bord supérieur. Les jeunes, quoique ayant la carapace fortement plissée, l'ont assez bombee et se rapprochent ainsi du P. occidentalis. Les femelles aussi l'ont assez bombée. Couleur jaunàtre ou rougeàtre. - Long. 0,016 ; larg. 0,022; front 0,007 .

Habite: Les Antilles, la Guadeloupe.

\section{Payopeus americanos.}

(Fig. 8.)

Minutus; testâ planà, precedentibus quadratiore. murginibus lobulatis.

Carapace plate un dessus, à peine un pu hosselée dans sa portion antérieure, ayant ses bords latéro-antírieurs très-tranchants, prolongés un peu plus loin que chez les espèces precedentes et partagés en quatre ou cinq lohes continus par des fissures qui ne sunt pas assez profondes pour dessiner des dentelures en seie. Front légèrement plus avancé au milieu. Orbites ayant leurs bords presqu entiers, a peine bosselés; leurs fissures du bord supérieur trésfaibles; le bord inferieur n'étant pas denté. mais seulement pen sinueux el 
l'hiatus de son extrémite interne ne formant qu'une laible échancrure placée très-haut, sous l'angle orbitaire externe. 13ras et mains à peu près lisses, carpe sans sillon ni dépression notables; son angle interne peu aigu. Les autres pattes très-grèles. Couleur jaunàtre ou rougeàtre. - Long. de la carapace 0,011 ; larg. 0,014 ; ; id. du front $0,0053^{\mathrm{m}}$.

IIabite: Les Antilles, la Guadcloupe.

Ce petit Panopece est lacile à reconnaitre al sa carapace plate en dessus el a ses bords à peine divisés. Mais surtoul la forme de la carapace est bien plus carrée el moins large à proportion que chez les espèces ci-dessus. Cette espèce forme une transition au genre Xanthe, soit par ses formes, soit par la petitesse de l'hiatus de l'angle orbitaire externe el inferieur.

\section{TIEIHE IDES IPORETUNENS.}

\section{Geyre PURTunUs, Fabr.}

Espèce ayant le front armé de trois dents ct la carapace presque unie et dépourvue de poils.

\section{Portunus guadulpensis.}

(Fig. 10.)

Testa lavis, 10-spingsa, marginibus latero-posicis concavis; mamus carinulate.

Carapace peu bosselée; la région génitale seule dessinée par deux sillons lattéraux profonds. Front orné de 3 dents également avanées; la médiane aiguë, les deux latérales plus arrondies el s'avancani bien au-dela des angles orbitaires internes. Espace compris entre les deux angles externes des orbites égal à la moitié de la largeur de la carapace ou un peu plus large. Bords latéroantérieurs de la carapace armés chacun de cinq épines très-aiguïs; hords lateropostérieurs concaves. Paltes assez fortement carénées; carpes carênés antérieurement, el armés à leur angle interne d'une très-longue épine. Mains forlement carènées, porlant sur leur face supérieure et antérieure trois lignes saillantes, sans compter celle du doigt fixe et celle du bord supéricur qui est tranchante et 
qui se termine par une petite dent. Les mains étant du reste finement et réticuleusement sculptées chez les individus adultes. Doigts fortement carénés chez

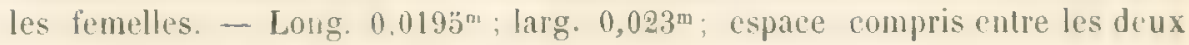
épincs externes des orbiles $0,0125^{m}$.

Habite: Les mers des intilles, la Guadeloupe.

\section{Gexre LUPEA, Leach.}

\section{Lupées nageuses.}

\section{Lupea micantila, Latr.}

Cette espece est très-répandue el très-commune dans les mers de l'Amériyue. Je l'ai prise a Haili, à Cuba, sur la côte du Mexique et jusqu'à New-Nork.

Elle n'est pas moins variable que répandue. Les dents du front sont sourent obtuses et presque nulles; les qualre miloyennes n'en forment que deux, dont la forme et la grandeur v arie. Ene femelle prise à Cuha offrail une carapace tris-bombé, des dents frontales toutes égales et les mains petiles. Mais la singularité la plus frappante de ces variations réside dins la dircrsité des formes que peut affecter l'abdomen du mà'e. Normalement cel organe a la figure d'un T renversé, mais dans un grand nombre d'indirilus que jai rapportés, il es parfaitement triangulaire. Chez les jeunes celle forme parail ctre constante, mais elle semble persister dans ertain indivilus mème a lahge adulte. Celte circonstanee m'aurait fail croire à l'existence d'une espèce nouvelle si je n'avais rencontré entre les deux formes des transilions de tous Jes degrés.

\section{Lupées marcheuses.}

Espèce ayant la dernière dent de la carapace très-grande, Jes dents médianes du front plus petites que les latérales el les mains moins longues que la carapace n'est large.

\section{LUPEA ANCEPS.}

(Fig. 11.)

Hinuta, latcribus dentibus armatis, quorum ultimus longissimus; manus graciles, spinose, lestî longiores. 
Carapace hexagonale, couverte de faibles sillons tortucux qui produisent des dessins sinueux; bords latéro-postérieurs armés de dix dents, toutes très-pelites et aiguës, sauf celle qui constitue l'angle orbitaire externe, laquelle est plus grande, et la derniere qui forme une grande épine dirigée transtersalement. aussi longue que le front est large, mais mème mesuréce a sun bord postérieur) bien moins longue que le bord latéro-antérieur de la carapace. Front armé de quatre dents, dont les moyennesplus petites. Pattas antérieures médiocrement longues; bras armés à leurbord interne de trois ou quatre épines et en portant une à l'extremité de leur bord postérieur. Carpes portant des lignes saillantes et armés de deux épines aiguès. Inins pl us longues à proportion que chez la $L$. dicantha, plus longues que la carapace, mais bien moins longues que son diamètre transwersal, mène sans compter les cornes latérales, assez grêles, fortement carćnées, armées à leur hase d'une épine qui figure comme une troisieme dent du carpe. et de leux autres á l'extrémité du bori supérieur de la main. Doigts grêles, fortement carénés, crochus aut bout et joignant bien; moins longs que la portion palmaire de la main. (îg. 11, b) - Long. de la carapace $0,012^{\mathrm{m}}$; larg. $0,0263^{\mathrm{m}}$; id. sans les épines laterales, au niveau de la pénultième dent des bords latéro-antérieurs $0,019^{\mathrm{m}}$.

Habite: Les Antilles. Prise a Cuba.

Cette gracieuse petite Lupéc représente peut-ètre le jeune àge de la $L$. forceps. Cependant ses mains sunt tellement plus courles que chez cette espèce qua moins dadmeltre unc transformation tolale dans les formes, il faut bien la considerer comme distincte

\section{FIMILE DES CATOUETOPES.}

\section{'TIRHE IDES 'THELPIISIENS.}

\section{Genre POT AMIA, Latr.}

L'espece que je place ici dans ce genre, mavail d'abord paru devoir servir de type à un genre nouveau, intermédiaire entre les Potamia et les Thelphuses el que j'ai publie sous le nom de Pseudothelphusa. Mais ensuite j'ai craint d'aroir contribué a multiplier les genres outre mesure et j’ai cru pouvoir faire figurer ce erustacé parmi les Potamia en établissant pour lui une petite division qui serait caractérisér ainsi que suit : 
Troisième article des pattes-màchoires à peu près triangulaire (fig. 12,a), donnaut iusertion à l'article suivant par une échancrure de son angle interne qui forme le sommet du triangle. Carapace conme chez les Potamia; très-large, plate; très-élargie aux régions branchiales, fortement rétrécie col arrière, mais dépourvue de crète postfrontale. Tarses armés, non pas de quatre rangées d'cpines comme chez les autres Polamics, mais de cinq rangées; la face supérieure du larse portanl la cinquième rangée sur son milieu. Régions jugales glabres et lisses, sans granulatious ni sillons; mais le cadre buecal entouré d'un duret tomenteux.

A ces caractères on peut ajouter que les régions de la carapace sont à peine marquées; que le front cst peu incliné, et que les pattes-màchoires sont larges et lisses, sans sillons ni saillies. Leur denxième article est relativement court. sa largeur élant égale à celle de son bord interne; son articulation avec le troisieme article se fait par une ligne droite, el le palpe est assez court pour ne pas atteindre à beancoup près le troisième article. Les bords et la carapace sont très-tranchants et dépourvus d'épines. Enfin les pattes sont plus grêles que choz les Thelphuses; la première paire est lisse, et porte des mains assez allongées, it doigts arrondis, lisses, sans sillons ni crètes, un peu arqués en cuillère et garnis d'une rangée de petites dents.

Ces crustacés ont le mème genre de vie que les Thelphuses; ils habitent les bords des rivières et des marais

\section{Potamia americana.}

Fig. 12.)

Testa marginibus acutis, haud dentatis.

I'seudothelphusa americana, Sauss. Revue el Mag. de Zool. 18:37, p. 305.

Pattes-màchoires lisses, sans crêtes ni sillons; dent triangulaire de l'épistome peu marquée. Carapace très-large, dépourvue de dents, plate, lisse, à peine bosselee. Front incliné, nullement rugueux; son bord sculement regardant en bas ot partagé par une gouttiere rudimentaire. Orbites petites et régulières, ovales, sans dentelures, sans cepines a leurs angles externes. Bords latéraux de la carapace tròs-tranchants, finement granulés. En arrière du front un petit sillon transver sal et sinueux. Bras ayant leur bord interne finement denticulé. Carpe lisso ot luisant, offrant seulement au milieu de son bord interne une forte dent. Mains lisses; doigts arrondis, finement ponctués, mais sans lignes de gros points. Less 
autres pattes grêles. A la face inférieure de loules les pattes, on voit à l'origine du troisième article un petit cercle enfoncé, figurant comme une espèce de granule. Première épine de la cinquieme rangée des tarses, double. Couleur d'un brun caf́c-au-lait ou blanchâtre.

Long. de la carapace $0,022^{\mathrm{m}}$; Jarg. $0,034^{\mathrm{m}}$, front $0,009^{\mathrm{m}}$; espace d'un angle orbitaire externe à l'autre $0,0195 \mathrm{~m}$.

On voit par ces mesures que la larg. In front équivaut à un peu moins de l'espace comprisentre !e milicu du front et l'angle orbititire externe, et que le luuble te cet espace n'équivaut pas aux deux tiers de la larg. de la carapace.

Ilabite : l'Ile de Haiti.

\section{THEHE DES GECARCINIENS.}

\section{Gevre CARIJISOMA, Latr.}

\section{Cardisoma Guaniomi, Marg.}

Le signalement de cette espèce doit être complété comme suit:

Carapace à peine bordée, très-convexe, très-renflée de chaque côté, et fortement rétrécic en arrière. Front plus large que les orbites. Portion libre des pédoncules oculaires aussi longue que la cornée. Bras en général cyindriques. Grande main énorme.

C.e cruslacé est très-commun aux Antilles, le long des lagunes salurées du bord de la mer, ou il creuse de gros trous qui se remplissent à moitié d'eau. Je l'ai pris à Cuba, à Ilaili, a la Jamaique. On le trouve aussi sur la eòte du Mexique, le long des rivières, souvent jusqu'à une grande distance de leur embouchure, et le long des marécages. Il affectionne un sol sec à la superficic, mais bien imbibe d'eau unc certaine profondeur. C'est toujours dans les lieux ombragés d'arbres et de buissons qu'il habite, aussi, jamais on ne le trouve sur la plage de la mer. Aux environs de Vera-Cruz, ce crabe habite en grand nombre les taillis qui couvrent le sable sec et brùlé des dunes, mais il reste toujours dans les bas-fonds ou l'humidilé se reneontre a une certaine profondeur sous la surface du sol.

Les vieux individus sont blancs; mais en général ce crabe a une couleur orangée. Il est moins limide que les gécarcius; lorsqu'on le surprend en promenade, éloigné de son trou ou de tout autre refuge, il fait face at danger, se 
dresse sur ses paltes postérieures et combat hardiment avec ses pinces redoutables. On s'empare facilement de lui en lui tendant un biton, qu'il saisit avec rage et par lequel on peut alors l'enlever de terre. Il périt rapidement lorsqu'on le tient caplif, faute de pouvoir retremper ses branchies dans l'humidité de sa demeure.

\section{Cardisoma quadrata.}

(Fis. 13).

Testa valde marginata, utrinque bidentata; brachia prismatica, marginibus inferis denticulatis.

Carapace anguleuse, assez carrée, bombe d'avant en arrière, ne l'étant guère transversalement; son bord antérieur presque aussi large que la carapace légal aus $5 / 6$ de sa largeur), plus large que la carapace n'est longue, et terminé de chargue còté par une épine (l'orbitaire externe), en arrière de laquelle est une petite dent. Front entre les pédoncules oculaires presque égal à la largeur des orlbites, un peu creusé. Carapace lisse, à peine bombéc, finement granuleuse le long des orbites et sur le front. Régions branchiales tinement plissées latéralement et portant une crête tranchante qui borde la carapace dans ses deux ticrs antérieurs. Celle-ci point bombée latéralement, mais au contraire tronquée obliquement, en sorte que ses taces supérieure ef latérales se rencontrent pour former un tranchant.

Patles garnies de pinceaux de poils noirs; leur troisieme article ayant sa face infirieure un peu convexe el ses bords tranchants. Tarses très-épineux.

Paltes antérieures inégales, bras prismatiques, olinant trois faces, séparées par des arètes, dont les inferieures, garnies de lubercules spiniformes obtus, et la supérieure ridée. Face externe du bras anguleuse. Carpe granuleux ou ponetuc. armé a son bord interne d'un angle épineux. Mains inégales, grossièrement et irregulièrement piquetées; leur bord inférieur granulcus. Doigts variables, un peu courbés; ceux de la petite main cannelés. Coulour d'un roux orangé. avec de grandes taches noiràtres. Les petits individus, jaundites, ou finement piquetés le rouge et de jaune, avec des teintes verditres à l'endroit des taches.- Long. 0,038 $8^{\mathrm{m}}$; larg. $0,043^{\mathrm{m}}$.

I'ai pris ce crustacé en assez grande abondance a llaiti, le long des mares salurces des bords de la mer.

Quelque dillérente que soit celte espèce du $C$. Guanhumi, il ne serait pas inpussible yu'elle n'en fìt le jeune. En eflet, elle vit daus les mèmes lieux. 
de la même maniere, et je n'ai jamais trouvé de pelits individus ayant les lormes du C. Guanhumi. Puis, les sujets les plus grands du C. quadrala ont les faces latérales des régions branchiales un peu plus hombées que les petits. II scrait possible qu'avec l’àge les épines el crêtes latérales disparussent el que la carapace se bombàt el s'élargit beaucoup. Iinsi chey les plus petits individus la cornée est deux fois aussi longue que la portion libre du pédoncule oculaire, landis que chez les individus plus grands elle diminue au poinl d'avoir la meme Inngueur que celte porlion, comme cola se voit chez le C. Guanhumi.

\section{Genre Gechrcinus, Latr.}

L'espèce nouvelle qui suit appartient a la section de celles dont les tarses n'ont que quatre rangées d'épines. La configuration remarquable de ses maxillipèdes me parait indiquer din s le genre Gecarcinus un groupe spécial.

\section{Gecarcinus depressus.}

Fig. 14

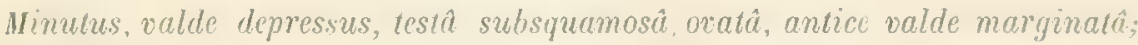
maxillipedum articulus tertius ovatus, a ntice haud coarctatus.

Carapace subcireulaire peu ou pas tronquée sur ses faces latéro-postérieures, très-plate cl déprimce, n'élant hombéc que sur la région stomacale; ses bords porlant une crête tranchante, mais qui n'en necupe que la moilié antéricure et qui devient très-avancée vers l'œeil, à còté duquel elle forme une petite dent. Derrière l'angle externe de l'orbite, une petile fossette. Front vertical. Pord anlericur de la carapace, entre les deux angles externes des orbites, sensiblement plus large que la moilió de la carapace. Celle-ci n'étant pas lisse, mais finement striolée, subécailleuse; ses faces latérales finement ef densément plissées, et ayant ses régions jugales couvertes de plis écailleux. Lobes sous-orbitaires internes très-étroits, presque prismatiques, porlant une forte crète oblique très-saillante qui part de l'angle inférieur du front. Troisieme article des palles-maichoires ovalaire (lig. If $a, 14 b, 14 c$ ), bicn moins large que le deuxième. mais n'étant pas rétréci en avant el l'étant à peine en arrière; son bord antérieur subéchancré; l'interne non angulaire, mais faiblement arqué. Troisieme article des pattes sans épine à son bord su- 
périeur. Paltes antérieures égales. Carpe armé d'une dent à son angle interne ol olliant en dessous de celle-ci une autre dent plus pelite. Tarses garnis de quatre rangées d'épines. Couleur jaunàtre, avee le devant de la carapace et les pattes antérieures rougeàtres.- Long. 0,015 ${ }^{\mathrm{m}}$; larg. 0,0183 ${ }^{\mathrm{m}}$.

Habite: L'lle de Haiti.

Cette jolie petite espice est bien nettement caractérise par la forme tout exceptionnelle de ses patles-mahchoires et de ses lobes sous-orbitaires internes. Sa carapace déprimée el couverte de strioles qui, à la loupe, lui donnent un aspeet écailleux, sont aussi trés-caractéristiques. Enfin la carapace est beaucoup plus circulaire que chez les autres espèces et ses crêtes latérales, sans être dentelées, sont plus saillantes. Quvique très-pelit, ce Géearcin me parail être adulte, car sa carapace est très-dure et surtout les régions branchiales sont très-renflées latéralement; or j’ai toujours remarqué que les jeunes l'ont au contraire plubt carrée, et II. Gersticker a dernièrement publié une observation du mème genre.

Pour la comparaison, je domne ici les principaux caractères du G. lateralis.

\section{G. Lateralis, Frem.}

Carapace bombée depuis la région cordiale; son bord antérieur égal à la moitić de sa largeur, ou la dépassant à peine. Carapace luisante, portant des points enfoncés épars. Lobes sous-orbitaires internes larges; leur crèle naissant en dedans de l'angle du front Troisieme article des palles-mâchoires fortement rétréci a sa base et au bout; son bord interne angulaire, son bord antérieur oblique et échancré, subbilobe. Crète latéro-antéricure de la carapace denticulée ou granuleuse.

\section{THEIL IUES OCYPOLIENS.}

J'ai rapporté des Antilles quelques ocypodes dont l'espece me parait douteuse quoique se rapprochant de l'o. rhomber, Fabr. J'ai aussi recueilli en grande abondance une ou plusieurs espèces de Gélasimes sur les còtes de IIaiti, de la Jamaique, de Cuba et du Mexique, mais il ma été impossible d'en fixer la détermination avec quelque certitude. La plupart des Gúlasimes se ressemblent du reste si intimément que leursespeces sont loin d'ètre élabl ies avec précision; il est probable qu'on les a trop multipliées en se hasant sur des variétés d'àge ou de 
sexe. Ceux que j’ai récoltés et qui paraissent se rapprocher le plus du $(\dot{r}$. vocans, ont la carapace fortement rétrécic en arrière; sa tranche oblique latéro-postérisure est inférieurement bordée par une ligne saillante qui part du point ou commence la troncalure de la carapace et va gagner la base de la cincuième patte en décrivant une courbe un peu sinuée en $\mathrm{S}$. La loranche inférieure de la grande pince offre à peu près au milieu de sa longueur un petit tubercule constant, et la face palmaire de la main porte des lignes de lubercules. Le borl sourcilier inférieur est plus ou moins arqué sclon l'àge. Les plus jeunes individus paraissent l'avoir le plus arqué. Les jeunes femelles nont que de petites pinces. mais les jeunes mâles en portent déji une grosse et courte.

Ces crustacés vivent en immense abondance le long des lagunes dés còtes et à l'embouchure des rivières, partout ou le sol est sablonneux. Les rives de ces eaux sont littéralement criblées de leurs trous et, le ınatin, on voit les gélasimes courir par milliers sur les sables humides qui leur servent de demeure.

\section{TREIBU ULG GIBAPSOIDIEVS.}

\section{Gerre SESAR IIE, Miln. Edw.}

Les deux espèces que nous ajoutons a ce genre n'ollient pas d'épine sur leur bord épibranchial autre que l'orbitaire externe. Le troisième article de leurs pattes-mâchoires est allongé.

\section{Sesarma hmericana.}

Frons verticalis, margine infero reflexo, lobis suprafromlalibus valde partitis, cormugatis; tarsorum articulus quintus latus; manus graciles.

q Carapace strioléc. Front très-large, plus grand que la moilié de la largeur de la carapace, vertical, mais ayant son bord inférieur fortement rélléchi en avant et disposé en lame horizontale. Lobes frontaux formant une crete transversale et profondément partagés par une gouttiere lisse, centrale et large, et pall deux fissures latérales. Régions branchiales plissées; portion antéricure de la carapaee et surtout les lobes surfontaux rides transversalement, presque écailleux. Régions moyennes et postérieures de la carapace distinctes, entourées de plissures ou rugosités fines. Portion réfléchic du front ruguleuse aussi. 
Paltes ayant leurs articles très-comprimés, fortement bordés; leur cinquième article relativement large et le sixième relativement court. Carpes très granuleux, portant une faible dépression et ayant leurs bords garnis de granules épineux. Mains allongées, couvertes de ponclualions granuleuses el ayant leurs doigts plus longs que la portion palmaire. Troisième arlicle des paltes-màchoires très-allongé, triangulaire, avecses bords fortement relevés, surtoutl'interne, dont le bord réfléchi est assez étroit. Couleur brunàtre ou jaunàtre. Long. $0,017^{\mathrm{m}}$; larg. postér. $0,0195^{\mathrm{m}}$; larg. antér. $0,018^{\mathrm{m}}$; front $0,010^{\mathrm{m}}$.

Halite: Les Antilles. Prise à Saint-Thomas.

Celte Sésarme ressemble fort à la $S$. cinerea, Bose., mais elle a les lobes surfrontaux bien plus saillants, le front plus large, plus réfléchi a son bord inférieur, la carapace plus fortement striée.

\section{Sesarma miniata.}

Testa praecedente convexior, punctis piligerisoperta; frontis lobae suprafrontales parlum proeminentes; maxillipedum articulus tertius piriformis.

Carapace à peinc bombée, unie el légèrement convexe, offrant sculement un sillon qui dessine la région génitale en arrière. Lobes surfrontaux pel élevés peu fortement séparés, noflrant pas une tranche verticale eomme chez la s. americuna; les litcraux surtout fort peu marqués; les centraux sćparés par un sillon plutòt que par une gouttiere. Front moins vertical, mais plus long de haut en bas, offrant quelques petites éminences. surtout sous les lobes medians. Vors le bas il s'élargit faiblement parce que ses angles latéraux s'avancent un peu latiralement, en sorte que le bord inféricur est plus large que la portion superieure. Les orbites echanerent un peu la crète surfrontale? Régions branchiales plissées, mais la portion anterieure de la carapace ne l'étant pas comme chez la S. americana, nolfrant aucune trace de rides. Toute la carapace couverte de petites poneluations qui émettent chacune un poil noir, et oflrant en outrede plus gros points épars qui portent deux ou trois poils de cette couleur (ceci, surtout visible a la loupe). Palles couvertes de grosses ponctuations ou écailles piligeres, surtout au troisième article. Cinquième article des quatrième el cinquième

\footnotetext{
' Ces caracteres sont très-distinctifs et ícartent toute confusion avec la $S$. americana.
} 
paires, grêles; l'étant plus à proportion que ceux de la deuxième paire et bien plus grèles que chez la S. amoricanx.

Pattes antérieures courtes et grosses; carpe gros, granuleux et garni de poils. Mains courtes el renflées. lisses et ponctuées, ayant les doigts plus courts que la portion palmaire. Troisième article des pattes-màchoires ponetué, sauf sur la portion marginale interne, qui est large; cet article moins long que chez la $S$. cinerea, n'étant pas triangulaire, mais pyriforme, arrondi au bout. Couleur d'un jaune orangé ou rougeàtre, finement moucheté par les poils noirs de la carapace; patles souvent marbrées, - Long. $0,015^{\mathrm{m}}$. larg. en avant $0,016^{\mathrm{m}}$; en arrière $0,017^{\mathrm{m}}$; front entre les orbites $0,008 \%^{\mathrm{m}}$.

Ilabite: Les Antilles; Saint Thomas. Jai rapporté plusieurs individus of et $q$ de cette espèce; elle est communc sur la còle de l'île.

Nota.-La largeur du front entre les orbites est égale ou plus petite que celle de la moitié de la carapace mesurée à sa portion postérieure. Chez la $S$. americana. c'est l'inverse; le front est plus large que la moitie de la carapace.

\section{Genre METOPOGRAPSUS, Edw.}

Espèces appartenant au groupe de celles qui ont la carapace armie de chaque coté de deux dents et dont le front n'est pas rabattu verticalement, mais seulement incliné obliquement.

\section{Metopograpsus gracilis.}

(Fig. 1) .

Frons teste dimidio latior; teste margines laterales recte, nullo modo arcuate; nanuum margo superior rugosa.

q Carapace régulièrement voùtéc; sa partie antérieure assez inclinée cl se continuant par le front, qui est oblique, et qui forme une bande transversale. légèrement concave, ayant son bord inferieur à peine relevé, mais tranchant. Lobes surfrontaux très-peu marqués; les latêraux nuls; les médians indiqués par deux pelites erètes obliques, finement granuleuses, n'oecupant pas la moitie de la largeur du front et séparces par une très-faible gouttière. Toute la carapace. lisse et luisante, ayant sa portion antéricure ridée et garnie de grands plis transversaux reguliers, le front seul en élant dépourvu. Régions branchiales 
couvertes de plus grands plis obliques. Régions génitale, cordiale el intestinale, bien dessinées, mais sans plis. Bords latéraux de la carapace droils, porlant dans toute leur longueur une crète tranchante; leurs dents aiguës el fortement séparées; la carapace élant également large au niveau de ces deux épines et se rétrécissant à partir de la seconde. Paltes très-comprimécs; leur cinquième article large. Le troisième article plissé, garni de petites épines le long de son bord supérieur el armé de trois ou quatre grandes épines aigueis à l'extrénité de son bord inféricur. Bras fortement ridés; leur crète interne bordéc antérieurement par trois ou quatre épines aiguës, et leur angle inferieur s'avangant en forme de dent. Carpe ridé, armé à son angle interne d'une grande épine courbe, souvent double. Mains comprimées, lisses, mais ridées à leur bord supérieur (fig. I: b); portant vers le bas de leur face interne une crète qui s'étend sur le doigt fixe. Doigmobile tuberculeux a son bord supérieur. Troisième article des pattes-machoires bien plus large que long. Toute la carapace est finement mouchelíe de jaunàtre et de brun en dessus; les pattes sont brunes, marhrés de blanchàtre. Les parties inférieures sont blanchâtres.-Long. $0,016^{\mathrm{m}}$; larg. maximum, mesurée entre les dents latérales de la carapace $0,021^{\mathrm{m}}$; larg. du front $0.014^{\mathrm{m}}$.

Habite: Les Antilles. Je l'ai pris sur les còtes de l'ile de Saint-Thomas.

\section{Metopograpses miniatus.}

\section{(Fig. 17.}

Frons teste: dimidio arctior; teste margines laterales arcuater; manus leeves; lobe suprafromales distincte:

$\sigma$ Espèce ressemblant beaucoup au $M$. gracilis, mais s'en distinguant bien neltement par les caractères suivants: Carapace plus bombée, moins régulièrement voùtée. Sa portion antérieure plus ereusee au milieu, plus bosselée. Lobes surfrontaux distincts, séparés par des sillons; les latéraux aussi larges que les médians et s'avanşant bien plus en avant. Front bien plus court ed sinueux, élant égal en largeur à la moitié de la carapace. Angle interne et posterieur des orbites formant presque un angle droit. Bords lateraux de la carapace plus arqués, en sorte que sa portion la plus large se trouve placée en arriere des epines; la carapace se rétrécil ensuite un peu vers les urbites en sorte que la dent postérieure est placée plus en dehors que l'antéricure. Pattes moins épineuses; leurs dents étant moins aiguies; celles du carpe obtuses. Mains et le doigt mobile, lisses et bien plus renfles que chez le $M$. 
gracilis, fig. 17 b) Couleur jaunâtre ou brunàtre. - Long. $0,012^{\mathrm{ni}}$; larg. $0,016^{\mathrm{m}}$; id. du front $0,0082^{\text {m }}$.

Irabite: Les Antilles; Saint-Thomas.

\section{Metopograpsus nubius.}

Fig. 16.

Frons lata, lobis suprafrontalibus distinctis; manus glabres; teste margines laterales vix arcuate.

q Ce type est pres(jue intermédiaire entre les deux précedents. En effet, il at le front Jarge comme celui du $\mathbf{H}$. gracilis, mais court el sinueux comme chez le 1. miniatus. La portion antéricure de la carapace est bombée, partagée par trois gouttières de facon it dessiner les lobes surfrontaux comme chez celte dernière espèce. Mais les bords latéraux de la carapace sont bien moins arqués; la plus grande largeur de cette derniere est à l'épine postérieure; les dents épibranchiales sont aiguës el bien séparées, presque comme chez le $\boldsymbol{M}$. gracilis, landis que ses carpes et ses mains sont conformés comme chez l'autre espèce. La couleur est brunàtre ou marbrée - Long. $0,013^{\mathrm{m}}$; larg. $0,0215^{\mathrm{m}}$; id. du front $0,009^{\mathrm{m}}$.

Hème patrie que les précédents.

Je ne contais pas suffisamment bien les rapports de différence qui séparent les crustacés assez rares de ce genre pour oser rien formuler de précis quant à celle espéce, que je serais enclin à considérer comme la femelle du. . miniatus, sans l'extrême largeur de son front et la forme bien différente de sa carapace.

\section{Gipre GONIOPSIS, de Haan.}

Les crustacés qui font partie de ce genre, vivent le long des lagunes salurées des bords de la moret sur les bords des rivicres, non loin de leur embouchure. Ils aiment à sortir de l'eau pour se promener sur les branches des arbustes qui la surplombent et dont les rameaux sont en partic immergés, de façon a leur offir un pont naturel pour regagner leur retraite aquatique. Ces animaux 
sont en mème temps agiles et ombrageux et on ne parvient pas facilement à s'en emparer, quoique leur couleur d'un rouge vif trahisse leur présence el les fasse remarquer plus que les autres crustacés amphibies ou terrestres.

Les individus que j'ai rapportés paraissent bien appartenir au G. ruricola, Deg. Ils ollrent toutefois certaines particularités dignes de remarque, qui indiquent peut-ètre une différence entre cette espèce et celle du Brésil. et qui m'engagent à en donner ici une description abrégée.

\section{Goniopsis ruricola', Deg.}

Fig. 18, $18 a$.

Eprstoma lobss suprafrontalibus arctius; fromtis latera utrinque cum line is yranulosis proeminentibus.

Carapace bien plus large que longue. Front aussi large que la moitié de la carapace, presque vertical, trois fois et demie plus large que haut; son bord infírieur très-avancé, n'étant pas aussi large que la moitié de la carapace, sinueux et granulé, surtout sur les còtés, ou les granulations deviennent subspiniformes, Lobes sous-orbitaires internes plutôt triangulaires que demi-cireulaires. Bord labial oflirant une épine médiane el garni de piusieur's autres petites épines. Lohes sur-frontaux formant une crête granuleuse transversale; les latéraux un peu moins larges que les médians. Front tout garni de petits tubercules, mais ses lobes médians souvent assez lisses. et les lateraux portant vers le bord orbitaire interne deux ou trois crêtes granuleuses transverses el superposées, surtout dans les gros individus. Carapace ridée transversalement, mais ayant les régions cordiale et génitale lisses et bosselées. Pattes antérieures très-épineuses; leur bord inférieur externe garni d'une rangée de grosses épines lamelleuses, et le bord interne et inféricur armé d'une grande crête mince, dont le bord est dentelé de longues épines. Carpes très-tuherculeux, tris-epineus vers leur is ro interne, couverts de lignes courbes de petits tubercules. Mains très-comprimées, en général inégales, avec leurs bords supéricur el inferieur garnis de tubereules ínineux, qui se prolongent sur les doigts, lesquels sont courbés en cuillère. Surface supérieure de la main lisse, avec une crète très-faible vers le bas, el souvent des tubercules près de sa base; sa face inférieure au contraire garnie de tubereules ipars, ete.

Ii. cruenialus, Latr. 
Carapace mouchetée de petites taches; pattes marbrées de laches assez grandes, rouges et jaunes. Pattes antérieures rouges avec les mains blanchàtres, sauf a leur bord supéricur. Poils des pattes noirs.

Ilabite: Les còtes de Cuba.

Je possède en outre deux individus originaires de la còte orientale du Mexique. et qui diflèrent des précédents par les caractires suivants. Front presque quatre fois aussi large que haut, plus creusé, vertical au sommet, son bord plus avancé, à peine granuleux au milieu, plus densément semé de tubercules, sans crètes granulcuses distinctes sous les lobes surfrontaux externes. Deuxième article des paltes-màchoires un peu plus ćlargi au sommet. Pédoncules oculaires plus courts; leur partie basilaire inférieure qui n’est pas recouverte par la cornée n’ayant guère que la moitié de la longueur de cette derniere. Carpes un peu plus épincux, mains plus granuleuses en dehors; épines des tarses plus longues. Carapace plus fortement plissée. Couleur entièrement rouge; la carapace ctant souvent courerte d'une teinte violette uniforme. Surtout le bord sousorbitaire externe oflre chez les individus pris à Cuba unc lame carrée, placée entre deux profondes gouttières $\langle$ fig. 18, $b$; ; celte lame est ici bien moins saillante; la gouttière qui la sépare de l'épine orbitaire externe n'est pas carrée. mais triangulaire, et la lame n'est pas séparée du bord orbitaire inférieur médian par une gouttière, mais seulement par une fissure oblique si étroite que ses deux bords se recouvrent et ne laissent entre eux aucun vide. linfin le bord antérieur de la carapace n'est pas égal au double de la largeur du front, et les poils des pattes sont noirs aree la pointe rousse.

\section{Genre GRAPSUS, Lam.}

Les especes de ce genre paraissent être assez nombreuses, mais, comme elles se ressemblent beaucoup cntre clles, il est dillicile de les reconnaitre aree cerlitude sur de brives descriptions, et on en confond plusieurs sous le nom de Grapsus maculatus, Catesh. (pictus Latr.

Les Grapses suivants appartiennent a la section de ceux dont l'épistome est tres-grand, a peu près aussi long que large à sa base. J'ignore s'ils doi-

vent être considérés comme de simples variétés de l'espèce citée ou s'ils en sont distincts. Je me borne done a les décrire sans leur donner mo nom précis. 


\section{Grapsus macolatus? Castesby.}

Frons magis quam bis arctior quam latior; lohoe suprafrontales fissuris disjunctae, cristam transversam efficientes; testa multo latior quam longior.

Grande espece. Carapace bien plus large que longue. Front bien plus large que la moitié du bord antérieur de la carapace, mas bien moins large que la moitié de cette dernière, tout à fait vertical, concave, terminé par un bord tinement granulé, arqué; sat surlace concave, très-finement granulée et oflrant vers son tiers inférieur deux très-pelits tubercules écartés. Lobules protogastriques larges et peu élevés, faiblement luberculés, séparés par dés sillons étroits, ayant la forme de fissures; les lubercules at peine surplombants. De chaque côté, juxtaposé à l'orbite, un tubercule placé sous le bord superieur du front. Région stomacale écailleuse, mais ses écailles n'étant pas assez élevées pour porter le nom de tubercules. Région cordiale lisse, pointillée; région intestinale placée entre des sillons a peine creusés. Plis des régions branchiales tout à fait plats; nullement saillants. Dents de leur bord latéral médiocres. Bord orbitaire inférieur tranchant; le supérieur offrant entre les deux crêtes sourcilières un espace arqué en bas. Pattes antérieures petiles. Face externe des bras plissée; leurs bords interne et inféricur armés chacun d'une forte épine, précédée d'une autre épine plus petite ef offrant deux autres épines versson extrémité antérieure. Le second arlicle de ces pattes, armé d'une ou derix épines grêles. Carpe portant de petits tubercules; son bord interne armé d'une épine, recourbée en haut, placée en arrière de son apophyse en forme de feuille. M ins portant des tubercules épars ct deux crêtes granulées dont l'une alteint le bout du doigt fixe; leur bord inférieur orné d'une multitude de petitescrètes obliques. Doigts creusés en cuillère au hout, leur bord interne armé de plusieurs petits lubercules. Les autres pattes ayant le bord postéricur des cuisses armé près du boul de deux ou trois dents, a perne marquées à la cinquième paire- - Couleur rouge, marbrie de jaune; portion antérieure de la carapace ayant des taches jaunes, orales.

Habite: Les Antilles, Cuba.

J'ai pris a Cuba d'itutres grapses de plus petile taille, qui sont ou des jeunes de cette espèce, ou des types diffèrents el qui se distinguent comme suit:

Le front est plus ineliné, moins verlical, plus de deus fois plus large que haut, mais sa largeur est un peu moindre que la moitic du bord anterieur de la carapace d'une dent orbilaire externe a l'autre, et son bord inférieur est moins arqué. Les lobes surfrontaux sont aussi plus largement séparés; ils ne forment 
pas une crète transversale. inais la crête de chacun des lobes moyens forme un are de cercle garni de trois ou quatre lobules; les lateraux onl leur crête dirigrec obliquement d'avant en arrière et de dehor's 'n dedans. Cette crète offre deux lobules et on voit. entre autres, une espece de saillie longitudinale qui longe le bord interne de lorbite, formée par trois on quatre lobules, placés les uns devant les autres. La cornée occupe plus des deus liers de la longueur du pédoncule. Lat couleur est un jaune blanchảtre, marbré de dessins rouges fins et deliés comme des dendrites; les pattes sont plus largement marbrées et réticulées de rouge. Chez les jeunes, la portion antérieure de la carapace est piquetée de brun ou de violet. - Long. $0,026^{\mathrm{m}}$; larg. $0,039^{\mathrm{m}}$.

\section{Gevre Plagusia, Latr.}

Espece appartenant au groupe de celles chez qui le deuxieme article des maxillipedes est aussi large que le premier, dont lat carapace est armée de quatre dents de chaque còté et chez lesquelles le troisieme article des paltes n'offre qu'une seule épine, près de l'extrémité de sin bord superieur.

\section{Plagusia gracilis.}

Manus loves, bisulcata ; testa rosea, verrucosa, ciliis oblita.

L'épistome se prolonge horizontalement en avant en une lame, dont le bord forme quatre lobes insensibles. Les fosseltes antennaires ne se prolongent pas jusqua la ligne qui joindrait le bord posterieur des deux orbites, ot le bord de ces fosselles est un peu élevé; l'interne est faiblement granulé par de petites élévations distantes. Le lobe situe entre les fosselles est échancré, partagé par une gouttiere el porte de chaque cotio un tubercule. La bord orbitaire superieur interne porte une elevation obtuse placée au niveau de l'épine orbitaire externe. En outre, la carapace est armie de chaque edte de trois petites dents. Elle est toute couverte de petiles plaques squammiformes, surmontees d'un tubereule. ce qui lui donne un aspect verruqueux. Ces especes d'écailles sont ciliees antérieurement. Sur la région cordiale, les verues sunt rangees selon trois lignes transversales; les deux premières de eos lignes offrent deux verves, et la dernière quatre. Les pattes antérieures sont armées d'une dent vers l'extremité supérieure du bras. Ie carpe offe en-dessus un profond sillon en forme de fer a cheval tordu. dans lequel sont deux ou trois verrues. Ce sillon etant complet en arriere, ressemble souvent à un ovale tordu. Le bord interne du carpe porte une petite crète 
fortement ciliće. La main est lisse, mais offre vers son sommet deux forts sillons longitudinaux et, plus en dedans, une ligne fort'ment ciliée. En dessous le deuxième article el la base du bras a une élévation oblique. Le bord interne du bras est innguement cilié. Les autres pattes portent une ligne de granules placée sur la partie antérieure du troisième arlicle; leur cpine est longue.

Couleur d'un jaune pàle avec des teintes couleur de chair. - Long. 0,0155"

Sur beaucoup d'individus, les villosités de la carapace ont disparu et celle-ci a un aspect glabre.

Habite : Les Antilles, Cuba.

La $P$. Sayi (depressa, Say. ) a, selon cet auteur, les mains granuleuses, garnies en-dessus de petits tubercules; ses carpes sont armés d'une dent échancrée; les doigts sont armés de tubercules obtus, tandis que dans notre espece ils ne portent le long de leur bord interne que d'invisibles granulations distantes. Les ossettes antennaires paraissent se prolonger plus en arrière, etc.

\title{
FAMILLE DES OXYSTOMES.
}

\section{TIBIBU IOSE CALATPIENS.}

\author{
Gevre HEPATUS, Latr.
}

\section{Hepatus tuberculatus.}

(Fig. 9).

Parnulus, manibus tuberculatis; testa supra gibtris quinque transversalibus verrucosis.

Petit, Ressemblant pour la dentelure des bords de sa carapace à l'H. chilensis. Chacun des bords latéro-antérieurs offre une serie de douze dents obtuses; les labes des prolongements latéraux des régions branchiales sont eux-mémes bilobés ou trilobés et sur le bord latéro-postéricur on voit encore une dent. située en arrière de l'angle latéral. La carapace est très-bombéc dans tous les sens, faiblement granuleuse, et offer plusieurs éminences transversales el tuberculeuses, qui ont un aspect framboisé; on en roit deux sur la région stomacale, 
une sur la région génitale, une sur la région cordiale el deux sur chaque région branchiale. Mains courtes, à crète supérieure dentelée; ayant leur face externe très-verruqueuse, garnie de trois ou yuatre séries transversales de grosses ver-

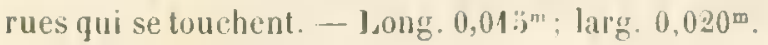

Habite: La Guadeloupe.

\title{
SECTION DES DÉCAPODES ANONOLRES.
}

\author{
FAMILLE DES P'TERYGURES. \\ TIRIIBU IMES IIIPPIEVS.
}

Genre REMIPES, Latr.

Ce genre a été établi sur une seule espece, et la description qu'en donne M. Edwards, a besoin de quelque modification pour ne pas ètre trop speciale.

Le bord antérieur de la carapace est variable et plus ou moins échanere pour former les orhites. Les pédoncules oculairesont leurs deux articles de grosseur variable. Les antennes internes se terminent par un gros filet multiarticulé et par un autre variable. Les antennes internes ont un très-gros pédoncule cl un filet très-court.

Le $R$. testudinarius a élé figuré de manières très-diverses par les anteurs. Desmarest pl. 29, fig. 1, représente te bord antericur de la carapace comme bidente, et M. Edwards (Regne animal, comme tridenté. Le premier lui donne des antennes internes grosses, comme les ofle notre espèce, et le second des antennes grêles, a filets très-inegaux, tandis que dans son histoire des crustacés, ces filcts sont représentés comme étant presque égaux. l'n individu que nous possédons a le bord antéricur de la carapace entier, sculement partagé par une gouttiere. Peut-ètre faut-il voir dans ees divergenees le résultat de l'examen de plusicurs espèces. 


\section{ReMipes cobensis.}

Fig. 19.

\section{K. fronte angulato, haud emarginato.}

Espèce voisine du $R$. testudinarius, mais ayant la carapace plus ovale, moins rétrécie en avant. Front aussi saillant que les angles externes des orbites, formant un angle obtus, sans trace d'échancrure. Echancrures des orbites très-peu profondes, simplement arquees; le urs angles externes obtus. La carapace offre une sculpture moins prononcée que chez l'espèce citée et l'ornementation de ses (bords latéraux (fig. 19 a) consiste en une simple zone de petits sillons obliques parallèles, disposés comme les barbes d'une plume d'un seul còté de sa còle mi-pennéel, tandis que chez le $R$. testudinarius le hord est canaliculé et les silluns sont très-courts, logés dans la goultière, laquelle n'est que submarginale. Les orifices de la région génitale unt à peine la forme de $\mathrm{C}$. La couleur est faure ou rougeàtre, souvent marbrée

Pour compieter la deseription de ce crustace par celui du systeme appendiculaire, j'ajoulerai les details suivants:

Pédoncules oculaires courls; leur premier article très-court, à peine plus gros que le deuxième, entiercment caché par la carapace. Antennes internes grosses, égales co longurur à la moitié de la carapace ; articles de leurs pédoncules irréguliers; le deuxic̀me faisant très-peu saillie au devant de la carapace; le troisi me le plus long et donnant naissance a deux filets, dont le supérieur gros, long, multiarticulé, et l'inferieur composé de trois ou qualre articles longuement ciliés. Antennes externes ayant leur deuxiène article basilaire armé en dehors d'une lungue apophyse terminale; le troisième assez petit, donnant naissance à une ligello courte dont le premier article est assez gros. Les pattes-màchoires et les pattes antéricures sont un peu plus grèles que chez !e $R$. testudinarius. Les deux derniers articles de celles-ci, olfrent des sillons yui sunt remplis par des lignes de poils noirs. Ces sillons sont tout a fait obliques of longitudinanx, non transversaux comme ceux qui se voient à la lace inferieure du pénultieme article chez le $k$. lesudinarius. Le dernier article n'est pas élargi dans sa premiere moilié. - Lons. de la carapace $0,024^{\mathrm{m}}$.

Mabite en grande abondance les còtes de Cuba. Grands et petits, les sujets te tous les àges se ressemblent parfailement. 


\title{
FAMILLE DES PTÉRYGURES.
}

\section{TREIBU IMTE PATIBIENS.}

\author{
Gemre pagurus, Fabr.
}

\section{Sous-Gienre des Pagures ordinaires, Edw.}

\section{Groupe des Sénestres, Edw.}

La pince gauche plus grosse que la droite. Front dépourvu de dent rostrale; anneau ophthalmique distinct.

\section{Pagcrus insignis.}

Fig. 20.)

Hanus tuberculis spinosis per series operlae; secundum et tertium pedum par squamosa; pedunculi oculares antennariis brevores; appendices pedunculorum antennariorum cadem longitudine ac oculares.

Anneau ophthalmique tout a lait à découvert. Pédoncules oculaires gros et courts, cylindriques. bien moins longs que les pédoncules des antennes externes; le fond de l'echancrure des yeux portant un pinceau de poils dirigés en avant; écaille basilaire des pédoncules, grande, dirigée en dedans et armée le long de son bord anterieur de quatre ou ciny épines aiguës. Pédoncules des antennes externes ayant leur premier article gros, armé de deux denls, l'une grande, externe, lautre petite interne; leur deuxieme article portant un appendice spiniforme plus long que lui, qui s'avance anssi loin que les yeux, et qui est garni d'une rangée de dents spiniformes. Portion antérieure de la carapace large et quadibatere, fortement siltonnee posterieurement, offrant en particulier un sillon bifurque en avant, en forme d'Y. Cetle portion de la carapace, lisse all milieu. garnie do grosses ponctuations éparses, plus rugrueuses an avant, ou elle est fortement ponctuée; ses bords latéraux garnis de princeaux de poils. Pord antérieur de la carapace à peine avancé au milieu, mais offrant entre les pédoneules oculaires 
et antennaires, de chaque côté une dent arrondie, assez arancée. Portion postérieure de la carapace ayant ses parties latérales sillonnées obliyuement et la portion médiane offrant des sillons concentriques. Pattes antérieures plaquant l'une contre l'autre, n'ílant pas très-différentes de taille, très-rugueuses. Bras gros et courts, comprimés et triquètres. à bords tranchants, subdentelés, garnis de gros points piligères; l'inféricur interne armé d'une rangée de grosses épines. la face interne lisse. l'externe ridée Carpes el mains très-rugueux de toutes manières, entièrment couverts de grosses rides raboteuses, qui portent des rangées de tubereules spiniformes rugueux et aigus, surtout sur la partie supérieure, ou ils passent à l'état de grosses épines et sur les doigts, ou les rangées de tubercules épineux deviennent très-régulirres. Entre ces rangées de tubercules ou d'épines, on voit, au moyen de la loupe, des bandes de poils couchés. qui les rendent finement velus. Face inférieure lles mains garnie de pinceaux d'énormes poils roides. Doigts terminés par des ongles noirs; ceux des doigts fixes aigus et dépassant ceux des doigts mobiles. Deuxième et troisième pattes. du côté gauche (fig. $20 a)$ ayant leur quatrieme article écailleux en-dessus avec leur bord supérieur garni d'épines; cinquième artiele de la deuxième couvert à sa surface supérieure de grandesécailles imbriquées, et à ses faces latérales de grandes rides; les bords de ces écailles et rides étant garnis de petites épines et de poils spiniformes, et émettant en-dessous des zones de petits poils couchés en brosse, qui dessinent les écailles. Cinquième article de la troisième patte couvert de gros plis qui porteut chacun une rangée de pelils tubercules spiniformes el qui sont aussi bordés dune zone de poils; ces plis etant pennés et se rencontrant sur la ligne médiane de la face externe, laquelle n'offre aucune crète $($ fig. $20 a)$. Sixieme article des pattes, $2^{\text {me }}$ et $3^{\text {me }}$ tout garnis endessus de lignes longitudinales de tubercules spinigères; leurs côtés oflrant ces mèmes tubercules en lignes obliques, figurant comme de grandes écailles, bordées par des zones de poils; leur face interne portant aussi des enfoncements piligères, etc., et l'extrémité de leur bord supérieur, pareouru par un large sillon piligère, qui se termine en dehor's de la griffe. Troisième article de la troisième patte lisse, semé de quelques gros points enfoncés épars. Quatrième patte petite, poilue, chéliforme, munie en-dessous d'un gros coussinet allongé et réticulé.

Les pattes $2^{\text {me }}$ et $3^{\text {me }}$ du còté droit manquent.

Couleur rougeàtre et jaunàtre; pédoncules oculaires annclés de rouge el de jaune. - Long. de la carapace $0,04: 3$; larg. de son bord antérieur 0.098 ; jéduncules nculaires, sans les écailles, $0,010^{\mathrm{m}}$.

Celte belle espece a été prise a la Guadeloupe. 


\section{Groupe des Aequimanes, Edw.}

Mains à peu près égales.

Espèce dont les doigts sont ongulés et les mains épineuses.

\section{Pagurus cubensis.}

Rufus, pedibus fusco-fasciatis; manus aequales, spinoso-tuberculate; pedes omnes hirsutissimi; primi et sccundi paris tarsi punctati, supra carinati.

Ce crustacé appartient au genre Pagure proprement dit de $\mathbf{M}$. Dana et rentre dans la section des espèces dont le front n’est pas tronqué au milieu.

Les pédoncules oculaires sont un peu plus longs que la carapace n'est large à sa région stomacale. Le bord antérieur de celle-ci est tronqué obliquement de chayue côté et porte au milieu trois dentelures, dont la médiane, un peu plus

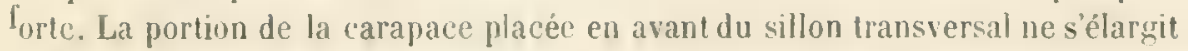
nullement en arrière; cette portion est bien moins longue et bombée. La portion antéricure est bien plus longue que large, et porte une espèce de sillon poilu en fer a cheval, qui longe ses bords lateraux at antérieur. La portion postéricure porte au milieu deux sillons longitudinaux el, sur chaque région branchiale, deux autres dont l'externe est arqué et rejoint le bord latéral de la carapace. Celle-ci est garnic de petits tuhereules piligères épars, surtout sur sa partie antéricure et ollre de longs poils blonds. Les pattes anterieures sont très-courles, Jeur troisieme article est très-comprimé; les trois bords sont garnis de tubercules piligères, et l'externe est armé d'une épine placéc près du carpe. La face externe porte des points piligères. Le earpe est petit, il est armé à son extrémité supérieure d'une forte épine el offre des tubercules piligères disposes an lignes longitudinales. Les mains sont petiles et égales, aussi lautes que larges, presque quadrilaleres dans tous les sens; courerles de rangées de lubercules épineux. ainsi que les doigts, qui sont all moins anssi Inngs que la portion palmaire de la main, et sont armés au hout d'un ongle tranchant. Le doigt mobile porte au miliru de son bord superie ur une forte dent, et le doigt fixe en offre une semblable. insérce a còte de l'ongle, garnissant son cxtremile. Toutes les pattes sont trèspoilues. La premiere paire atteint un peu au dela du milieu du troisième article de la deusiène paire. Celle-ci est très-longue, ansi que la troisième paire; 
elles sont garnies toutes deux de grosses ponctuations piligères, et leurs tarses sont armés de poils spiniformes el portent en-dessus une crêtle mousse. placée entre deux lignes de points enfoncés. L'appendice caudal gauche est le plus grand. La couleur est rouge de brique, avec des bandes longitudinales de brunviolet, qui s'étendent sur toute la longueur des pattes. Les pédoncules oculaires sont verdàtres, et les mains sont plutòt mouchetées de brun. - Longueur de la carapace 0,010 ; id. avec les pattes antérieures $0,018.3$; id. avec les pattes de la deuxième paire 0,061 .

Habite: Les còtes de Cuba

Cette espèce ressemble au $P$. tuberculosus Edw.; clle n'en est peul-ètre pas distincte, mais il est impossible d'en juger d'après la description abrégée. qu'en donne l'auteur'. Elle diffère toutefois assez notablement de la figure qui accompagne sa description, soił par son rostre plus aigu, soit par la forme moins allongée de ses pinces.

\section{SECTION DES DÉCAPODES MACROURES.}

\section{FAVILLE DES ASTACIDES.}

\section{Genre ASTACUS Fabr.}

Les crustacés qui font partie de ce genre sont répandus sur toute la surface du globe et se ressemblent biaucoup par la forme de leur corps et de leurs appendices. Néanmoins les auteurs l'ont fractionné en plusieurs sous-genres, dont on a fait ensuite des coupes génériques qui ne nous paraissent que fort peu nécessaires. Les différences sur lesquelles se basent ces divisions semblent toutefors correspondre a certaines tendances dans les mours de ces animanx ainsi les espèces du sous-genre Astacus habitent les ruisseaux d les eaux claires. tandis que celles dont on a formé le groupe des Cambarus, affectionnent plutòt les marais et les eaux vaseuses el vivent dans des trous qu'elles se creusent au fond des rivières el des laes. Les caux de l'Amérique du Nord nour-

' Annales Sciences Naturelles, ze série. VI, 278. 
rissent un très-grand nombre d'astaciens, dont la distinction est fort embarrassante. En effet, ces écrevisses sont si voisines les unes des autres, que leur cilude est une des plus difficiles dans les crustacés. Souvent les espèces nu diffierent que par des caractères trè-minimes. De plus les différences individuclles abondent et doivent donner licu a erreur, comme je l'ai remarque sur un srand nombre de sujets pris dans un mème lieu of specifiquement identiques. La longueur du rostre varie indubitablement dans certaineslimiles chez la même espece. comme il est facile de l'observer chez les Palémons. Or, la distinction des Cambarus repose principalement sur ce caractere de longueur absolue, que les auteurs ont acceple comme plus infaillible qu'il ne l'est en réaliti. d'ou il est résulté que le nombre des espèces a été multiplié outre nesure

Dernierement M. Girart a donné les diagnoses de 20 espèces do Cambarus des Elats-Unis, dans un travail qui n'exclul pas la nécessit d'une monographie plus détaillée Proceed. of the Acad. of Philad. 1833, p. 87), et d'après lequel il n'est guère possible de reconnaître les especes. Nous perisons yuc l'auteur en a trop augmenté le nombre et qu'il en a base plusicurs sur des caracteres purement individuels; cependant il serat impossible de rien dire de positif a ce sujet, tant que l'auteur n'en aura donné des descriptions plus complètes, aceompagnées de dessins exacls.

La ressemblance inlime el te grand nombre des écrevisses de l'Amérique du Nord ont aussi conduit a des confusions el à des erreurs synonymiques quil ne mappartient pas de relever ici el qui necessilent un nuuvel examen scrupuleux de ces crustacés, examen auquel ne pourroul ste consacrer avec sucès que les naturalistes fixés sur les lieux mèmes. Ces raisons mont mis dans l'impossibilité de determiner avee soin plusieurs Cambarus que jai pris aux Etats- Lnis el au Canada, et dont je ne donne pas la description, quenique deux de leurs especes me paraissent nouvelles.

\section{Sous-Gienre Cambinus, Erichs. \\ 10 Espèce dont le rostre est armé de trois dents.}

\section{Cambarus covsobrinos.}

Fign. 21.

Punctatus; pedes antici compresst, granulasi, digitis carinulatis; rastrum elongatum. acutissime acuminaum; cauda articulus primus utringue mullispinosus. 
$.0^{\circ}$. Corps très-comprimé, plus haut que large. Rostre alteignant à peu près le milieu du troisième article des pédoncules des antennes internes, lancéolé, allongé, concave en-dessus. terminc par une épine longue ct aiguë, plutòl que par une dent (fig. 21); ses bords cilies, armés chacun d'une dent spiniforme, a la hauteur de l'origine on du milieu du deuxieme article des pédoncules des antennes interness, fi porlant chacun une crète tranchante qui sétend jusqu'à l'épine latérale. Carênes laterales de la base du rostre très-saillantes, terminces antérieurement en une épine aiguë, et creusées d'un sillon longitudinal.

Carapace lisse, ponctuce, armée de chayue eòlé d'une petite épine, en arrière du sillon oblique (cefte epine parlois peu distincte), mais nullement tuberculeuse. Région cordiale démurvue de sillons. Les deux sillons des bords latéro-posterreurs de la carapace écartés mais parallèles. Pattes de la première paire grêles, très-granuleuses. couvertes de prits tubercules qui deviennent épineus le long du bord inférieur du bras, lequel est arme d'une rangée d'épines rapprochées. Celui ci est aussi armé d'une épine placie plus cn-dessus, près de son extrémiti antéricure é d'une autr latérale, a son angle externe, souvent peu sensible. Carpes plus longs que larges, luberculeux, n'oflrant qu'un enfoncement mal marqué; leur lace externe simplement ecailleuse; leur bord interne armé de deux épines; leur face inféricure en othrant quelques autres. (Chez les petits individus, ces cpines sont peu marquérs.) Vains grèles, comprimés, très-tuberruleuses; les lubereules derenant presque épineux au bord supérieur. Doigls grèles, très-comprimés, granuleux, porlanten-dessus et endessous une carène longitudinale lisse. Pattes antérieures très-variables, en géral égales, mais souvent aussi très-inégales alors la main qui reste pelite est presque lisse? Ahdomen plus long que la carapace, presque aussi large qu'elle; premier arliele de sa nageoire médiane arme de plusieurs épines $\left\{\begin{array}{l}4 \\ \text { ou }\end{array}\right)$ à ses angles latero-postérieurs, ct ayant son bord postérieur légèrement concave. Longucur du corps, 0,038m

Var. Souvent les pattes de la premiere paire sont petites et presque sans caractères, les doigts sans carênes, ponclués au lieu d’êlre tuberculeus. Céci se voit surtout chez les màles.

○. Deuxième article de la troisième paire de paltes, arme pres de sa batse dun gros crochet, dont la longueur équivaut a la moitié de cefle de l'article.

Ilabite: Les mares vaseuses de lible de Cuba.

" Ceci montre que le caractère dont Erichson se sert dans ses descriptions et qu'il ure de la longueur des bras, comparee à celle du cisps, wu de la longueur d'un des bras par rapport a celle de l'autre. n'est d'aucune utilití. 
Explication des figures supplémentaires: Fig. 21 a, base d'une anterne externe vue en dessous.$21 b$ idem, vue en dessus. - $21 c$, anterne interne.

\section{$2 \circ$ Especes dont le rostre n'offre pas de dents latérales.}

\section{Cambaros Montezume.}

(Fig. 22.)

Hinutus; rostrum integrum. lateribus haud dentatis; pedes antici inermes: caudee articulus primus utrinque bispinosus.

Sauss. C. Montezumø, Revue zoologique 18:j7, p. 102.

Carapace inoins compriméc que chez le C. cubensis. a peine plus hate que large, lisse ou couverte de très-fines ponctuations écartées, qui ne se distinguent guere qu'a la loupe. Son sillon lranswelsal lable el placé très-en avant, surlout sur les cỏtés. Les deux sillons qui bordent ses angles latéro-postérieurs écartés et presque parallèles, comme chez le Ć. cubensis. Rostre plat, à peine concave, court fig. 22, a), n’alleignant pas l'estré mile du deuxieme article des pédoncules des antennes internes, n’utant pas triangulaire ou élargi en arrière mais ses bords, presque parallèles ou insensiblement convexes en dehors ; son rulrémité subitement termince par un angle oblus, dont la pointe se prolonge un pea en forme d'angle a peine aigu. Les bords ue donnenl pats de chaque còté naissance a un dent spiniforme, mais s'arrondissent pun gagner la poinle, et son trolevés en carènes suillantes. Carénes laterates de la base du postre, canaliculées el nul. lement lerminées en épines. point disergentes "n arriere. Cótés de lat carapace sans ancune épine; région cordiale sans sillon. Paltes de la premiere pare assez courles, grêles, (2ntierement inermes. mais ponctueses fig. 2ze e, fl. Carpe subtriangulaire, sélargissant vers la main, a peu pres ausis long que large à son borl anterieur; celui-ci offant une pelile lissure a cotio du condyle qui sert a l'articulation avee le bord interne ou supéricur de la main. Lee long de son bord inferieur est un sillon qui hui est parallole. Mans de la longueur des doigls, petites, comprimées dans la femello fig. $22 /, g)$, qunifur convexes rn-dessus el en dessous; irregulierement ponctués en dessus. Les doights portant chacun deux sillons ou lignes de ponctualions. -. Chez les màles fig. $22 h$, les mains sont bien plus grèles, plus longues et très-cylindriques, avec los doigts griles ot linéares, offrant les deux mèmes sillons, 'ntre lesquelsust une ligne élevéc. Le doigt mobile, très-concave en-dessus. Ibdumen moins large, ses anneaux por- 
lant 'n-dessus deux sillons transversaux. Premier article de la nageoire médiane de la queue, armé de chaque còté d'une ou deux épines à ses angles postérieurs; son bord postérieur droit au milieu ou légèrement convexe.- Longueur du corps, $0,027^{\mathrm{m}}$.

б. Truisieme article des pattes de la deuxième et de la troisième paire armé à sa base d'un gros crochet.

Se possède, de celte espèce, vingt-cing individus qui offrent peu de variations. sauf celles qui tienent au sexe et qu'on serait tenté de prendre pour des différences spécitiques, si l'on ne possédait que des individus isolés. Moi, qui ai pris ces crustacés à plusieurs reprises, je sais qu'ils ne forment bien qu'une seule espece.

Hubite: Les marais de la vallée de VIexico; les mares du pare de Chapultepec. à une lieue de la capitale, ou je les ai pris en grande abondance.

Explication des fugures supplémentaires: Fig. 22 b, patte-màchoire. - 22 c, màchoire. - 2.2 d, antense interne.

Nota. Erichson a decrit deux especes du Mexique appartenant au mème genre. La premiere, le $C$. Wiegmanni, paraît ressembler assez à notre espèce, mais elle a les bras tuberculeux et le carpe épineux, etc. Son C. Mrricanus en est bien distinct par le troisiene article inerme de la quatrieme paire de pattes. L'auteur n'a pas dit si ces espèces habitent les rivières des terres froides ou celdes des terres chaudes.

\section{Cambarus azticis.}

(Fig. 23).

Manus purve, compressa, gramelose el squemosa: brachiorum margo inferior spinosa; pedes tertii paris o basi emaryinati, dente obusearmati.

Carapace fortement ponctuée, devenant parfois granuleuse sur les còtés dans sa région antérieure, n'offrant aucuue épine latérale. Rostre court, large, concave, a bords relevés, lout garni de ponctuations of parfaitement arronli au bout, ou it ne forme qu'un angle très-obtus (fig. 23, a). Carènes latérales trèspeu divergentes en arrière, émoussées, se terminant en avant d'une manière arrondie et sans former trace d'épine. Pattes de la première pare médiocres. Mans petites et comprimées, a peu pres comme chol le $C$. ronsobrinus, rugueuses, fortement granuleuses, toutes couvertes de petits tubereules écailleux, qui sont bordés interieurement par une brosse de poils couches, de fason à dessiner des feailles. Doigts de mème longueur que la portion palmaire de la main. 
offrant ces mèmes granules écailleux, et, au milieu de chaque face. une carène lisse. Carpes écailleux de la mème manière, portant une dépression longitudinale, et offraut plusieurs petites épines a leur bord interne et inférieur. Bras plus grossièrement granuleux, ayant leur bord inférieur garni de deux rangées de petites épines. Abdomen ponctué, presque anssi large que la carapace.- Long. $0,030^{m}$.

$\sigma$. Mains conformées comme chez la $q$; troisième paire de pattes armée a sa base d'une très-petite apophyse, précédée d'une échancrure (fig. 23 b): deuxieme paire n'offrant qu'une échancrure rudimentaire sans apophyse.

Habite: Les ruisseaux du Mexique. -Pris à Tomatlan, dansles Terres-Chaudes. Celte écrevisse se rapproche évidemment beaucoup du $C$. mexicanus, Erichs. mais elle paraît en être bien distincte, puisqu'ici les mains sunt comprimées, non cylindriques comme chez l'espèce citée, puisque les bras sont épineux, etc.

\section{FAMILLE DES SALICOQUES.}

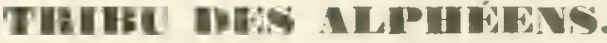

\section{Genre ALPHEUS, Fab'.}

Espèce munie d’un rostre aigu.

\section{Alpieus lutarius.}

(Figr. 24.)

Testa levis, antice in medio earinata el in spinam rostralem producta; manus dextragracilis, cylindrica; sinistra compressa, maxima et valde deformis.

Sauss. Halopsyche lutaria, Revue zoologi(ue 18:57, p. 100.

Carapace lisse, très compriméc; ses bords latéro-antérieurs réfléchis en dedans, de façon a recouvrir les bords de la bouche; olliant entre les voùtes des or-

1 C'est par une de ces erreur's auxruelles on est expose lorsqu'on n'a pas pour s'aider le secours des collections, que j'ai méconnu le genre $\mathbf{A}$ lpheus au point de décrire l'espèce dont il s'agit ici comme formant un genre uouveau. On considerera donc comme nul cf non avenu tout ce que j'en dis dans la Revue zoologique de 1857, p. 99 et 100 
bites une carène saillante qui se prolonge en avant et se termine par une dent rostrale aiguẻ, laquelle dépasse le bord droit du front. Antennes internes bien plus longues que la carapace $\{\mathrm{fig}$. $24 \mathrm{f}$ ), a pédoncule assez allongé; leur filet interne long, l'externe court, comprimé et élargi près du bout, ou il émet la tigelle terminale et laisse voir un rudiment de bifurcation; appendices foliacés des pédoncules, terminés par une dent aigü. Antennes externes longues $($ fig. 24, $g)$, leur appendice, en forme de demi-fer de lance. convexe et longuement cilié à son bord interne; un peu concave, avec une forte côte à son bord externe; sil pointe dirigée en dehors, mais terminee par une dent aigue qui vient se placer au dessus de la partie foliacée. Maxillipèdes très-longs (fig. 24 $c$ ), atteignant bien au-delà des pédoneules antérieurs, très-comprimés, et munis d'un appendice longuement cilié; leur deuxième arlicle lamelleux; le troisième n'étant pas à moitic aussi long que le deuxième. comprimé, tranchant en dessus; le quatrieme deux fois plus long que le trosième, moins comprimé, cilié et creusé d'un sillon a sa face supérieure. Palles antéricures très-inégales: celle de drotle très-grêle el longue; son troisième arlicle très-comprimé, atteignant au dela des pédoneules antennaires; carpe plus long que large; main eylindrique, très-grèle. aussi longue que la carapace et le premier segment de l'abdomen pris ensemble: ses doigts grèles, cylindriques, égaux, aussi longs que la portion palmaire; joignant bien et ciliés au bout. La patte gauche difforme $($ tig. $24 a)$; son troisieme article tris-court; le carpe rabougri, très-court, ne formant qu'un anneau d'union; la main énorme, très-compriméc, un peu torduc; sa face externe plus plate que l'interne. Les deux faces de cette main sont bosselécs avec difformité; son borł supéricur, comme l'inférieur, est creusé d'une gouttic̀re transversale placée en arrière do la base des doigts; ceux-ci sont bien plus courts ifue la portion palmaire et forment comme un bee de perroquet. Le doigt fixe est creusé d'un profond canal qui recoil le doigt mobile; il est complétement excavé (fig. 24 b); sa pointe est très-irrégulière, ayant son bord droit tronqué et cilic. el le gauche prolongé en une dent qui emboite le bout du dorgt mobile. Colui-ci est tres-comprime; ses bords externes sont tranchants el forment un anglio carré; sa pointe inferieure est prolongee en bec de perroquet qui deborde le doigt fixe, et sa base offre au-dessous de la tête articulaire une forte apophyse dirigee en arriere, qui remplit tout le vide interieur du doigl fixe (fig. 246 ). Diruxiome paire de pattes filiforme (fig. $24 h)$; son troisième article partage par une artirulation fixe placée a son deuxième tiers externe; son quatrieme article très-grand, ayant la même forme que le troisième, c’est-à-dire plutit rétréci qu'ílargi au bout; le reste partage en trois portions, dont la premieremoins longue que le quatrième article, la deuxiome phus longue que le quatrieme articie, partagee en quatre 
segments, et la troisième formée par la petite pince, qui est régulière. Pattes suivantes très-comprimées, ayant leur troisième article partagé à son premier tiers par une fausse articulation ; cinquieme article cilie; celui de la cinquieme paire faiblement élargi vers le bout. Dernier arlicle des larses faiblement lancéolé, et portant une carène médiane sur sa face externe. - Long. $0,030^{\mathrm{m}}$.

Habite: Le's cotes de Cuba.

Explication des figures supplémentaires: Fig. $24 d$, màchoire de la première paire. $-24 e_{\mathrm{i}}$ id de la seconde paire. - $24 i$, fausse-patte abdominale.

\section{Genre Caritina, Edw.}

\section{Caridina mexicana.}

(Fig. 26.)

\section{Mnnus carpo longines, usque ad basim diffisse}

De tres-petite taille. Rostre très-aigu, droit, tout a fail styliforme, triquètre, offrant en dessus une carêne el, de chaque cotce de sa face inférieure, un bord tranchant; son extrémité atteignant le milieu du deuxieme article des pédoncules des anfonnes supérieures. Yeux très-gros; bord de la carapace fortement échancré pour les recevolr, el formant de chaque coté d'une épine situce au-dessous de l'incertion de leurs pédoncules, yui sont très-courts. Antennes internes à pédoncules gros et longs, fortement ciliés en-dessous; leurs filets grểles et longs; l'externe un pu plus long gue l'interne. Pattes des deux premières paires comprimées, à carpe court et échancré an bout, pour receroir la base de la main $(\mathrm{fig}, 2 f, d, e)$. Mains ressemblant, dans l'étal de repos, a un gros article pyriforme termino par un pinceau aigu de poils roides, el fendu dans tonte sa longueur (cet article ressemble assez a un grain de ble allongé); onvert, it a la formse d'une pince didaclyle fendue jusqu'a a base et presque dépourve de portion palmatre fig. $26 /$; ; le bord interne de ses deux moities est garni de tres-longs poils roides qui se prolongent en deux longs pinecaux. La deuxieme paire est plus longue que la premiere (fig $26 \mathrm{e}$ ), mais le carpe est loujours bier plus court qur la main. Les autres pattes sont grêles. Nageoire caudale médiane terminée d'une manière arrondie, garnie au bout d'une rangéc de longs poils roides, placés entre deux dents laterales. - Long. 0,013 a $0,014^{\mathrm{m}}$ : id. des anternnes inféricures $0,01 \mathrm{z}^{\mathrm{m}}$. 
Habite: Les ruisseaux de la còte du Vexique; se loge sous les pierres ıu dans la vase. Cette espèce a été prise dans le voisinage de Vera Cruz.

Explication des figures supplémentaires: Fig. $26 a$, animal de grandeur naturelle $-26 b$, maxillipède. - $26 \mathrm{c}$, mâchoire. $-26 \mathrm{~g}, h$, $i$, troisième, quatrième et cinquième pattes. $-26 k$, fausse-patte abdominale.

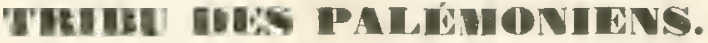

\section{Gente Pal EMON, Fabr.}

Les nombreuses espèces que renlerme ce genre sont en général difficiles à différencier, parce que leurs formes n'olfrent pas de notables différences. Les principaux caractères sur lesquels on se base pour teur séparation, résident dans la configuration du rostre et des pattes, mais l'examen d'un grand nombre d'individus m’a montré que ces organes mèmes sont très-variables, soit que l'àge ait une influence notable sur leur diveloppement, soit que leurs formes varient accidentellement d'individu a individu. Isa longueur absolıe et nème la courbure sont des indices trompeurs sur lesquels on ne peut baser arec certilude la délimitation des rspeces. Les mains varient aussi beaucoup avec l'àge et no doivent pas itre décrites avec trop de précision. Ces considérations montrent que les Palcmons ne sont pas sultisamment caracterisés par les deseriptions que les auteurs en ont donne, et elles s'appliquent jusqu' it un certain degré à divers autres genres de salicoques.

La natgeoire caudale médiane offre pres de soll extrémite, de chaque còté, deux petites épines articuleses, dont l'anterieure est en general de beaucoup la plus grande. Ces épines varient selon les especes quant à leur grandeur et quant à leur position, mais comme elles sont sujeltes a lomber, le caractère quion en tire est d'un ordre tris-secondaire.

Les Palamons que nous avons recueillis appartienneut tous au groupe de ceux dont le bord anterieur de la carapace ne porte qu'une seule épine, placée audessus de l'insertion des antennes, mais qui ofl'rent une seconde épine plus en arriere, sur les collis de la carapace.

On peut les arranger dans lordrejsuivant: 
I. Mains allongées, grêles, $p l u s$ ou moins cylindriques; doigts joignant souvent bien, mais leur portion palmaire toujours grêle.

1. Carpes plus courts que la portion palmaire de la main s'évasant l'arrière en axant.

a. Nageoire caudale médiane dépourvue de dent terminale jamaicensis.

$b$. Nageoire caudale médiane termince par une dent médiane:

a. Rostre long, grêle, terminé par deux dents super-

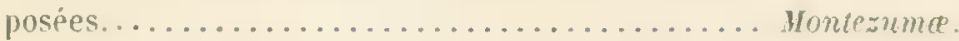

B. Rostre court, terminé par une pointe aiguë....... astecus.

2. Carpes plus longs que In portion palmaire de la main, cylindriques.

a. Carpe plus long que la main................ mexicanus.

b. Carpe plus court que la main:

a. Rostre aigu, arqué, armé de petites dents régulières. consobrimus.

B. Rostre long, droit, armi de dents espacées et terminé par deux ou trois dents.............. forceps.

II. Mains comprimées, dilatées; dnigts arqués, ne joignant pas.

Pattes tres-inégales ...................... Fuustimes.

\section{Pal famov Jamaicensis, Herbst.}

Les mains de ce crustacé sont d'une grosseur variable. Le's doigls des pinces sont tantot assez droits pour joindre exactement. les buuts crochus se croisant, tantit arqués, ne joignant pas. Le duigt mobile, est alors tress-crochu, tandis que l'autre est fortement tronqué. Le rostre est arqué, recourbé en haut à sa pointe, mais quelquefois aussi presque droit, cependant en général il est arque, ayant son bord inférieur convexe, et il se termine toujuurs par une pointe aiguë unique, qui n'est pas formée par deux dents superposées. Son bord supérieur est armé de 12 a 15 dents régulières, bien moins espacées que chez to $P$. forceps; l'inféricur in offre 3 ou 4. En genéral, le boul du rostre s'avance 
jusqu'au niveau de l'extrémité des pédoncules des antennes supérieures/dans nos individus pris à Cuba et au Mexique), mais souvent il est sensiblement plus court (surlout chez les individus pris au Brésil). Enfin certains gros individus, dont les doigls sont difformes, ont le rostre prolongé bien au dela de ces pédoncules, cependant jamais il n’atteint l'extrémité des appendices foliacés des antennes inférieures.

Ln individu jeune, pris à Vera-Cruz, qui appartient indubitablenent à celte espèce, offre un rostre allongé, arqué. Il a les mains presque cylindriques, finement épineuses, ainsi que le carpe, qui est plus long a proportion, car la portion palmaire de la main n'est pas deux fois aussi longue que lui.

Le bout de la nageoire médiane est arrondie ou insensiblement trilobé. et ses quatre épines latérales sont souvent presque de mème grandeur, assez petites et placées très-en arrière, loin de la ligne médiane.

Ce salicoque habite en abondance les còtes des Antilles et du golfe du Mexique. Sa chair est d'un gout exquis.

\section{Palemon aztecus.}

Fin. 29

Minutus; rostrum breve, elevatum, subtus arcuatum; carpi breves.

Rostre court, élevé et ayant son bord supérieur convexe et arque, mais sa pointe courte, peu relevée el aiguë, n’offrant pas une double dent; son bord inlérieur est très-convese en bas, de façon à dessiner une espèce de ventre audessous de la crête des faces latérales du rostre. Extrémite du rostre atteignant le bout des pédoncules des antennes supérieures; son bord supéricur armé de treize dents régulieres et rapprochées, et l'inférieur de trois ou quatre plus espacées. Pattes de la deuxième paire médiocrement longues, parsemées de petites épines couchées ( lig. $29 b, c$ ). Carpe court, dépassant faiblement les appendices foliaces des antennes inférieures. Mains trois fois plus longues que le carpe, presque cylindriques. Doigts joignant bien, cylindriques, a peu près de mème longueur que la portion palmaire de la main, velus. Nageoire caudale médiane, arrondie, el ofirant de chaque coite une grande épine, précédée d'une autre tres-petite. - Longueur du corps $0,060^{\mathrm{m}}$.

Halite: Le golfe du Mexigue. Jai pris ce Palémon en assez grande quantité sur la cote de Vera-Cruz el al l'embouchure du Rio de Tampico. Malgré sa petite 
taille, il ressemble beaucoup au $P$. jamaicensis, mais il s'en distingue sulfisamment par la forme du rostre, qui est très-caractérislique, par sa largeur, et par ses dents nombreuses et rapprochées.

\section{Palemon Montezume.}

(Fig. 28.)

Rostrum elongatum, gracile, arcuatum, apice dentibus duatus superpositis; carpi breves.

Petite espice, dont le rostre est constitué comme chez le $P$. forceps, e'est-à-dire allongé et étroit, avec son extrémité étroite, mais point aigué, parce qu'elle est formée par deux dents superposées (fig. 28). Toutefois le rostre est plus arqué, comme chez le $P$. jamaïcensis, ou mème encore plus, et atteint ou dépasse l'extrémite des pédoncules des antennes supéricures. Son bord supérieur est armé de dix it onze dents assez espacees; et les trois ou quatre dents du bout sont séparćes des autres par un espace assez grand. Paltes de la $2^{\text {me }}$ paire $($ fig. 28 b,$c)$ assezcourtes, grêles, cylindriques, à carpe très-court, constituées comme chez le P.aztecus. Nageoire caudale médiane terminée par une dent qui porte de chatue còté une grande épine articulée, suivie d'une autre tres-petite ${ }^{1}$. - Long. $0.030^{\text {m. }}$.

Habite: Le golfe du Mexique. Pris at Vera-Cruz, a l'embouchure des ruisseaux.

\section{Palfanov forceps, Edw.}

Magnus; pedes secundi paris graciles, cylindrici, carpis longissimis, cylindricis.

Je crois devoir donner la description complete de cette espèce, parce que ce n'est pas sans un certain doute que je la rapporte à celle de M. Edwards.

Grandeur du $P$. jamaïcensis, on un peu moindre. Paltes de la deuxieme paire très-longues, grẻles et cylindriques, garnies d'une multilude de rangées de petites épines, sauf à leur face supérieure, ou elles sont couvertes de gramulations tres-denses et aigues. Carpes toujours bien plus longs que la portion palmaire

\footnotetext{
${ }^{1}$ Ces épines tombent souvent dans les collections, mais alors il reste toujours la dent médiane qui n'est pas articulée.
} 
des mains, et celle-ci bien plus longue que les doigts. Pinces longues et grèles; les doigts cylindriques, joignant bien, mème a leur bord opposant, et tout garnis d'un duvet serré. Rostre droit, très-long /atteignant en général le bout des appendices foliacés el les dépassant souvent, élroit, son extremité n'étant pas arquee de façon a regarder en haut; son bord superieur armé de dix à douze dents, grandes ef longuement espacées; la pénultieme presque superposée à la dent lerminale; son bord inférieur armé de cinq ou six grosses dents. Nageoire abdominale médiane terminée par une dent; ses épines Jatérales inégales assez rapprochées de la dent médiane. - Lung. 0,18

Habite: Le golfe du Mexique, les còtes des Antilles et du Brésil.

Ce Palémon n'est peut-être pas le $P$. forceps. Edw., car la description que cet auteur donne des pattes de son espèce ne lui convient pas.

Chez un individu de très-petite taille, pris à Vera-Cruz, et que je considere comme un jeune appartenant à cetle espèce, on voit déjả uux pattes de la deuxième paire, les vestiges des rangées d'épines. Le rostre est très-long, et surlout arqué, son cxtrémilé étant recourbée en haut.

\section{Palemon menicates.}

Fig. 97

Medius; rostrum perlonqum, arcuatum; carpi secundi pedum paris manibus longiores

Rostre tres-grand, eleve et fortement recourbe en haut vers le bout dans la plupart des individus; son extrémité dépassant en général les appendices foliacés des antennes. Bord supérieur du rostre arme de neuf à dix dents, dont les deux dernicres sunt très-rapprochées et superposées. (II existe au contraire un espace assez long entre les trois dernières et celles qui les précèdent; cet espace est variable. Bord inférieur du rostre armé de quatre ou cinq dents. Pattes de la deuxieme paire longues, cylindriques el très-grèles, garnies en-dessous de fines granulations spiniformes (fig. 2r a. Carpe extrèmement long, bien plus long que le quatricme article et plus long que la main. Celle-ci grèle el cylindrique, ayant sa portion palmaire plus longue que les doigts, qui sont aussicylindriques, joignant parfaitement el assez velus. Portion médiane de la nargeoire caudale terminéc par trois petites dents. - Longueur du corps $0,12^{\mathrm{m}}$; longueur du carpe de la deuxième paire $0,023^{\mathrm{m}}$.

Ce Palemon est un comestible recherché sur la cote du Hesique 
Il est facile à distinguer à ses pattes de la deuxième paire qui sont plus grêles que chez aucune autre espèce américaine; à la longueur du carpe, qui l'éloigne du $P$. forceps, et à la forte courbure de son rustre très-allongé.

\section{Palamon consoninus.}

Minutus; rostrum mediocriter elongatum, supra 15-dentatum, apice acuminatum, subtus arcuatum; carpi longissimi.

Petite espèce, voisine pour la forme du rostre, du $P$. aztecus. Celui-ci attcint ou dépasse faiblement l'extrémité du pédoncule des antennes supérieures et se termine aussi en pointe aiguë; son bord supérieur est armé de 13 dents couchées, très-aiguës et spiniformes; l'inférieur est arqué et convexe en bas, armé de deux ou trois dents. La carêne latérale partage les faces du rostre en deux portions presque égales, par suite de la dilatation du rostre vers le bas. Pattes de la deuxième paire grêles cl longues; carpes dépassant l'extrémité des appendices foliacés des antennes, pas tres-cylindriques, mais plus gros vers la main qu'a leur base, moins longs que la main, mais plus longs que sa portion palmaire, et parcourus à leur face supérieure par un sillon longitudinal. Mains grèles, un peu comprimées; doigts cylindriques, joignant bien. Cette paire de patte est toute garnie de granules spiniformes ot asse\% velue. Nageoire caudale modiane cannelée ou parcourue par un sillon longitudinal, se terminant par une dent médiane et, de chaque côté, par deux é pines latérales qui sont assez écartées de ta médiane. - Lung. 0,060m.

Ilabite: Le golfe du Mexique et particulierement l'embouchure des petites rivières. Pris non loin de Vera-Cruz.

\section{Palimox inustivus.}

(Fig. 30.)

Rostrum breve. serrato-dentatum; pedibus secundi paris incequalitus, spinosissimis; major manus supra villosissima.

Espèce de taille moyenne. dont les formes rappellent le $I$ '. spinimanus. Rostre atteignant ou depassant le bouldesantennes supericures, termineen pointe aigue. peu arqué, ayant son bord supérieur armé de treize a quinze dents régulières el 
également espaccés (la pénultième en général petite); l'inféricur arqué et convexe en bas, armé de trois ou quatre dents. Les carènes latérales partageant les faces latérales du rostreen deux parties égales. Pattes de la deuxième paire très-grandes, très-inégales, très-variables; la grande patte souvent bien plus longue que le corps de l'animal. Bras et carpes renflés; ces derniers minces à leurbase, pluslongs que la portion palmaire de la main a la petite patte, plus courts à la grosse. Des rangées irrégulières de grosses épines occupant la face inféricure et interne de tous les articles; leur face supérieure couverte de granules ou de tubercules spiniformes etcomme chagrinée. Grosie main comprimée, bien plus longue que la carapace, fortement épineuse le long de son bord interne; ayant son bord externe garni d'une infinilé de petites épines, et le milieu de ses faces supérieure et inférieure lisse, vecupé par un duvet tomenteux de longs poils laineux. Doigts grèles, arqués, inégaux, de la longueur de la portion palmaire ou un peu moins longs, très-épineux; ayant leur bord prélsensile longuement cilié et garni d'une rangée de tubereules arrondis. Petite main finement épineuse, à doigts égaux. peu arqués, de mème longueur que la portion palmaire ou plus longs, el garnis le long de leur hord prehensile d'une épaisse brosse de longs poils. Les autres pattes très-grèles. Nageoire caudale médiane terminéc par une dent; ses épines laterales assez rapprochées, dépassent de beaucoup la dent médiane.-Longueur du corps $0,073^{\mathrm{m}}$. - Couleur fauve ou rosée, avec le bord interne des doigts el leur extrémité, verdàtres.

Vır. Dans certains sujets la grosse pince est mal développée, presque cylindrique, avec des doigts qui joignent bien et qui sont presque dépoursus d'épines; la petite pince est alors dépourvue de brosse.

Habite: Les còtes des Antilles. J'ai pris ce Palémon à l'embouchure des rivières de Haiti, près Jacmel.

Ce crustacé ressemble pour le facies au $P$. spinimamus, Edw., il se distingue suffisamment par ses mains dont le bord n'est pas crénelé.

Lesjeunes ont la grosse patte moins épineuse et les doigls moins arqués.

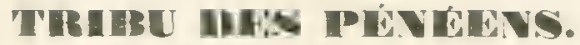

\section{Genre PENAEUS, Fabr.}

L'embouchure des rivières du Mexique est peupléc d'une grande abondance de Salicoques, parmi lesquelles on trouve de nombreux individus du genre Pénée. 
Ceux que j'ai rapportís ont été pris principalement dans le Rio de Tampico et dans les lacgunes salurees de la còte; ils paraissent se rapporter tous au $P$. setiferus, Lin. Mes individus offrent toutefois quelque diflerence avec ceux qu'a décrits M. M. Edwards: leur longueur ne deprasse pas \& pouces. Le rostre est plus étroil et il n'atteint pas l'extrémite des appendices foliacés des antennes inférieures. La carapace me paraît ètre plus subitement arquée a ses bords latéro-postérieurs. La lame médiane de la nageoire caudale se termine par une épine aisuë.

Un certain nombre de ces Pénées ont été pris sur les còtes de Cuba.

\section{Genre SICYONIA, Edw.}

\section{Sicyoyia cristata.}

Fig. 25.1

Rostrum s-dentatum; testae carina 4-dentala.

Celte espèce est voisine de la $S$. carinata, mais elle en diffère essentiellement par la forme du rostre el do la crête de la carapace.

Le rostre est assez court, il dépasse seulement l'extrémité des yeux ct se termine par deux très-petites dents, placées l'une en dessus de l'autre; il porte en outre sur son bord superieur trois plus fortes dents dirigées en avant. La crête de la carapace est très-élevíe et armée en dessus de quatro fortes dents, dont l'antéricure est la moins grande el appartient deja presque au rostre. On voit de plus une épine dirigéce obliguement en haut à l'angle externe de l'échancrure orbilaire et unc antre bien en arriere de celle-ci, de chaque coté de la carapace, à l'extrémité d'une saillie longitudinale. In dessous de cette saillic est une grande gouttiere qui oceupe presque toute la longueur de la carapace. Celle-ci est rendue très-raboteuse par divers enfoncements et proeminenees, mais clle n'est point tuberculeuse. Les antennes inférieuresont leur filet comprimé et cilié; leur pédoncule n’atteint pas le bout de l'appendice foliacé; celui-ci se termine par une pointe longue et acérée, séparée de la partie lamelleuse par une très-profonde lissure dont le fond est dépassé par l'cxtrénitć des pédoneules. Les pédoncules des antentues supérieures sont plus avancés que ccux des inférieures, mais n'alteignentpas au bout des appendices foliacés. L'abdomen est extrèmement raboteux; sa crète estélevée, ses segments sont 
creusés de sillons profonds et de plus tout couverts de petits tubercules qui les rendent très-rugueux. La partie médiane de la nageoire caudale est creusée de trois sillons et offre près du bout, de chaque côté, une très-petite dent. La carapace est garnie d'un épais duvet rugueux de poils courts, qui se voit aussi dans les sillons de l'abdomen. - Longueur du corps 0,07 .

Habite: Les côtes de Cuba.

Celte Sicyonie a le rostre et la crète dorsale armés de plusieurs dents, comme chez la s. lancifer, Oliv., mais ces dents paraissent moins nombreuses et autrement disposées. L'espèce d'Olivier est du reste originaire de l'Océan Indien.

\section{Genre OPLOPHGRUS, Edw.}

Cette petite division générique est cncore peu connue et ne doit peut-ètre pas être séparée de celle des Ephyra, Roux. Aussi n'est-ce pas sans un certain doute que $j$ y fais rentrer l'espèce qui suit et qui offre certainement dans ses caractères généraux de grandes différences avec celle qui sert de type à ce genre. Néanmoins c'est bien évidcmment de ee type que notre crustacé se rapproche le plus et il peut former dans le genre oplophorus une section caractérisée comme suit: Corps comprimé, dépourvu d'épines; abdomen très-long; pattes de la deuxième paire grèles el allongées.

\section{Oplophords americayes.}

Fir. 31.

Rostrum testa longius; antenne externe corporis longitudine equales; abilominis segmento sexto perlongo.

Carapace médiocrement comprimée, inerme, lisse, el fortement échancrée à l'endroit des orbites. Front armé d'un rostre comprimé el filiforme, légèrement arqué et bien plus long que la carapace; ce rostre $(f i g .31 b$ se termine par unc pointe aiguë, en dessus de laquelle on voit deux ou trois autres petites épines subterminales; son bord supérieur est garni dans son tiers basilaire de neuf ì douze dents; l'inférieur est garni d'une multitude de petites dents spiniformes, dirigées en avant, qui cependant ne s'étendent pas jusqu'a l'extrémité du rostre et qui commencent au point ou les dentelures du 
bord supérieur sarrêtent. Youx très-gros fiğ 3i b) portes sur des pedoneules assez longs el rétrécis a leur base. Intennes inférieures (fig. 31 c aussi longuesque le corps; leurs appendices foliaces deux fois plus longi que les pédoncules, atteignant un peu au-dela du milien du rostre. Antennes supérieures (fig. 31 d) aussi longues que la carapace avee le rostre; leur pédoneule alleignant le milieu du rostre, composé de deux articles longs et d'un troisièmecourt; le premier porte un appendice styliforme aussi long que lui'. Abdomen comprime, trèslong. composé de sis segments, dont le dernier est trís-comprine et trés-long, (aussi long ou plus long que les deux précédents pris cusemble). Le test de ce segment ne forme pas seulement un arerau dorsal, mais il est complet en dessous et ressemble par conséquent à une espèce de tube comprimé il offre de chaque côté à son bord postérieur deux petites dents entre lesquilles vient s'articuler la nageoire caudale laterale. Nageoire caudale, au repos, aussi longue que le sixieme segment; mais la lane médiane bien plus courte que les latérales. terminé par un angle très-oblus: Maxillipedes longs el cylindriques. Pattes garnies de longs appendices llabelliformes fig. 31. Celles de la première paire assez courtes fig. 31 /. 32a lerminées par une pince assez grosise, précédée d'un earpe aussi large que long. Celles de la deuxième longues et grèles (ig. 31 g, 32 b) terminées par une petite pince. Les autres grèles. Fausses-pattes abdominales noffrant rien de particulier, terminées par deux appendices foliacés. - Longueur du corps $0,023^{\mathrm{m}}$, ill. du rostre $0,006^{\mathrm{m}}$.

Ce eurieux crustace habite les caux des Intilles. Je l'ai pris a l'embouchure des rivieres de l'lle de Haiti

'Cet appendice a l'air de tenir à une pièce basilaire suiformerait le quatrième article.

Par la dessication cette nageoire devient cannelée. 


\title{
ORDRE DES AUIPIIIPODES.
}

\author{
FAMILLE DES CREVETTINES.
}

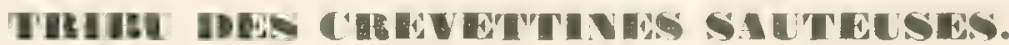

\section{Genre AMPHITOE, Leach!}

Liespece que nous renous ajouter a ce genre se dislingue par les caracteres généraux suivants:

Antennes supérieures plus courh's que les infélieures. leux presyuc circulaires. Palles de la deuxieme paire beaucoup plus grosses que eelles de la premiere. Dos arrondi, point carêné, mais fes deux premiers anneaux de l'abdomen so terminant frat une épine mestiane. Font depursu de rostre.

\section{Ampiltoe aztecus.}

Fir. 33.

Minulus; antennet superiores inferioribus breviores; pedes secundi paris maximi.

Antenues assez couptes. Les superieures moins longues que les inférieures celles-ri ayant un pedoncule très-lons, compose de trois articles dont le premier tres-rourt, le deuxicme long of le troisieme plus long encore fig. 33 a . La tigelle a peu press de ha longueur da pédonculo al composen de dix an douze

1 Les petites meveltines sont si difficiles a bien etaler, a dessiner et it iludier. qu'il a dil se glisser bien des fautes daus leurs descriptions. Ia figure que jo donte dr cette espèce n'est pas parfaite, mais elle requésente avec exactitude chacune des parties, quoique leurs rapports de: grandeur laisse quelque chose à désirer. 
articles eylindriques, dont le premier ent presque aussi long yue le deuxiome.

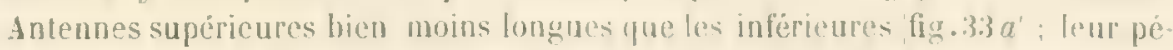
doncule compose de trois articles, dont le premier gros, le deuxieme presque aussi long mais moins gros, le troisiène plus rourt el plus miner; tigelle composée de 9 ou 10 arlicles presque igaux ; un peu plus longae que le pedoncule; celui-ce natteignant pas au milieu du pélonoule les autennes inférieures. Rostre nul. Carapace lisse sur les coltes. (OFil presfue dirculare. Paltes de la premiere paire petites fig. 33 h), terminces par une main carréc. Colles de la deuxième paire très-grandes $\{\mathrm{fig} .33 \mathrm{c}$ ), portant une tres-grosse main, dont le bord préhensile est comme déchiré el cilic. Les autres palles grèles ifig. 33 d,el, wifrant aux arliculations des poils roides: celles des deux dernières paires lrés-longues, el armées de fortes griffes qui se replient a angle droil sur le sixicme arlicle; relui-ci offrant à toules les pattes simples quelques dentelutes le long de son bord interne. Les deus premiers segments abdominaux lermines par une épine médiane. Fausses-palles ablominales des trois premières paires simples, assez longues; celles de la quatrieme paire longues; celles de la sixieme paire terminées par un article styliforme qui depasse l'anus de foute sa longueur. Couleur jaunatre, - Longueur. 0,00:3 à $0,006^{\text {m. }}$.

Habite: Le Mexique; pris en abmence dans une citerne de Vera Cruz. Jai pris dams les ruisseaux du pare de Chapultepee, pres Mexion. un grand nombre de petits Amphitoës dont l'etat de conservation est trop mauvais pour permettre une élude exacte des caractères, mais qui me paraissent ètre spéifiquement identiques a l'A azlecus. Il est bien singulier que cetle espèce, de taille si exiguë, habite simultanément les eaux douces de la còte chaude du Mesigue ef celle du plateau, dont le climat est infiniment plus frois. 


\section{ORURE DES ISOPODES.}

\section{SECIION DES ISOPODES MARCHEURS. \\ FAMILLE DES CLOPORTIDES.}

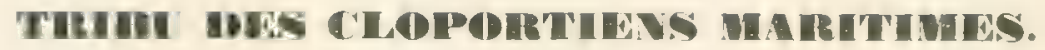

Gevre Ligia, Fabr.

Un certain nombre d’individus pris a Cuba ne nous ont pas paru différer de la L. Baudiniana, Edu.

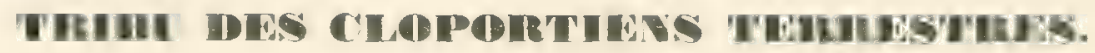

Genre Porcellio, Latr.

Il ne me parait guere possible de distinguer avec certitude les nombreuses espè ces de ce genre qui se louchent entre clles. Les caractères tirés de la forme du front sont trop vagues pour permelle d'elablir des sections suffisam. ment nottes, et le travail de $\mathbf{M}$. Hrandt relatif à ce genre n'est pas de nature à léclaircir beaucoup. Nous ignorons si le sexc ct l'àge rinfluent pas sur la longueur des appendices caudaux que l'on considere generalement comme un bon caraclère spécifique.

Pour l'arrangement des espèces qui suivent, nous préférons ne pas recouril aux caractères assez vagues tirés des lobes du front et nous en tenir seulement aux deux sections que voici 


\section{A. Lispèces chez lesquelles les angles postérieurs des pre- miers anneaux thoraciques ne sont pas prolongés en arrière.}

\section{Poncetilo Porre.}

Hig. 34 :

Abdominis segmentum ultimum duplo latius quam tongius, primum artuculum appendicum pediformium analium haued superans.

Lobes latéraux du front médiocrement grands. arrondis de tous eòtés dirigés en avant, non latéralement, et dépassant sensiblement les angles antérieurs du premier segment thoracique. Milieu du front obtus, subangulaire, bien moins avancé que les lobes latéra ux. Te'st insenciblement granulé, offrant comme le P. aztecus denx handes de granulations blanchitres. Dernier anteau abdominal triangulaire, deux fois aussi large que Iong, son extrémite angulaire seulement, point styliforme, ne dépassant pas le premier article des dernieres fausses-pattes el creusé d'une fosselle. Dernieres fausses-pattes courtes: leur premier article plus la rge y ue long, an moins deux fois aussi long que le deuxieme, qui est court à peu prós de lá longueur du dernicr anneau abdominal . - Longueur du corps 0.010 ; largeur $0.006^{\mathrm{m}}$.

Pris dans l'intéricur de lïle de Cuba

\section{Porcello cubersis.}

(Fig. 3ij).

Frontis toba media, minima, arcuuta; abdominis segmentum ultimum mediocriter productum.

Lobes latiraux du front grands, depassant de bea ucoup les angles antéricurs du premier anneau thoracique, arrondis et diriges en avant. Lobe median rudimentaire, simplement arqué. Test a peine granulé. Dernier segment abdominal plus large que long, lerminé par un prolongement styliforme un peu triangulaire el creusé. qui dépasse de son dernier tiers le premier article des 
dernières fausses palles. Deuxième article de celles-ci court, slyliforme , mais plus long que chez le P. Poeyi, ef de mime longueur que le dernier segment de l'abdomen. Conleur d'un brun verdàtre. - Longueur 0,011 ; largeur $0,0095^{\mathrm{m}}$.

Pris dans l'ile de Cuba.

\section{Porcello sumichiasti.}

Fig. 36.

Frontis loba intermeden aix distincta: pedium analium articulus secundus brevis, subhastiformis.

Lobes lateraux du front grands, diriges un peu en dehors, arrondis a leur bord interne, ayant leur bord cxterne droit, n'élant que peu relevés horizontalement; concares en dessus. Lobe médian a peu près nul. napparaissant que sous la forme d'un cordon arqué. Dernier segment abdominal un peu plus large que long. terminé pal un prolongement oblus, presuue styliforme, ereusé en dessus et dépassant de tròs-peu le premier article des fausses-pattes, qui est très-court. Denvicme article de ces dernières. substyliforme, un peu rétréci à sa base; appendice interne des fausses-pattes dépassant de beaucoup le dernier segment abdominal, atteignant au monns jusqu'au milinu du deuxième article des fausses-pattes anales, lequel est sensiblement plus court que ee segment. Test prespue lisse, dou gris cendré uniforme. Articles intermédiaires des anlennes un pel carénés en dessous. - Longurur 0,011; largeur 0,0063

Ce Porillion ressemble beaucoup au $P$. cubensis, mais il a le deuxieme arlicle des fausses-paltes anales plus court, plus ovale, el les appendices internes de ces dernières sont plus longs.

Je le dédie à mon ancien aide el compagnon de voyage .I Sumichrast, qui l'a pris dans l'tle di Cuba.

\section{Porcellio Cotillae.}

Fig. 37. )

Fusco-cinereus; pedum analium articulus secundus longissimus; frontis loba imermedia vix distincta .

${ }^{2}$ Ces letails ne peuvent ètre décrits avec assez de précision puur ètre parfaitement saisis sans le secours des figures. 
Espece tres-roisine du P. Sumichrasti, ayant la tète eonstitué de la mème maniere; sa couleur semblable, elc. mais !e deuxieme arlicle des fausses-patles anales long el styliforme, ayant la longueur des deux derniers segments de labdomen pris ensemble. Appendices internes des fausses-pattes très-longs, aiteignant le milieu de leur dernier article. Dernier segment abdominal constitué comme chez l'espèce citée, mais offrant a la hase de son prolongement deux éminences longitudinales forme par de tres-petits fubercules.

Pris a l'entrée de la Grolte de Cotillat a hut lieues de la Havane

\section{Porcillio aztects.}

Fig. 38 .

Articulus secundus pedum analium primo duplo longior.

Tète Iransiersale fig. $38 a_{\text {; }}$; lobes lateraux du front grands, depasiant de beaucoup les angles antérieurs du premicr an weau thoracique, arrondis et réflechis en avant. Portion moyenne du froul offrant une petite saillie triangulaire. Derniev segment dépassant de heaucoup l'arlicle basilaire des dernières fausses-paltes et un peu crensé en gouttiert. Ippendices internes de ces fausses-pattes depassant de beaucoup l'extremite du dernier anteat abdominal. Deuxieme article des dernières fausses-palles slyliforme, court, ll ayant que deux fois la longueur du premier arlicle. Test convert de tres-faibles gramulations obluses, d'un gris verdâtre ou brunàtre. aree des marbrures pàles qui couvrent la tète, puis se partagent de façon a dessiner sur le corps deux larges bandes de granulations ou marbrures pâles, tandis que la ligne mediane du corps reste en général brune. Cependant te milicu dı lest est sourent aussi marbré. - Longueur 0,0133: largeur $0,008^{\mathrm{m}}$.

Pris à Cordova; terres chaudes du Mexique

\section{Porchilato mexicanus.}

Nin. 39.

Secundus articulus pedum analium primo ter longior.

Un peu plus grand que le P. atsecus; son corps plus earré, ce qui tient a la forme plus large du premier anneau thoracique. Telc constituee 
comme dans l'espece citée, mas ses lobes lateraux dirigés plus en dehors, moins arrondis it leur bord interne. Corps couvert des mèmes granulations irrégulières et faibles et offrant à peu près les mèmes marbrures. Dernier segment abdominal ayant sa portion postérieure creusée en goutlière, moins styliforme que chez l'espice citée et ne dépassant que de très-peu l'article basilaire des dernières fausses-pattes abdominales. Deuxieme artiole de celles-ci aigu et très-long, ayant trois fois la longueur du prenier article lequel est aussi plus long que ehe? le $P$. aztecus, - Longueur 0,015; largeur $0,009^{m}$

Pris à Cordova et dans les régions chaudes du Vexique.

Nou. In individu de la mème localité a les dernières fausses-pattes abdominales moins longues que les autres sans qu'il soit possible de bien définir la différence lig. 10 . On est constamment embarassé dans l'étude des Isopodes par ces difrerences insensibles qui semblent établir le passage d'une espèce à l'autre.

\section{B. Espèces chez lesquelles les angles postérieurs de tous les segments thoraciques sont prolongés en arrière.}

\section{Porcello Montezuma.}

Fig. 41

Frontis loba intermedia lateralibus tequalis; appondices anales brevissimi, se undo articulo lanceolato; testa valde gramulata.

Lobes latíraur du front très-allongés, régulièrement excavés, dirigés obliquement en dehors et plus ou moins arrondis fig. $41 a^{1}$. Lobe median du front en triangle arrondi, prolongé horizontalement en avant, graud, aussi saillant que les lobes lateraux. Dernier segment de l'ablomen triangulaire, aussi large que long, portant une goultière longitudinale; sa pointe alteignant au milieu du deuxieme article des dernières fausses-pattos ablominales; celui-ci ayant une forme lancéolée (c'est-a-dire rétréci à sa base), tries-court, égal en longucur aux deux tiersdu derniersegment. Premier articledes fausses-pattes, gros et court. An-

\footnotetext{
"Is ne sont pas tailles de mème chez tous les individus, un en voit de plus ou moins carrés et plus ou moins etroits. Un individu offre même le lobe droit rétréci an bout et prolongé.
} 
tennes grosses, alvant leurs trois arlieles intermediares un pencannelés el carenés en dessous. Test tout couvert de grosses arannlations rugneuses. densement tuberculeux ; les tubereules formant densepiestransversales; plus nombrux et plus forts vers la partie anterieure du corps, sultoul sur lat lite. sur le burd posterieur des derniers segments du thoras el ar celui des semments ahdomninams, on voil une rangée de tubereutes diriges an arriere: ol pres de la base du dernier segment il existe deux granules du meme genre lianghe posteriene du bord de

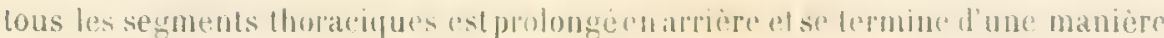
aigur, mème celui du premire. Co Porerllio est le seul chez lequel on remarque we caractere; chey lontes les autres especes lo pmolongement de l'angle posterieur des segments ue sto voil guère qu'a partir du cinquieme anneau. Couleur d'un

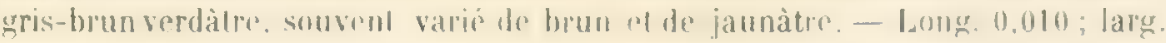
$0,0053^{\mathrm{m}}$

Pris a Tustlan, a neut lieues de perote, dans les terres froites du Mexigue.

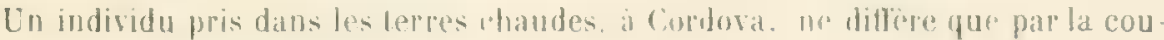
leur plus brume du corps

Nous possedons encore quelques antres Percellions du Mexigue que nous renoncons a decere paree que leur blat de eonservalion n'est pas parfait.

\section{Genre: ARMAI)llido, Latr.}

\section{Armainleo cubexsis.}

liin. 12

Abdominis segmentum ultimum longius quam margo postica latior, in medio subcoarctatum; pedes anales valde longiores quam latiores

Espéce d'atsez petife laille. dunl les formes ocupent le milieu entre eclles propres aux genres Armarlillo ol liubaris de Brandl!

Töre transversale, plus large all milieu que sur les bords. Bord inferieur de la tèle avané en forme de lame transirersale. Burd inferieur du premier anteau thoracique retrousse, continuant la lame marginale de la tìte. Angle latéropostérieur des deux premiers segments lhoraciques prolonge en arriere en forme d'apophyse large el obtuse; celui du deuxième Ironqué arrement. Les deux

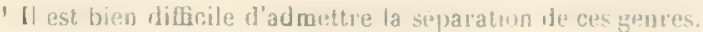


anneaus suisants loffrant ce prolongement que lris-laiblement el les autres n'étant presque pas dirigés en arrière. Hord postérieur de tous les segments portant un large sillon transversal qui se reillechil le long du bord latéro-inferieur : ce sillon, très-marqué sur la lèle et sur lres premiersanneaux thoraciques. mais l'étant moins sur les derniers. Dernier segment abdominal plus long que son bord postéricur n'est large, etranglé au milieu, puts' blargissant unpeu en arriere; sa hase plus largeque le segment n'rst long. Faussers-palles abdominales bien plus longues que larges, terminées par un bord droit. Pord postérieur du denxième anneatu thracigue ferdu. chevauchant sur to suivant. mais sa lame interne bien moins grande que lesterne. Les autres anneatux nollrant pas detle particularite, si ce n'est le premier, gui en porte des vestiges incomplets. Couleur d'un gris rendré - Longueur $0,009 \%$, largeur $0.00 \%{ }^{\mathrm{m}}$.

Pris dans l'Ile de Cuha, a lentree de la Cirntle de Contlli, non lom de la Havane.

\section{(ienre PSEUJARHAl)Halo, Nor. gen.}

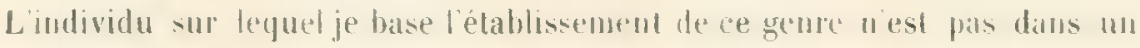
parfait elat de conservation, ee qui memperehe d'on dunner une description complete

Lá conlormation de la tète liend te molien entre celle des trmartillo el celle des trmadillidium. son bord anterieur oflere lrois sallirs. savoir une mé-

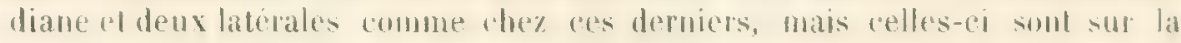
meme lagne que lit mediane et ne servent paskle support alux antemes. It n'existe all-dessus d'elles allune gouttere dans larguedle ces organes puissent se loger, mais clles se contimuent par un seul el mime hord avec la saillie médianc, comme ehe\% lespremiers. Lesfausses-pattes ahdominales sont constituees d'une manière tout exceptionnelle; leurpremicr article est tress-court, nullement visible en dessus; le deuviène pst grand irregulier, remplissint loute l'échanrrure entre fos deux depicessegments, mais comme le segment anal est large. il est plus juste de dire qu'ils dehordent les burds latero-postérieurs de a Hernier et font saillie en arrière de ee segment. De plus il eviste un troisième article rudimentaire quis'arlicule a l'angle interne, nuplutol posterieur, du deuxieme. Les segments thoraciques ont tous leurs portions laterales dirigées en arrière en forme d'apophyses, et le bord inferieur de chacun des deux premiers est fendu et chevaluche sur l'anneall suivant. Le eorps est phus ou moins difforme. anguleux et rugueux; l'abdomen est laille en forme de loit, presque prismatligue. Les yeux paraissent fare lotalement défaut. Lo corpsest tres-comprime. 


\section{Pseudarabillo carivelatus.}

Fig. 4.3.

Rugosus, tuberculatus; thorucis segmentum ulimum valde bituberolutum. abdomen serie mediana tuberculorum oinutum.

Bond inférieur de la lite formant trois lobes arrondis saillants en avant, dont te median est fe plus largo a un peu plus avancé que les latéraus, lesquels sont dirigésobliquement fig. 43 a . Dernieres fausses-pattes abdominales assez difor-

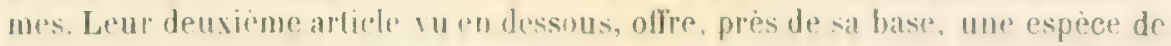

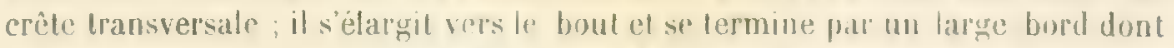
les deux extremités sarrondissenl au lieu de former des angles. la bord interne de cet article est épais, de facon a ofluir une pelite face un pru creusée. séparée de la face inferieure par une erele tordue el tranchanle. I la hase de cette face on voit mo petile lame aceolle entre elle, qui ast probablement l'appendice interne des faussespallos. Endessus, fo deuxieme article apparait sous la forme d'une band" qui longe le burel latemal du segment lies. 93,6 ;

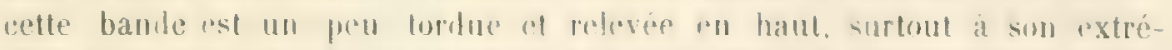
mite antérieure, ou elle est aussi un pen plus larege a son extremité postérieure elle forme un angle gui rst langle interne du botd des fausises-paltes.

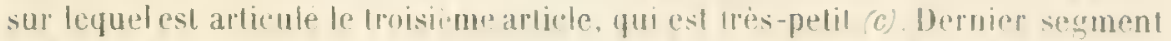
abdominal en forme le" trianglo troneque, ne dipassant pas lo bout des fanssespattes lequel sen cearte un peu; sos bords latiraus nélant pas droits mais ma peu sinues. Copps tros-raboteux. toul cousept d. pelits tuberoules rugueux. La

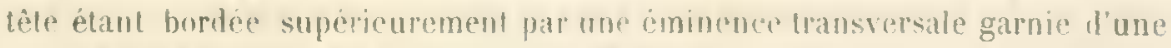
ligne do tubernotes. Premior segment thracique loul couvert de mgosites, saut sur les coles, qui sont prolongés en arriore an forme de large apophyse arrondie, ot dont les bords infericurs sont releves, de façon a former unesurface

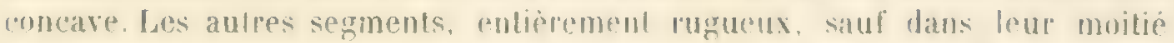
anlorieure, qui est lisse, pour l'articulation; leurs extremiles infericures sont prolongeesen arriere en forme dapophyses choiles, un peu relevees, moins rugueuses ot portant co dessus une ligne saillame longitudinale, qui se voit encore sur lr troisieme segment athominal. Derniel anneau thoracique armé en dessus des deux gros tubereules tripuetres, diriges en arriere fig.t3. Ablomen rugueux, taillé en forme dr: toil: ses deux premiers segments incomplétement visibles; les suivants tous armes an milieu d'un forl lubercule, dont le dernier. 
placé sur la base du stgment amal. wl le plus grand. Couleur d'un gris-brun uniforme. - Longueur $0.010^{\text {m }}$

Jai malheureusement perdu l'indication préesse de ld patric de cette intéressante espece. Elle se Imorve au Mexique ou dans l'lle de Cuba

\title{
FAMILLE DES CYMO'TIIOIDES.
}

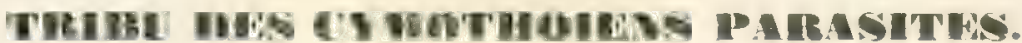

\author{
Genre A NII, OCBA, Leach.
}

\author{
Avilocra mexicava. \\ Epimeri spiniformes; segmentum nllimum rotundanum.
}

Tèle triangulaire. Yeux ovales. husants comme le reste de lat lèle, finement granulés; les gramblations tresindistinetes, comme onduites de rernis. Antennes internes eomprimeses, alleignant ou prestue lextremite posterieure des yeus, leurs deusieme a trosiome arlicles beacoup pios grands que les suivants. Antennes externes tresenomprimees, composées de dix arlicles, alteignantle deuxieme segment thoratipue. Premicl segment llsoratique ofrant de chaque cole un tuberente ohlus qui rmboite ha base de la lide et avant sou angle latérn-postéricur fablement edranere on arriere. Ephmeres des segments 2, 3, ovales: du quatrieme obtus, el des suivants agusus, spomiformes. Derniel segment abulominal aussi long que. large nu libant un peu mous, el presque circulaire, ou en calre arrondi; poist retrée en arriere de facon a prendre une formo triangulaire. Pattes pusterieures tres-longues, dres-grèles; lat russe. n'étant point renflée. Les fausses-pattes abdominates sont malheureusement brisers, mats lespece est bien monnaissable a ses epimeres trminces ell apophyses spiniforires et a ses yeux lissest. - Lung. 0,034; id. du dernier segment 0,008"

Habile: Le golfe du Mexique.

Ce crustacé se rapproche peut-être de l'A. laticauda. Edw., mais il s'en dislingue neltement par la longueur de ses antennes internes. cte. 


\section{Genre CYHothoA, Fabr.}

Liespece qui suit appartiont a la section de celles dont les anternes sont écartées à leur insertion.

\section{C'YMOTHOA PARASITA.}

Fig. +4 .

Capul margine antico recto il inter tuberculos duos primi corporis segmenti commissa.

Corps comprimi an avant seulement. Téte presque polygonale, ullrant de chaque coté en dessus unc espèce de fossette qui a continue avec un sillon oblique, lequel descend vers le milieu du bord anterieur; celui-ci large et presque droit, abrilanl la hase des antennes, mais trop large pour se replier entre leurs insertions. Premier segment du thoras grand, ofliant des tratees obluses de sillons transiersaux el. de chaque coite, un luberule dirige en avant, qui comboite la base de la lete, mats sans atteinder fo milieu de sa longueur. Ias trois ou quatre dernicrs anneaux lhoraciques ayant leur bord inférieur partage par un sillun ou une fissure qui correspond a la partie postérieure de la hanche. Ibdomen ayant ses preniers segments de moitié moin. larges que les derniers du thoras. s'elargissant jusiquad penultieme qui est presque aussi large que le dernier. Celui-ci en carre large presque denx fois aussi large que le premier, el plus de drux hois aussi large que long, ayant son bord posteriou un peu excisé an milicu Cuisses des pattes $4^{\text {me }}$ a $7^{\text {tm }^{n}}$ élargies it leur bord posterieur fig. fig en une lame. sous laquelle les articles suivants se replient; cette lame atse\% pelite a la quatrieme paire, sagrandissant aus suivantes jusyu a la derniere, ou elle alteint une dimension extraordinate. Ippendices caudaux trè-petils. atteignant peu au dela du milieu do la longneur du dernier segment: l'externe un pen plus long que l'interne. - longueur 0.030 mill.

Pris sur les ròtes de Cuba atlaché au rentre d'un poisson.

Ce crustacé me parait se rapprocher de la $C$. Dufrenii, Leach: mais il on differe par les prolongements ilu premier anneau thoracique qui sont bien moins grands et part la forme des pattes. 


\section{ORDRE DES OSTRACODES.}

Les Ostracodes d'ean douce comprennent les genres Cypris, Muell, Candona, Baird et Votodromas, Liljeborg, auxquels Zentier a ajouté les Cyprois et les Cypria, en considérant toutefois les Cypria comme formant un simple sousgenre des Cypris

Le petit erustacé que nous ajoulons a ce groupe nappartieut evidemment ni an genre Votudromas ni au genre Candona. Ses màchoires et ses pieds lui assignent une plate pusitive dans le groupe forme par les Cypris, les Cypria el les Cyprois Zenker" ne base la distinction de ces trois genres que sur des variations dans la struchure des rganes génératcurs et des zonspermes. caractères qui ont le grand desavantage d'itre d'une etude forl dificile et mime impossible sur les exemplaires conservés dans l'alcool. Aussi crovons-nous quon fera bien de considerer non-seulement lis Cypria, mais encore les Cyprois comme de simples sous-genres des Cypris. It ne nous a pas été possible d'étudier les organes genéraleurs sullisamment pour decider si molre Ostracodo appartient a l'un de ces sous-genres phutit qul a l'autre.

En revanche cel animal nous a offert un caractere lout particulier, d'observation facile, qui nous semble bien plus propere a permeitwe l'ablabsement d'ume subdivision du gente Cypris, que les caracteres choisis par Zenker. Le bord antérieur de chacunn des valves est muni d'un appendice qui lui forme une sorte de revêtement courbe on dabat-jour li fig. $4:$, a dont la concavite est tournée vers l'interieur. La partic posterieure est ornce d'un appendice ou abat-jour semblable fig. $40, a^{\prime}$ mais beaucoup plus petit. Chaque valve se compose par suite de trois loges, l'unr médianc el tres-grande. Ies deux autres

'Ce crustané a fit: eludit par II. E. Claparede atuguel on duit auss fes dessins quise voient sus la Pauche ti.

Moncgraphir dei Ostracuden. Wiesmanns Archiv. 1854. 
terminales et beaucoup plus petites. Liune surtout est fort peu développée. Lorsque les deux valves sont appliquées l'une contre l'autre elles se trouvent done renfermer trois espaces ou chambres; la grande chambe mediane est remplie par le corps de l'animal, les deux chambres accessoires sont complétement vides.

Celte particularite dans la slluclure du test ne me parait atvoir ete signalée chez aucune autre Cypris. II. Iublonch' a tigure, il est vrai, sous le nom de Cypris brasiliensis un pelit crustace ostracode de Maldonaldo donl les valves paraissent, à en juger par le dessin. ornées d'un appendiee analogue a celui que nous venons de décrire. Walheureusement le desin de cet auteur est tres-insuftisant, of la diagnose latine qui laccompanne ne fat pas la moindre mention de refle particularite du reste assez pemarqualoke. - Ta constance de forme el de développement des appendices de la valve chez lous les individus que nous avons collectés, nous engage à adopter ce caractèe comme base d'un sous-genre anquel nous donnerous le nom de chlamydotheca. 11 est wrobable que le cypris brasiliensis. Lubb. devra rentrer sous rette rubrique.

Ceci posé, mous allons passer a l'étude de l'especer qui nous oceupe spécialement ici.

\section{Cirphe (Chramyotheca) azteca, Sallss.}

Pl. Il

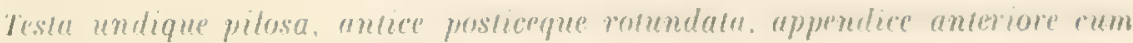
margine valvule dorsali sensim coulescente. rum margine ventrali autem anguhem manifestum efficinte; appendire posteriore minima. Allitudo maxima pone medium et propius ventralem quam dorsalem margincm silu: exinde pars postica

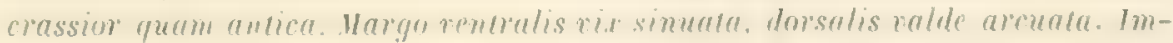
pressio musculuris paulo ante medium sita.

Les antennes de la premiere paire se composent de seplarlicles. Ce nombre concorde avec les données de Zenker el de Liljeborg "sur les Cypris en général el il parait que Baird se trompe lorsquil porte a huil le nombre normal de ces

\footnotetext{
On the Freshuater Entomostraca of South America - Transactions of the Entomological So. ciely of London HII. 1855. p.34. PI. II lig. 1.

¿ Om de inom skàne förebommande crustacoer af urdningarne Claducera. Ostracoda och Copepoda, Lund 1853, [1. 103 .
} 
articles. - Lamurau basal est gramel et mo do trois soies dont deux fort longues tig. 47). Le second anmeau est tros-court. He porle aucune soie et a sa suite riennent les ciny anneaus suivants dont le premier est un cylindre a peu pres quatre fois aussi long que large, tandis que les autres ront en diminuant gradueflement de longueur et de largenr. Liansau no 3 porte deux

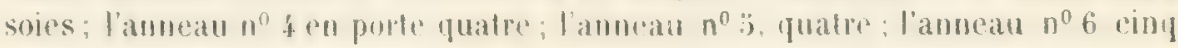

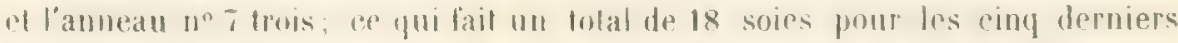
anneaux. Lat phupart de ces soles sont longurs al roliers; quelepues-unes /Voy. la fig.t somt plas courtes el depourvers de rils.

Les antemes de la seronde parre se composent de six anneaus tig. 3.8 dont deux $\left(n^{\circ}\right.$ \& et 3 sont plus ou morns complitement soudes l'un a l'autre, comme Zenker a deja remarque gu cela arrive the\% plusieurs especes ${ }^{1}$. Le sixieme anuran est excessivenent anurt el pour ainsi dire rudimentaire. On sait que chez les cypris l'extremile du lonsiome anmean porte un faisecau de longues soles. Che lasceau se compose, selon Zenker on general de huit soles, el dapres biljeborg, seulement de einq a six. Chey la r. nzteru fe faiseeau se composi

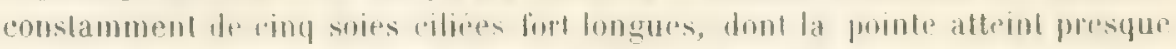
l'estremite des unglets qui forment le sommet the l'antenne. line sole plus

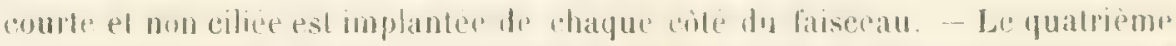

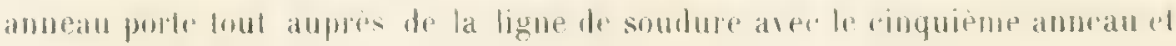

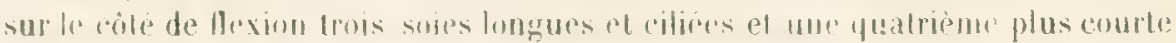
et non riliere. Lne sole nom cilier est implante à la pat tire eorrespondante du mème anmeau du colo de l'exlension. Le sommel de l'anfenne est forme par un faisceau de ring onglets longs denteles of en forme de sabre, dhont Irois sont portes par le cincluieme andeatu el doux par lesixiome.

La machoire de la premiere pare fig. 49 selon la nomenchature de Zenker. la mandibule dans le systeme de Liljeborg el dautres atuteurs est composé

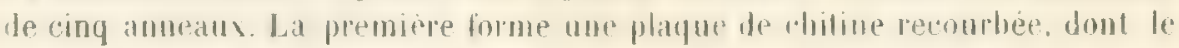
hord destine a la mastication porte six dents bitides al quelyues petites soies. Sa base interme presente une losse large at profonde qui sert de point dattache aux musches de la mastication. Dans son milieu cet article presente le trou dans lequel vient s'articuler le socond article. Colui-ri forme aroe les trois suivants ce quion peut appeler le palpe. Du coble de lextension il porte une branché que nous tronvons eontamment lormé de sept rayons, bion que Zenker donne lo nombre six comme élant general pour touldes tos espèces. En outre le bord

1 C'est ce ugui explique prourquos Liljeborg ne cumple que cinq anneaur dans les antennes de la deurième paire. 


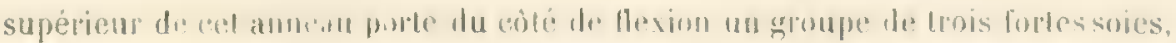

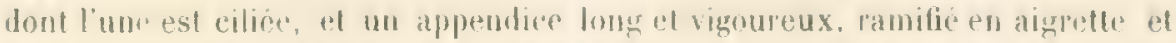

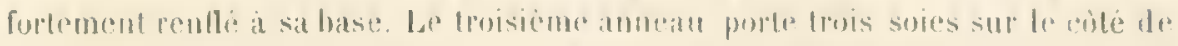
lextension el qualde sur celui do la llevion. Liexamen de la figure montrera d'une manione sulfisante ha disposilion on le monbre de sobes des deus derniers imneaux

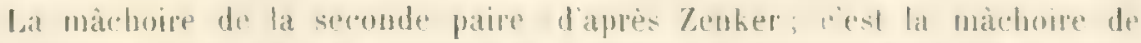

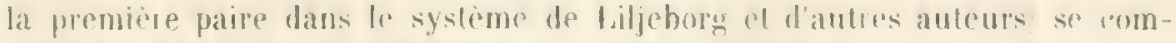
pose fig. 50 d'un trou portant a son axtremite quatre branches dont lune r'st biarliculée. Zenker a montre que ces dillérentes branches doivent idre ronsiderées comme lormanl morphologiguement des anneaus sureessifs. la

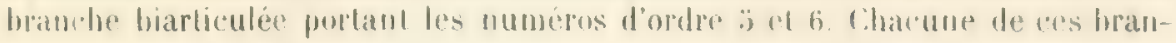

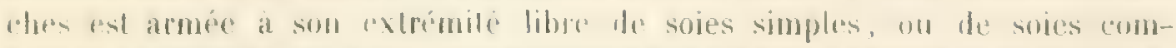

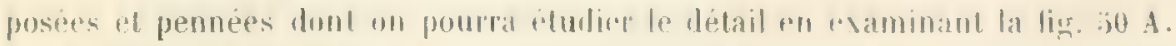

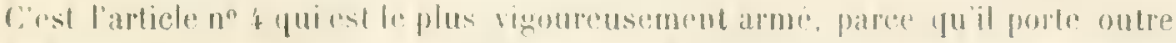

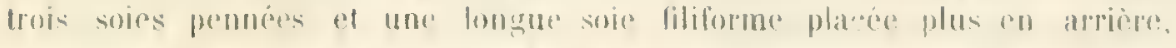
un groupe de ring onghtels larges. forts et rescourbes, dont l'un ast dente.

- Larticle basal porte une brandhe trestheveloppre dans lapuelle mons avous compté en genéral 18 19 19 rayous.

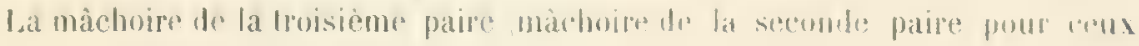
qqui admettent des madibules, ne laisste pas recombailme de divisions d'al-

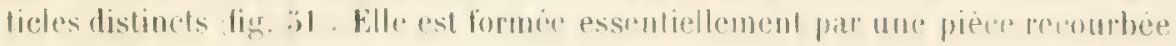
dont le hord anterieur est bordi de soles preuneses of qui porte en arriere une

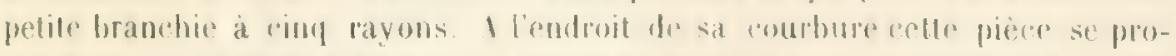

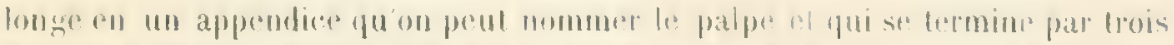
soies longues at pennes. Zenher a reommu qur che\% les jemes individus en: palpe est compose de trois artictes qui se soudent phas lard. If siest en mulre

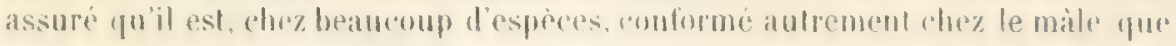

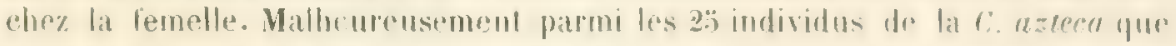
nous avons entre les mains, il ure se'st pas lrouvé un sen! male.

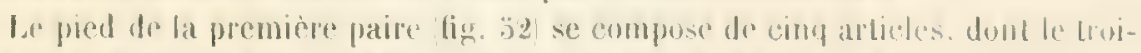
sième of le qualrieme sont a peine mobiles l'un sur latulde. Le einquiemes atu contraire, est fort court ol tres-mobite. It purte un onglet ou sabre très long ot dentele. Lexamen de la figure montere puedle est la distribution exate des soir's de cette extrémitio.

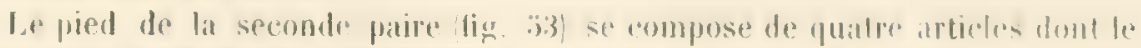

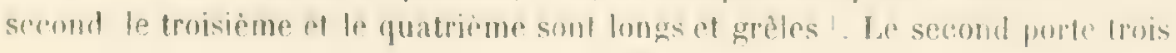

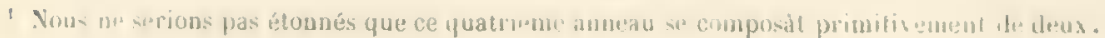




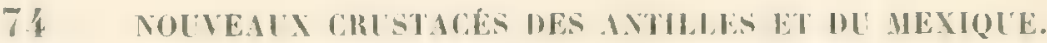

soies; les deux suivants chacun une. Le cinquieme article est peu développé el son arliculation avec le yuatrieme est si singulière quau premier abord on napercoit de lui que le plus fort des deux onglets qui le terminent. Le cinquième article est en effet completement enchassé dans le quatrieme qui lui forme une veritable gaine. Celle gaine est fendue sur l'un des côtés fig. 33 A "f met ainsilarticle à à découvert. Lun des bords de la fente est orné d'une rangèe de dents en peigne. - La'article invagine se termine par une soie simple 't par deux onglets recourbés dont l'un est tout a fait rudimentaire. - Aucun auteur ne parle dune conformation semblable chez le pied correspondant d'autres espèces. Tenker se conlente de dire que le pied de la seconde paire est termine par un onglet, tandis que Lilijeborg lui on fait porter deux. Ces auteurs paraissent du reste faire porter! ces onglets directement par larticle que nous avons marque du $n^{\circ} 4$.

Le membre caudal enfin fig. "If est tout à lait semblable à celui des autres Cypris. Il ue laisse reconnaitre aucune articulation el porte à son extrémité deux onglets dentelés et deux soies.

La couleur de ce crustaciest jaunàtre, marbre de vert.

Habile: Les eaux de la cote orientale du Vexique: pris dans les mares des enviruns de Vera-Cruz. 


\section{ECPLICATION DES PLINCIIES.}

PlaXiHE I.

Fui. I. Mithrax minutus, Sauss., grossi. - I a, sa granden malurelle.

Fis; 2. Carapace de la Perirera spinosissima, Sauss, de granderr naturelle.

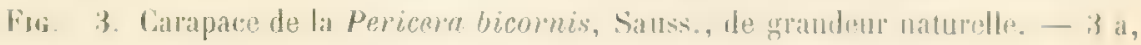
sa grandeur naturelle. - $3 \mathrm{~h}$, main droite de la memo, orossie. - 3 c, brandentr naturelle du: lit main.

Fin. 4. Lambrus cremulatus, Sauss. grossi. - 4 a, earapace du mème de granderig naturello.

Fus. 5. Chlorodius americanus, Sauss, du grandent haturelle.

Fin. 6. Panopeus occidentalis, Sauss., grussi. - li a, caralpales du meme de grandeul naturelle.

Fig. T. Panopeuserratus, Sanss, grossi. - 7 al, calrapace lu mème de grandeur naturulle.

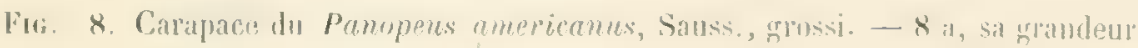
naturulle.

\section{Pesкue Il.}

Fig. 9. Irepalms tuberculabes, Sauss. grossi. - 9 a, sa grandeur nallurelle.

Frg. 10. Carapace du Portumes guadulpensis, Sauss., faiblanent grossie.

Fis. 11. Lupea anceps, Sauss. grossie. - I1 il, earapaeo de grandeur naturelle. 11 b, main grossie, vue par levallt.

Fus. 12. Polnmia americana, Sausi., de grandeur maturelle. - I1 it, maxillipede.

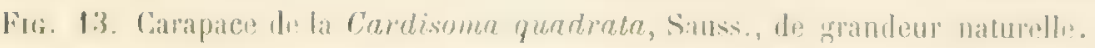

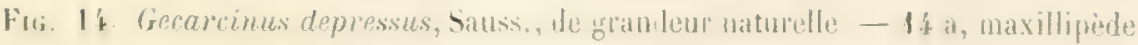

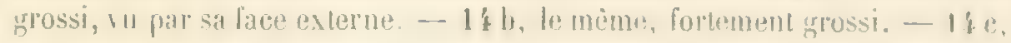

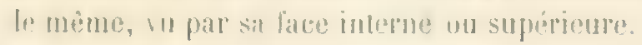

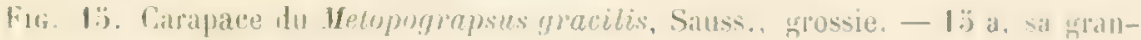
deur naturelle. - Iöh, main satuche grossie. - 1.j c, sia grandera naturelle.

Fin. I6 Carapace da Metoporgrapsus dubius, Sauss, grossie. - 16 il. sa gran-

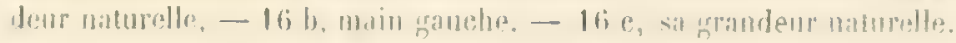




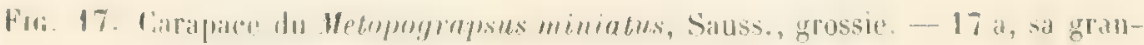
deur naturwll. - 17 b, main sauche - 17 c. sal gramdent naturelle.

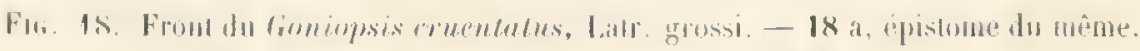

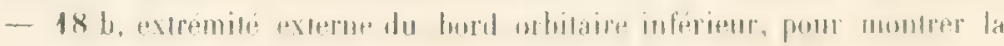
gounieme qui se voll che\% rertains sujets.

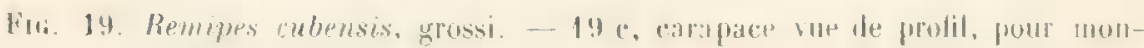

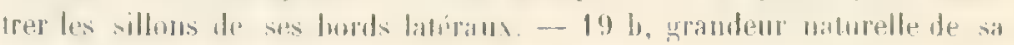
rarapares 1 .

\section{PI.Axche III}

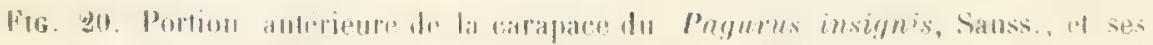

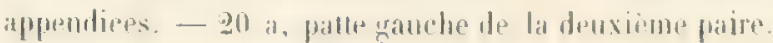

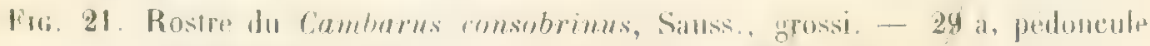

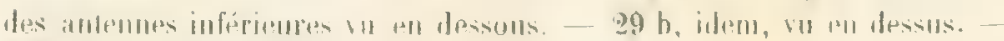

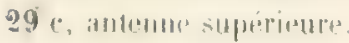

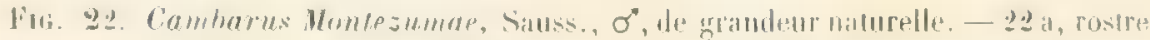

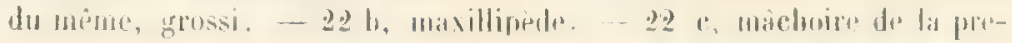

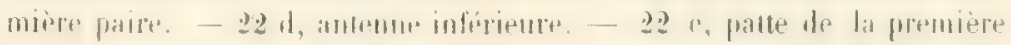

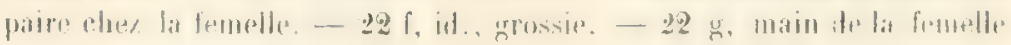

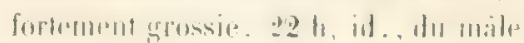

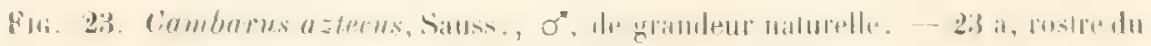

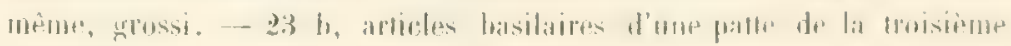

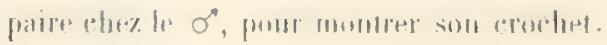

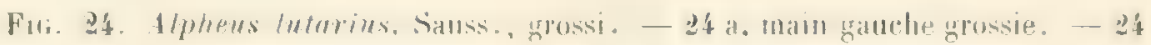

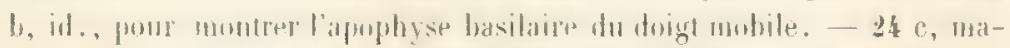

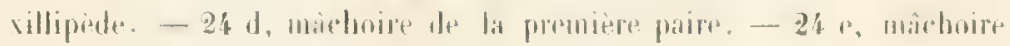

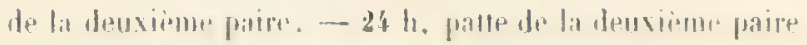

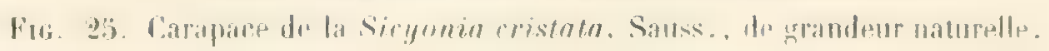

\section{Peaviur: IV.}

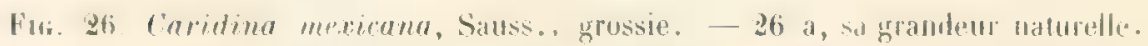
- $26 \mathrm{~h}$, maxillipide. - $26 \mathrm{c}$, machoire. - $26 \mathrm{~d}$, palte de la premiere

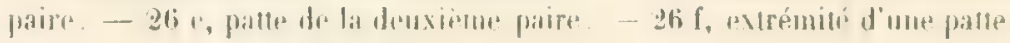

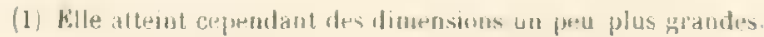


de la premiere parre, plus forternent grossie, representant la main ou-

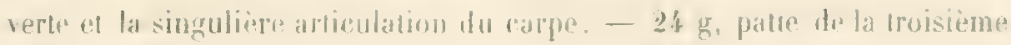

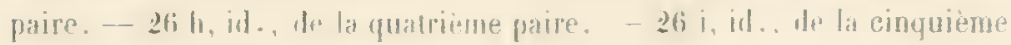
paire. $26 \mathrm{k}$. Camsse-patle abduminale.

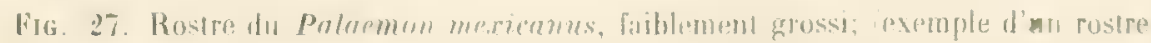

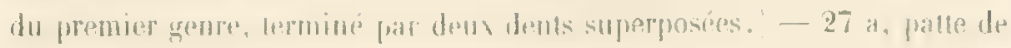
la denxiome paire da mame, faiblamont grossio.

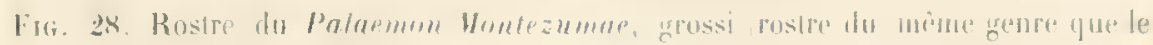

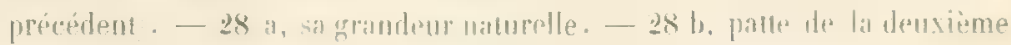
paire. - $28 \mathrm{c}$, la mîmm. de grandeur naturelle

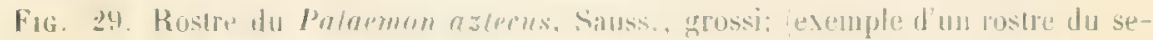

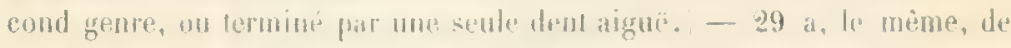
grandeur Haturelle. - 29 b, pallu de la demvieme paire, grossie. $-29 e^{2}$

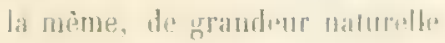

Fis. 30. Palapmm Fuustimus. Situss.. de grandeur naturalle.

Fus. 31. Oplophorus umerimnus, Sauss.. grosisi. - 31 a, sa gramdeur naturelle.31 b. rostrr du même, fortement grossi. - $31 \mathrm{c}$, antenne inférienle. $31 \mathrm{~d}$, antenne supérienro. - 31 f, patte de la premiere paire. - $31 \mathrm{~g}$,

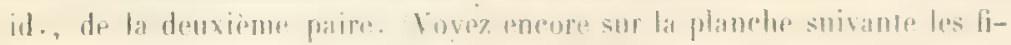
gurs: 32 .

\section{PIANCHR: I.}

Fici. 32. a. Patle de la premiere paire de l'oplophorus americanus, forlement grossie. - $32 \mathrm{~h}$, id. de la secombla paire.

fig. 33. Amphitoë azlecus, Sauss., fortement grossi. Togez sal grandeus nalu-

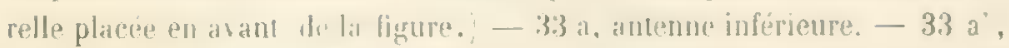
antenne supérienre - $36 \mathrm{~h}$, patte de la premiere pare.- $33 \mathrm{c}$, id. de la denxième pare. - 334 1. id. wo la cinquibme paire.

Fui. 34. Abdumen tu Percellin Pueye, Sauss., grossi.

Ful 3:i 11. da Porenllio cubensis, Sanss. grossi.

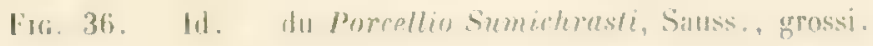

Fin. 37. Id. du Purcollin Cotillate, Sillss., lal.

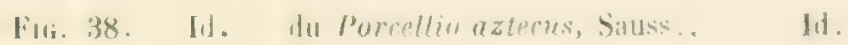

Fri. 39. Id. du Porcollin mexionmus, Sauss., lil.

Fili. \$0. Id. do mème, variétio. 
Fig. 41. Porrellio Hontezumar, Sillss., grussi. - 41 a, tite et premier smoment thoracieque, vus far devant. - it b, gramfeur naturelle de l'animal.

Fus. 22. Tek et premiers annealux thoraciques de l' trimedillo cuhenses, Sauss., grossi. - 12 a, abdomen du mènc.

Fua. 43. Abdomen In Psemdarmadillo carinulatus, Sauss., frossi. - 4 il, teite at premier andean thuraciphe du mene.

Fis. 44. Cymothon parasitu, Sauss., de grandeur maturelle. - it a, portion de l'animal vo en dessons, représentant uns partie du pigridium, une fausse-

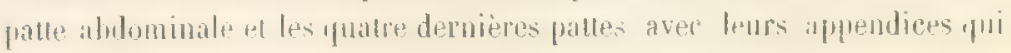
vont rrandissant du premien and dernier.

\section{P'LAXCHE VI}

Cypris Chlamyduheca azteca, Sauss.

Fin. 4.j. Test de la C. aztera, Sauss., Cortement grossi. - "sal pièce appendiculairn antérieure. - a' sa pièce appendiculaire postérieure. - o ail. $m$ imprression musculaire. (Sa division en parties et surtunt sa qusition sont d'une hatute importance pour lat détermination de l'especes.)

Fuc. 46. Test ve par lo dos. Cirosicsement de 14 diametres.)

Fir. 47. Anteme te lat premiere paire (grossissement de 6.j diamitres). Les sept

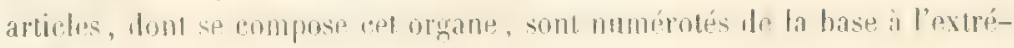
miti.

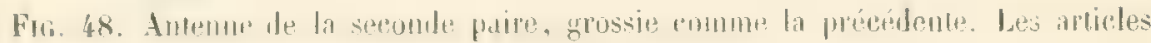
son numérotes de la mène maniere.

Fu. 49. Michoire de la premiere paire. Grossissement de i6 diamètres.

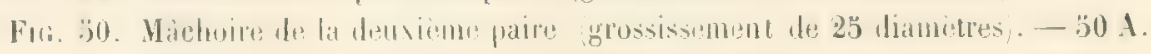
Evtríniti de cetle machoire, fortement grossie, pour montrer l'arrangement des poils et appondiess.

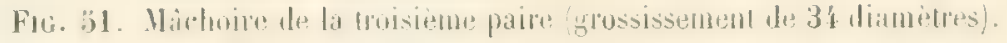

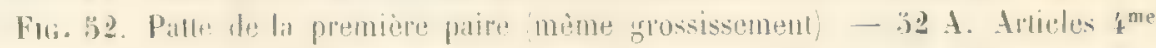

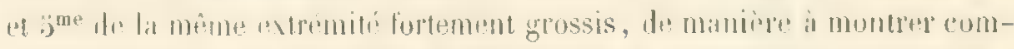

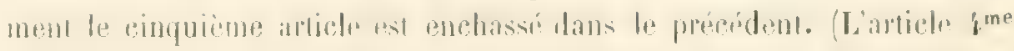

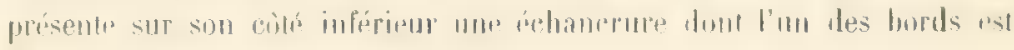
dentelé en peigne.

Fus. 93. Patte wr la seconde paire (mème grussissement). - 33 A. Evtrimité de cette palte, forlement grossie pour montrer l'invaginalion du :; me artirle.

Fu. 34. Appendice caudial grossissement de 30 diametro 


\section{Table des gemes el des esperess doul il ast lait mention dalls cet mémoirer.}

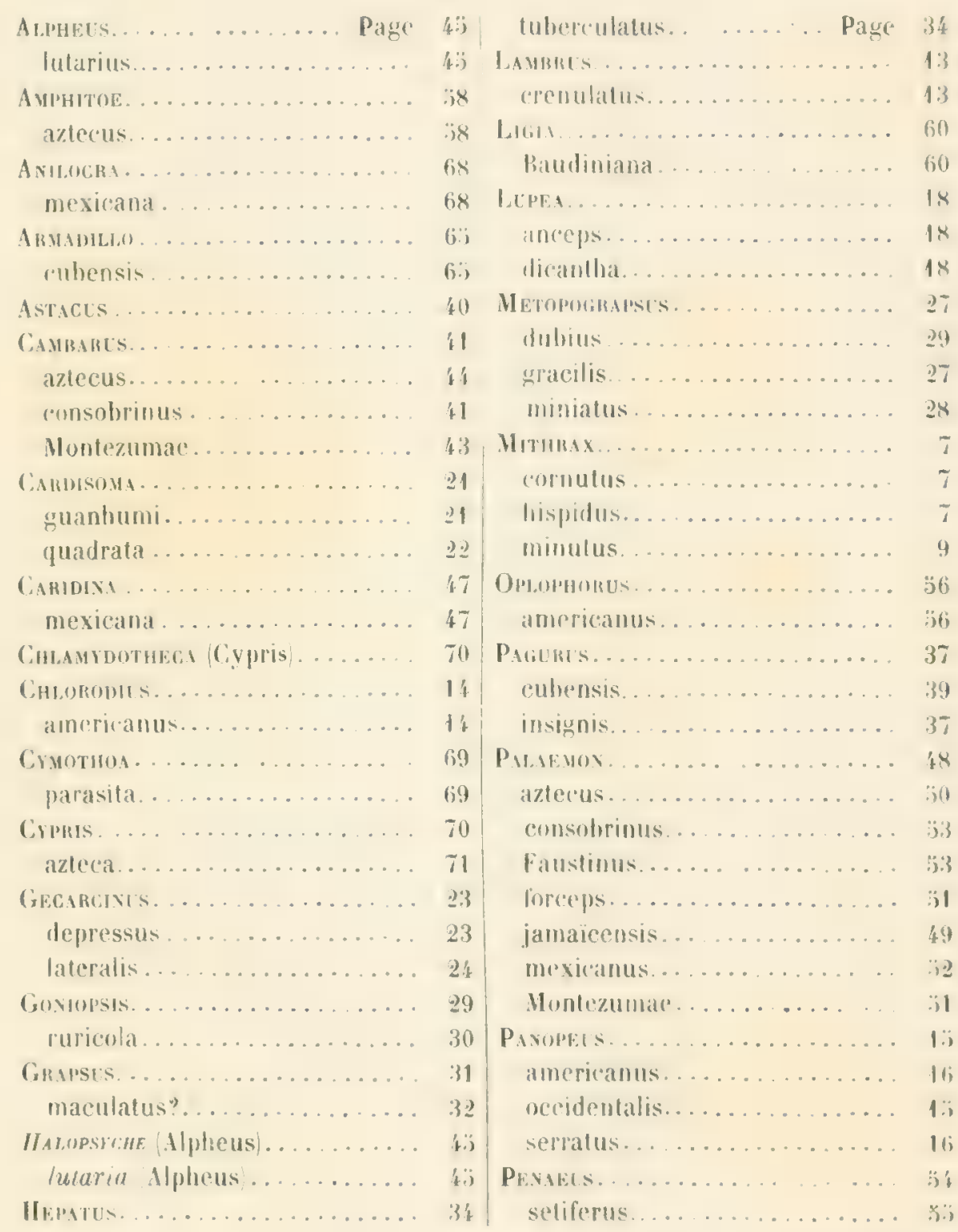




\begin{tabular}{|c|c|c|}
\hline Pericera . . . . . . . . Page & 10 & guadulpensis.......... Page \\
\hline bicornis................ & 12 & Potamia .................. \\
\hline spimosissima ............. & 10 & americalla.............. \\
\hline Platalsia . . . . . . . . & 33 & Pámodakadila, . . . . . . \\
\hline gracilis............. & 33 & catrinulatus.......... \\
\hline Porcellato ... & 60 & 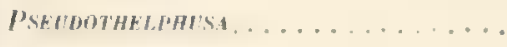 \\
\hline aztecus......... & (ii) & ameriramu Potamial......... \\
\hline Cotillae............ & $1 ; 2$ & Remipss............. \\
\hline rubensis. .. & 61 & cubensis......... \\
\hline mexicanus........... & 6.3 & 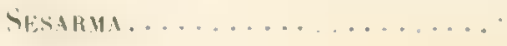 \\
\hline Montezumae ............. & 6.4 & 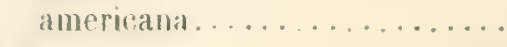 \\
\hline Poeyi.................... & 61 & $\operatorname{miniala} \ldots \ldots \ldots \ldots \ldots$ \\
\hline Sumichrasti............... & 62 & 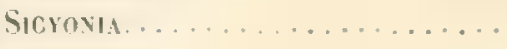 \\
\hline 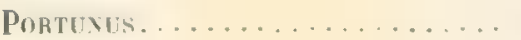 & 17 & 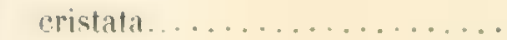 \\
\hline
\end{tabular}

\section{ERRITA'.}

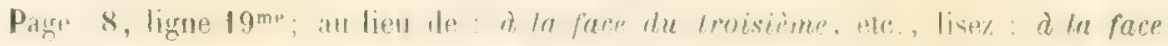
postéripure du troisième, ete.

9, 1:3me ligme à partir du has; all li+u d, : hombée, lisez: hassolép.

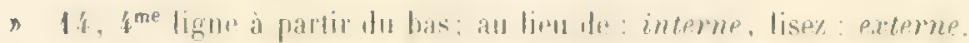

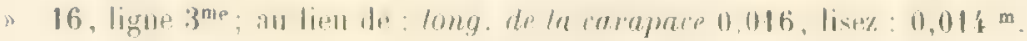

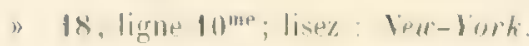

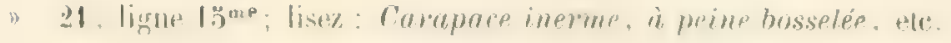

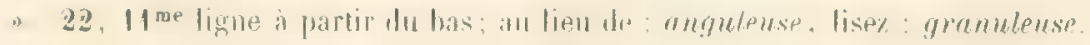

D. 25. lise\%: Crem SEsarma.

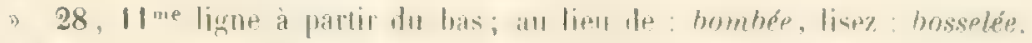

"29, ligne 10me: lisez: busselse.

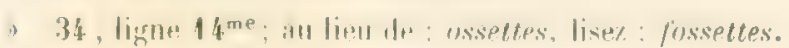

- Le lecteur est prié d'introdure res arrections essentiolles dans lo be ste. 


\section{APPENUICE.}

M. W. Stimpson, si versé dans la connaissance des Crustacés américains. a publié sur ce mémoirc une analyse crilique, dans laquelle il rapproche plusicurs de mes espèces de celles que les auteurs américains ont décrites '. Comme il est souvent impossible en Europe de sc procurer les ouvrages américains, je n'avais pu prendre en considération ni les travaux de Gibles, ni ceux de De Kay, qui n’ont pas été envoyés à nos bibliothèques.

Je m'empresse done de reproduire ici le résultat de lexamen de mes espèces, fait en Amérique par M. Stimpson. La pénurie de nos colleclions ne me permel pas de vérifier l'exactitude de ses jugements, mais je n"en conserve pas moins une complète confiance dans les assertions d'un homme aussi compétent.

P. 12. Pericern bicomis. Cette espèce est très-voisine de la P. bicoma (Edw.) Gibbes, peut-être identique.

P. 13. Le genre Lambrus est nouveau pour l'Américiue.

P. 14. Le Chlorodius americamus rentre probablement dans l'une des nombreuses variélés du Chl. floridamus, Gibbes.

P. 15. Genre Panoreus. Les trois especes décrites ici sont trì-voisines du P. Herbstii. - Le P. serratus a aussi été trouvé sur les cỏles de la Floride.

P. 17. Le genre Portunus est nouveau pour l'Amérique septentrionale.

P. 27. Fenre Metopogrupsus. Les trois especes de ce genre doivent platòt rentrer dans le genre Pacilygrapsus. Le jremicr parail ètre spécial ḋ l'hémisphere oriental; dans ce genre, le lobe sousorbitaire interne se joint au front.

Le Metop. Ihubius est te même que le Parhygr. transversus, Gibbes.

I. 33. La Plagusiu gracilis diffère de la PI. Sayi par le bord quadrilobé de l'epistome.

P. 34. Le Ilepulus tuberulutus est it comparer avec le jeune de l'II. decornes.

(1) American Jnurnal of Scionce and ir/s, 18:30, p 440. (Mai.) 


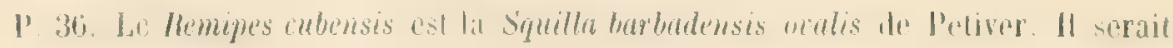
done peut-être convenable de conserver lo nom de barbedensis que M. Stimpson lui a donné presque à la menr époque où je lui donnai celui de cubensis. - Depuis. jai Irouvé cettr espeece liguréc dans Gronovius. Il faut donc ajouter à sa synonymic:

Gronovius, Zoophylac. Gronovian. 11763). Emerill. 110 1001, 1. 234, tab. xirn, fig. 10.

I'. 37. Le Pugurus rubensis est probablement le meme que in Clibunarus selopeturius. - Il s'est glissé une importante fiute typographique dans la description de cotte espèce. Ligne neuvième, it partir du bas, il faul lire : rinquième article, au lieu de: troisième article. (Sur le manuscril javais écrit en chiffre $5^{\circ}$; le compositeur a lu $3^{e}$, et l'a imprimé en toutes lettres.)

P. 45. L'Alpheus lutarius pourrait itre identique à l'A. heterochelis, Say.?

P. 47. La Caridina mexicana est plutot une Atö̈cu, car, dans les Caridina, la deuxibme paire de paltes a un carpe long et grêle, non fourchu.

$\Gamma$. 48. Te me suis imparfaitement exprimé en disant que les Palémons halitent la côte ou le golfe du Mexique. J'aurais dì dire : le's lagunes des cóles. Je les ai, en effet, pris dans les lagunes salurées des bords de la mer on lans l'embouchure des rivicres, et non en pleine mer, comme pourrait le laisser supposer mon expression trop générale : le golfe du Mexique.

Entin, Ic langouste (Palinurus) ne sétend pas jusqu a la latitude de Philadelphie et de New-York, comme je laa dit par crreur dans l'introduction, sur le témoignage des marchands de poissons de ces villes (voyez p. 5). 


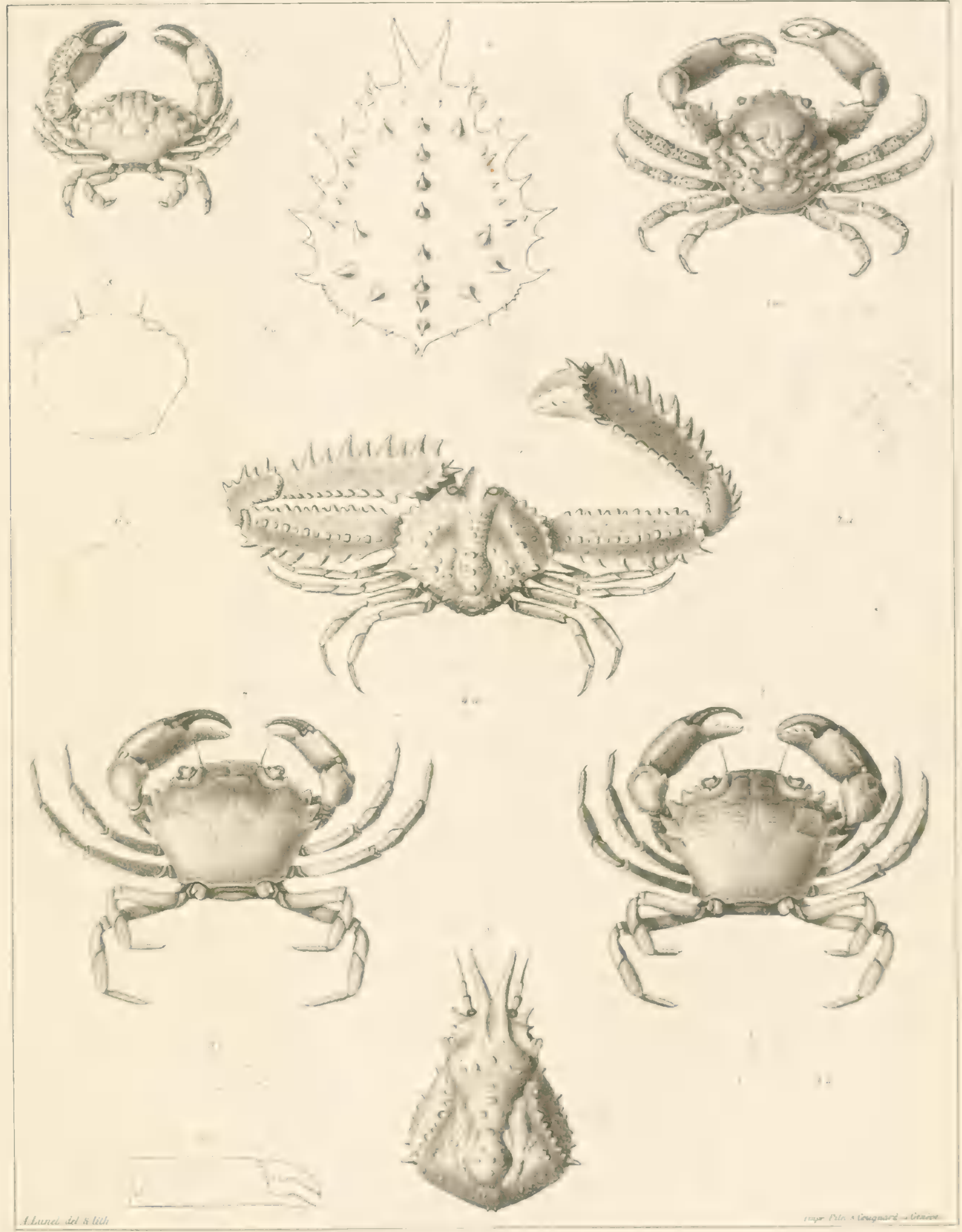

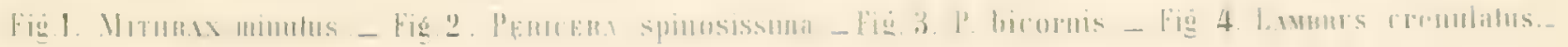

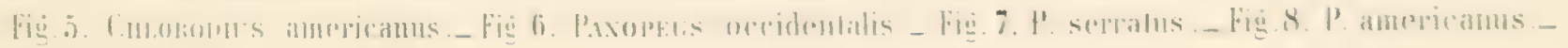





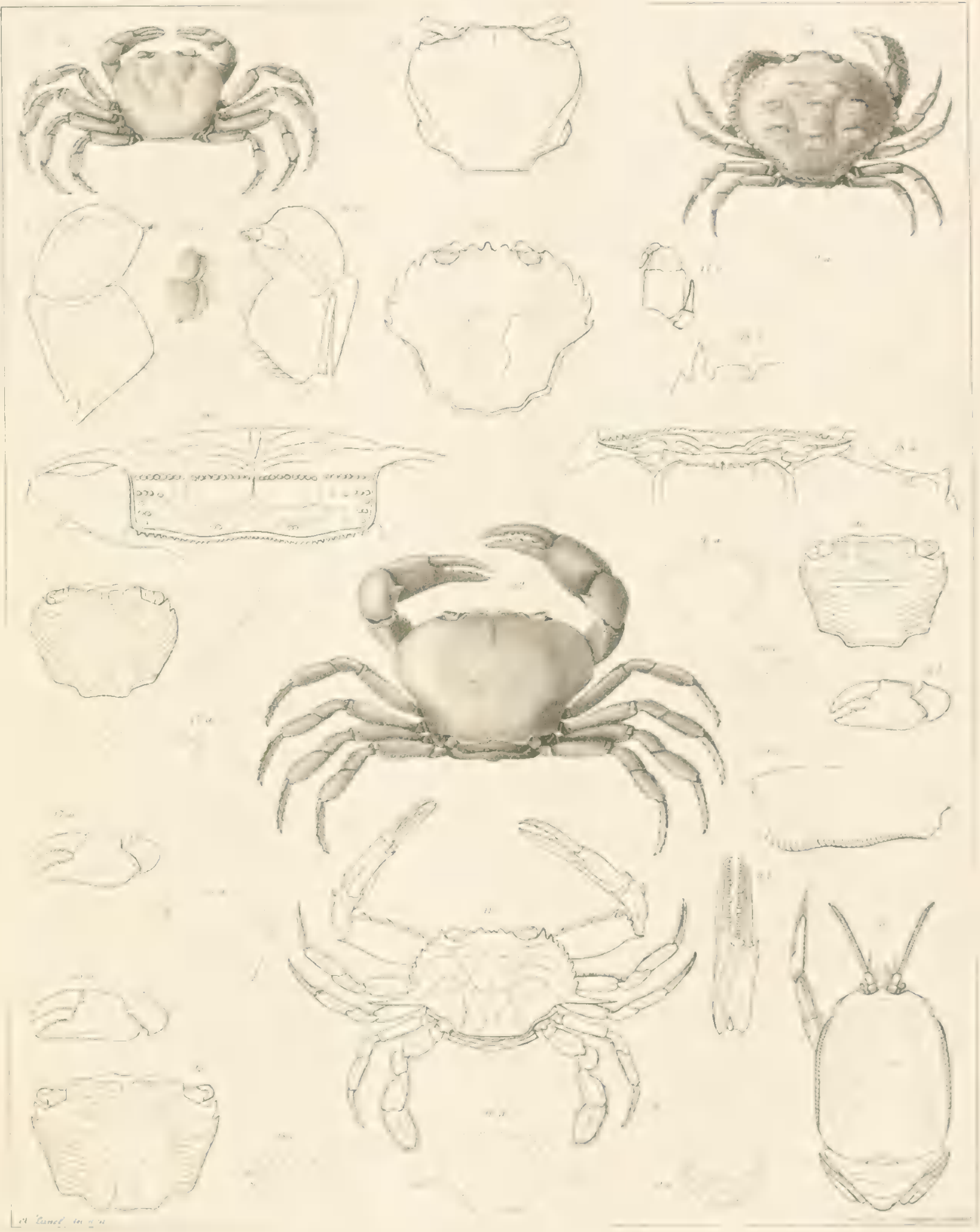

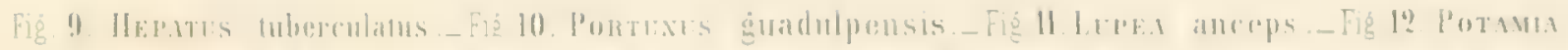

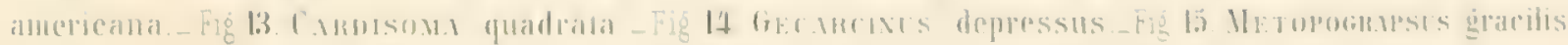

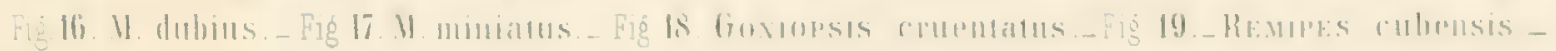





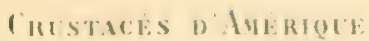

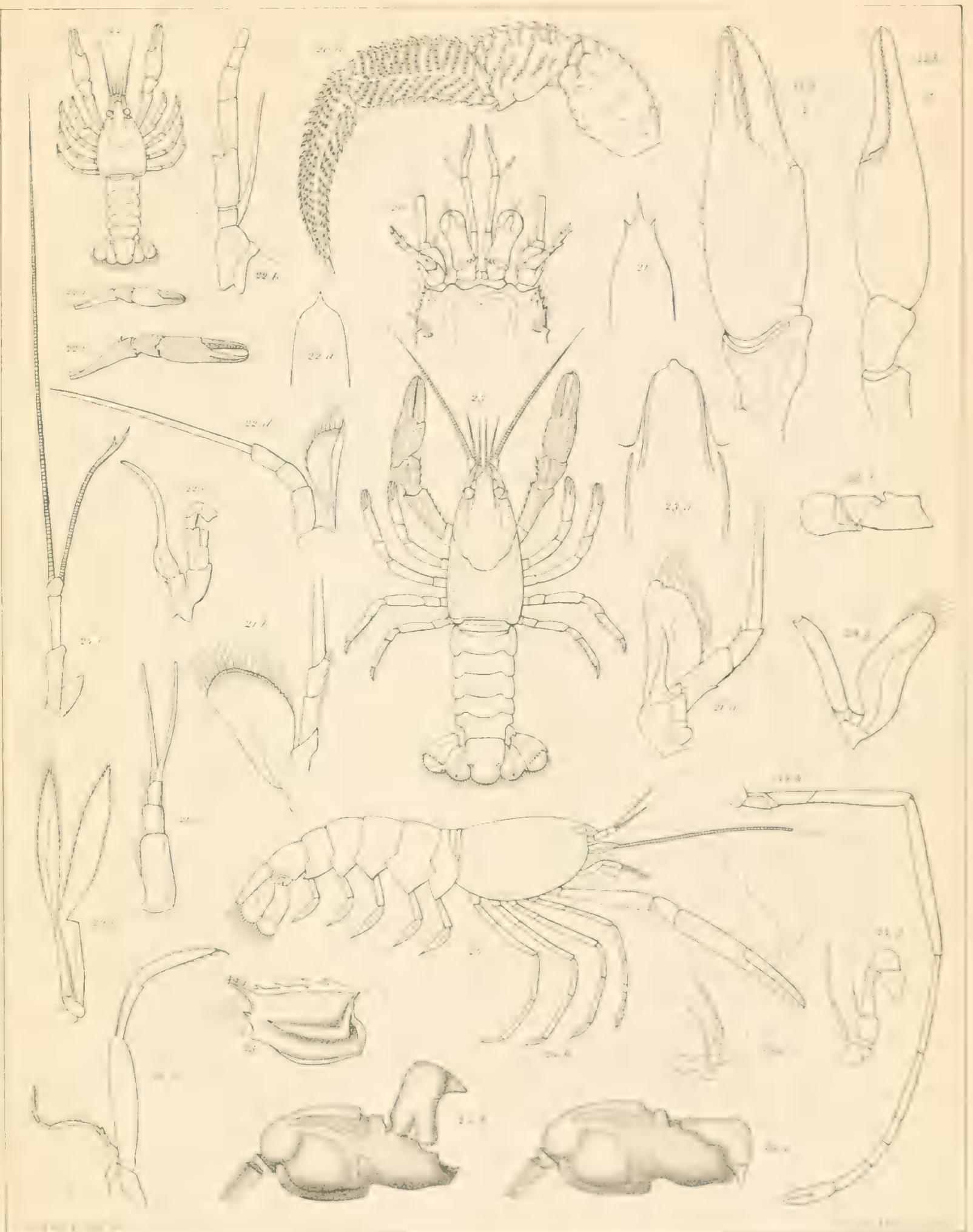

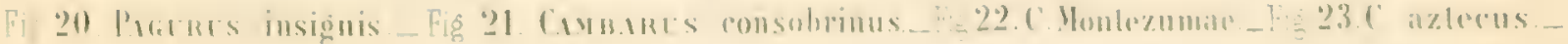

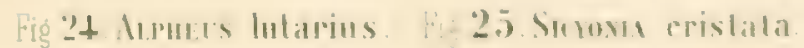




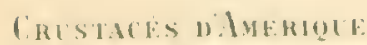

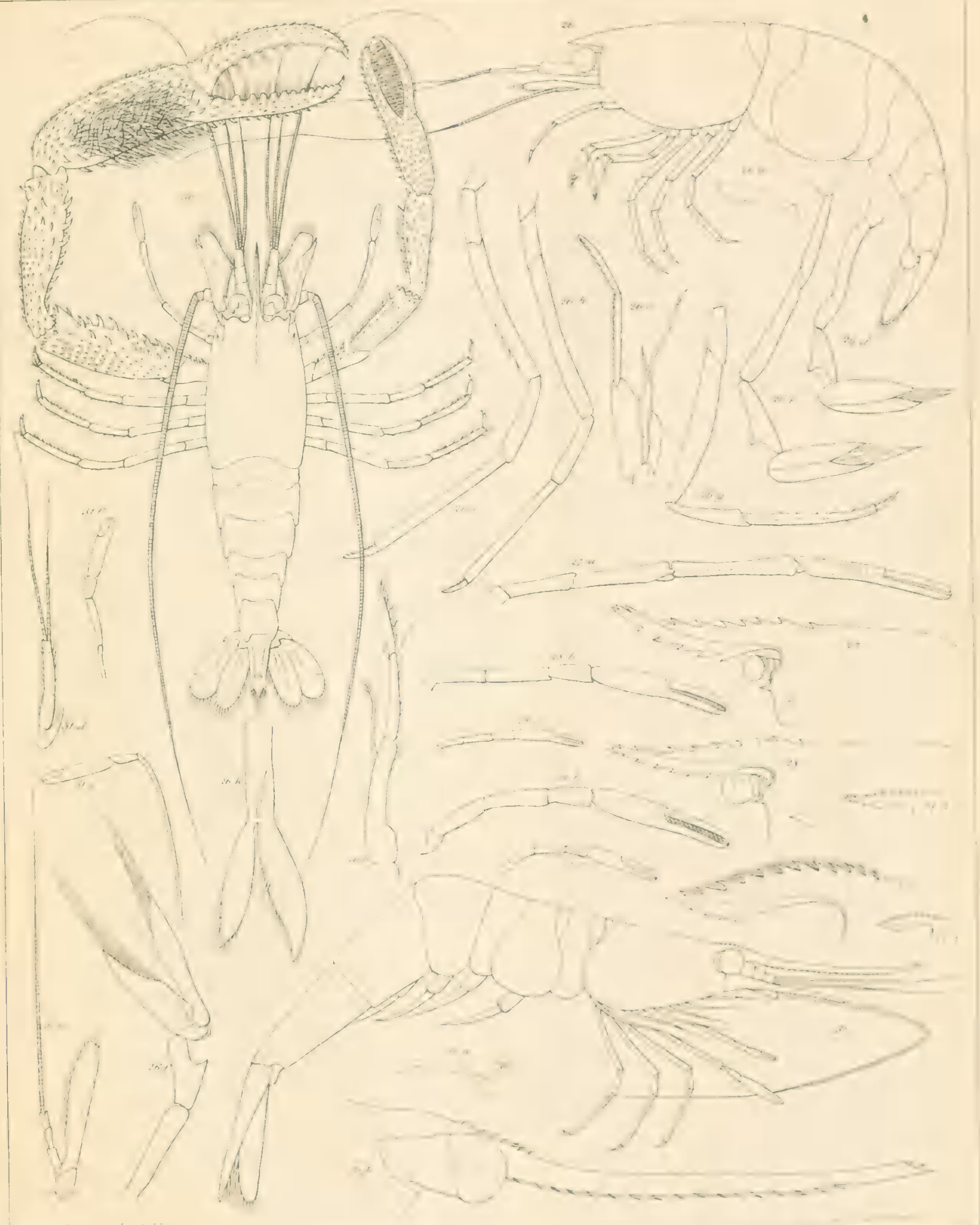

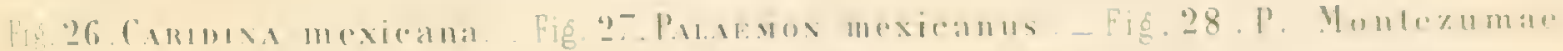
Fig. 29) P. a\% 



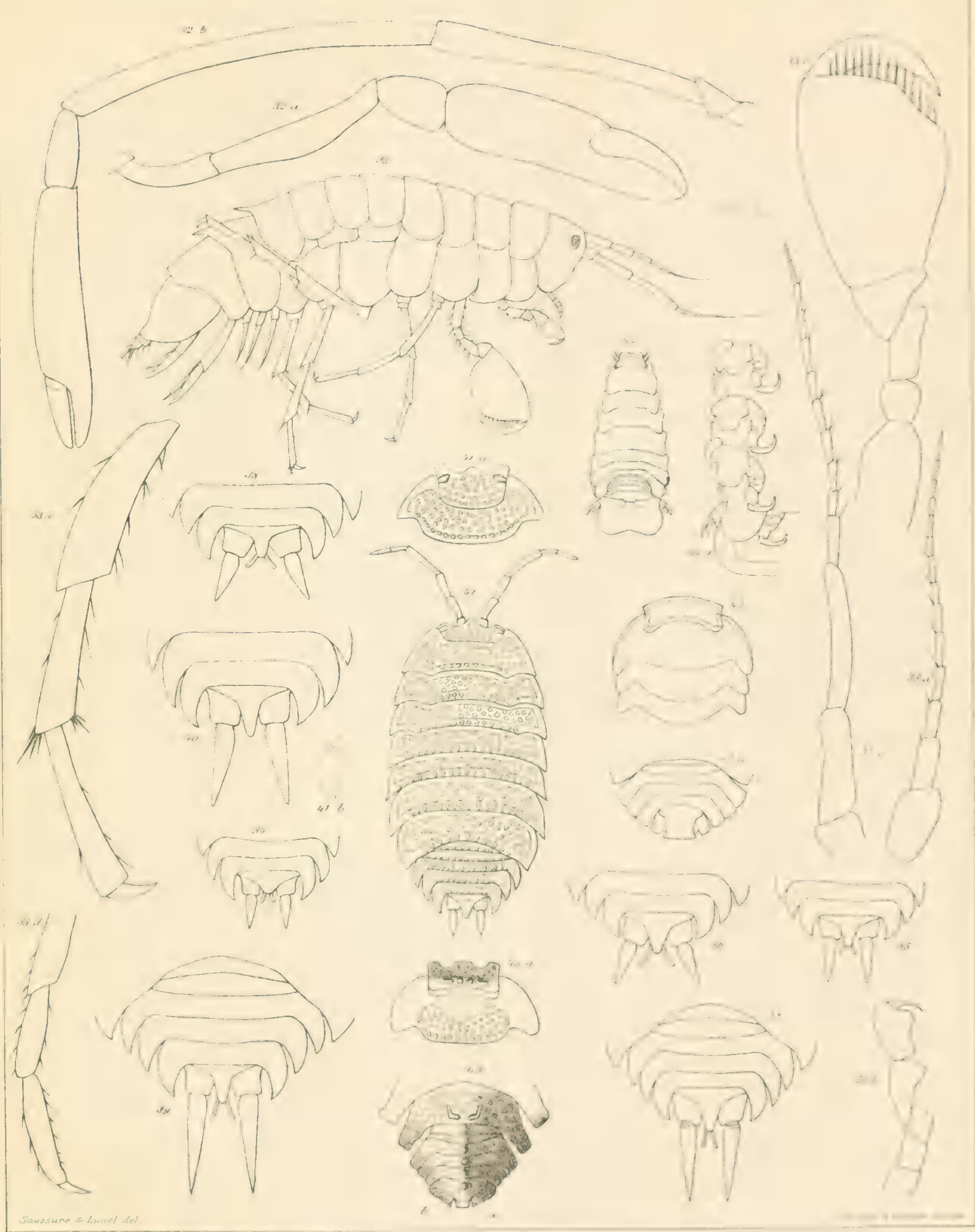

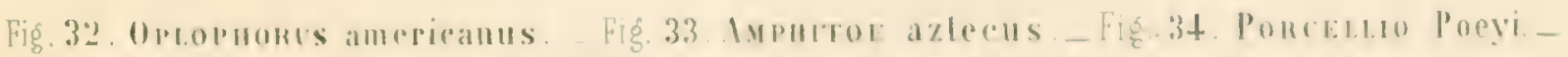

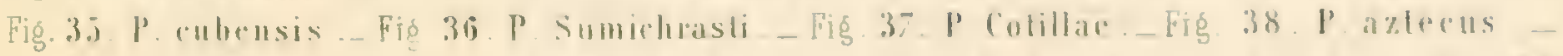

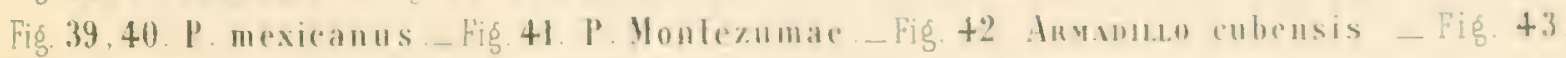

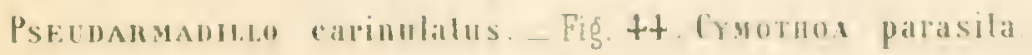








\section{OUVRAGES IIE L'ALTEUR}

EN VEXTE CIHEZ LES MÈVS LIBRAIRES ET I:HF\% L'IUTELR,

\section{ÉTUDES SUR LA FAMILLE DES VESPIDES}

$$
3 \text { rol. gr. } 8^{\circ} \text { pl. col. }
$$

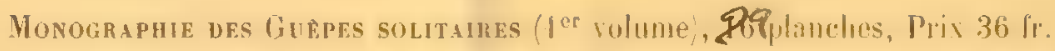

Monographe ues fiupes sociales (2e solume arec allas colorio de 38 planchos. Pris $66 \mathrm{fr}$.

Monographe des fausses Guepes at le supplément ja la monographie des furpus solitaires ( $3^{e}$ volume), 1 if $\mathrm{p}$ nethes coloribes. Pris $80 \mathrm{fr}$.

\section{MÉLANGES hYMÉNOPTÉROLOGIQUES.}

B:. $4^{\circ} 1$ planclue coloriée. Pris $\&$ fr.

\section{MÉMOIRES POUR SERVIR A L'HISTOIRE NATURELLE DU MEXIQNUE,}

DES ANTILLES ET DES ÉTATS-INIS.

Cet outrage se composera d'une série de mémoires indépendants qui se remiront it part, el qui formeront mo deax rolumes $4^{\circ}$. 






